\title{
WestVirginiaUniversity
}

THE RESEARCH REPOSITORY @ WVU

Graduate Theses, Dissertations, and Problem Reports

2020

\section{Alternative Media and Mulches in Organic Vegetable Production}

Heather R. Griffith

West Virginia University, hgriffi2@mix.wvu.edu

Follow this and additional works at: https://researchrepository.wvu.edu/etd

Part of the Horticulture Commons

\section{Recommended Citation}

Griffith, Heather R., "Alternative Media and Mulches in Organic Vegetable Production" (2020). Graduate Theses, Dissertations, and Problem Reports. 7684.

https://researchrepository.wvu.edu/etd/7684

This Thesis is protected by copyright and/or related rights. It has been brought to you by the The Research Repository @ WVU with permission from the rights-holder(s). You are free to use this Thesis in any way that is permitted by the copyright and related rights legislation that applies to your use. For other uses you must obtain permission from the rights-holder(s) directly, unless additional rights are indicated by a Creative Commons license in the record and/ or on the work itself. This Thesis has been accepted for inclusion in WVU Graduate Theses, Dissertations, and Problem Reports collection by an authorized administrator of The Research Repository @ WVU. For more information, please contact researchrepository@mail.wvu.edu. 
Graduate Theses, Dissertations, and Problem Reports

2020

Alternative Media and Mulches in Organic Vegetable Production

Heather R. Griffith

Follow this and additional works at: https://researchrepository.wvu.edu/etd

Part of the Horticulture Commons 


\title{
Alternative Media and Mulches in Organic Vegetable Production
}

\author{
Heather R. Griffith \\ Thesis submitted \\ to the Davis College of Agriculture, Natural Resources and Design \\ at West Virginia University \\ in partial fulfillment of the requirements for the degree of \\ Master of Science in \\ Horticulture
}
Sven Verlinden, Ph.D., Chair
James Kotcon, Ph.D.
Nicole Waterland, Ph.D.

Division of Plant and Soil Sciences

Morgantown, West Virginia

2020

Keywords: Deficit irrigation, transplant production, organic mulches.

Copyright: 2020 Heather R. Griffith 


\section{ABSTRACT \\ Alternative Media and Mulches in Organic Vegetable Production}

\section{Heather R. Griffith}

Reducing or eliminating waste from organic vegetable production can conserve money as well as resources. Conventional greenhouse production of vegetable transplants often relies on abundant fertigation which produces large amounts of polluted runoff, and the field production of organic vegetables frequently relies on the use of polyethylene mulch. A greenhouse study was conducted to determine if organic transplants can be successfully produced in a greenhouse under reduced soil moisture in order to reduce leaching of nutrients and potential water pollution. To test this, we compared the effect of reduced irrigation volumes to the standard practice of irrigating with $120 \%$ of container capacity on plant growth. A second and more detailed aspect of our study investigated the influence of irrigation levels on nutrient changes in the media throughout transplant production. We compared unfertilized organic media to a conventional medium which was fertilized with every irrigation, which is the standard conventional industry practice. Three concurrent experiments were carried out on lettuce, tomato and pepper transplants over the course of six weeks. EC and $\mathrm{pH}$ of soil leachate as well as plant height, leaf number, shoot fresh weight and shoot dry weight were compared. We found that the choice of potting medium influences transplant production, with some organic media performing comparably to the conventional control. Additionally, it was discovered that organic transplants can be produced under $80 \%$ volumetric water content (VWC) deficit irrigation. These findings will allow organic producers to implement production protocols that conserve water and reduce the financial impact of fertilizer use. In a field experiment we compared soil moisture retention, soil temperature regulation, and sweet pepper yield using the organic mulches hay, wool, leaf litter, two sizes of conventional polyethylene mulch with hand weeding and no weeding (control). Four blocks containing the seven treatments were laid out with treatments placed randomly within each block. Soil moisture and temperature probes were placed in the center of each plot and connected to centrally located data loggers. Data were recorded hourly over the course of the experiment (90 days). Pepper fruits were evaluated in terms of harvestable weight per plot. We found that plots with plastic-mulch were hotter and drier and had greater yield than plots with organic mulch. Among organic mulches, wool had the greatest yield, and all mulches were superior to the control. These findings will hopefully allow producers to make informed choices regarding mulch use in organic vegetable production. 


\section{ACKNOWLEDGEMENTS}

I owe much gratitude to many without whom this project would not have been possible. I give a huge thank you to Dr. Sven Verlinden, who cemented my decision to attend this university, advised me through my undergraduate years, wrote countless recommendations, and supported me through my graduate research. I'm grateful for my committee members, Dr. Nicole Waterland and Dr. James Kotcon. Thank you both for always taking the time to answer my questions and for supporting me over the course of my undergraduate and graduate research. I could not have done the statistics alone and for that I owe Ida Holásková so much gratitude. I am thankful for Sue Myers, former greenhouse manager, who always worked my projects into the greenhouse, never let me give up, and never let anyone kill my research subjects. I'm thankful for all the greenhouse staff, student workers, friends, and others who put in countless hours in the greenhouse and on the farm assisting with my research. Many thanks to current greenhouse manager Andrea Landis, Jamie Saunders, Dixie Green, James Bradley, Michelle McIntyre, Jessica 'Lee' Catoe, and anyone else who helped me rake leaves, bury plastic, water to the milliliter, and all the other myriad little tasks that, taken together, made this research possible. I won't bother you guys any more. 


\section{TABLE OF CONTENTS}

\section{Contents}

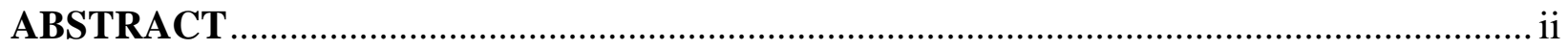

ACKNOWLEDGEMENTS ........................................................................................

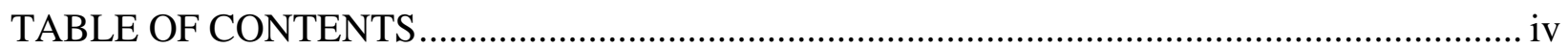

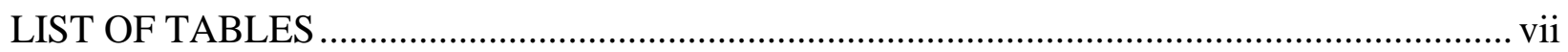

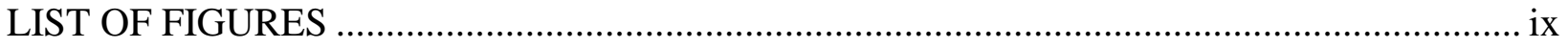

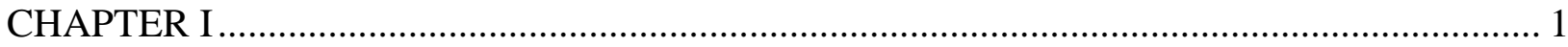

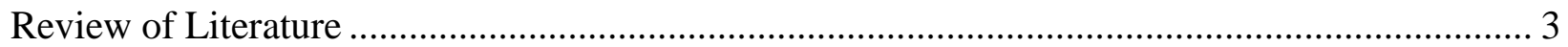

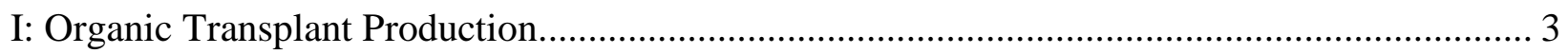

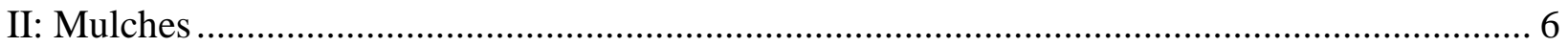

CHAPTER II: Media Moisture Effect on Organic Transplant Production..................................... 11

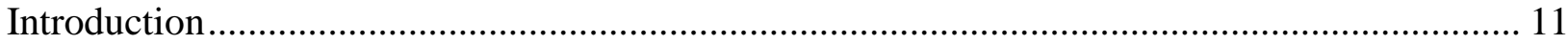

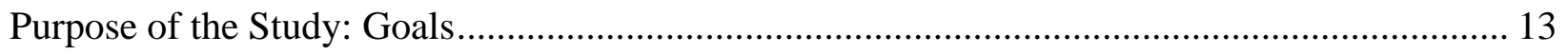

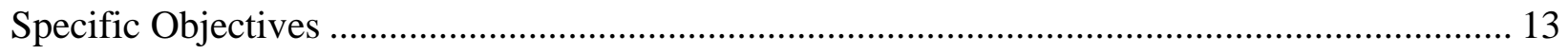

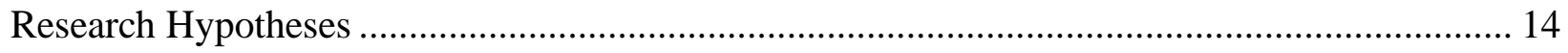

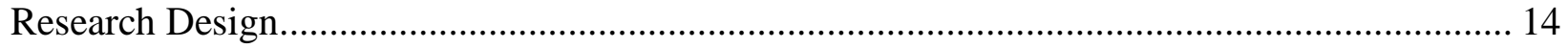

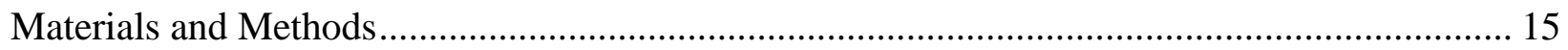

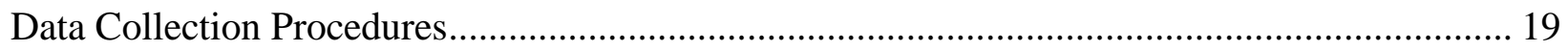


Statistical Analysis

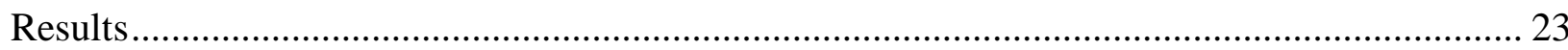

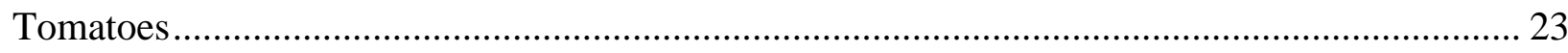

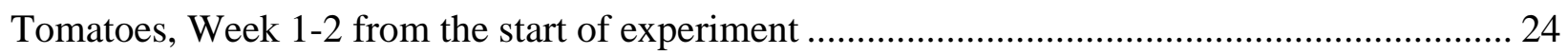

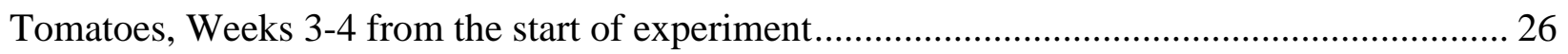

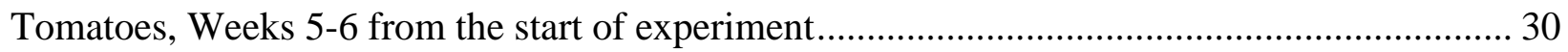

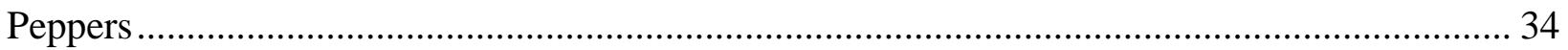

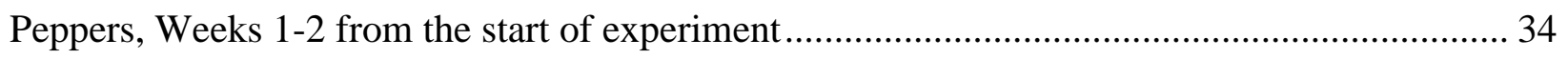

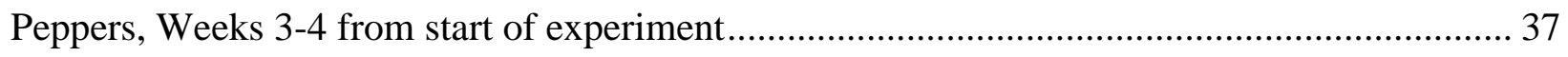

Peppers, Weeks 5-6 from start of experiment .......................................................................... 40

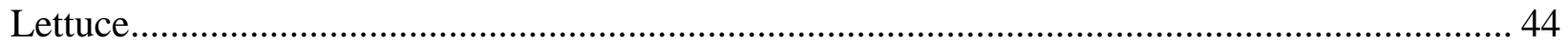

Lettuce, Weeks 1-2 from start of experiment …………………………………………….... 45

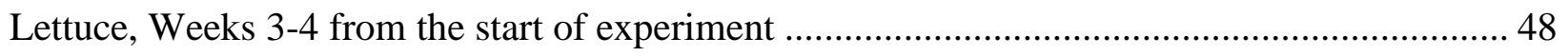

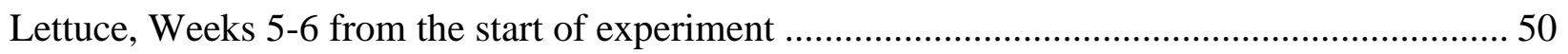

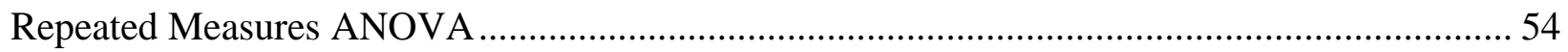

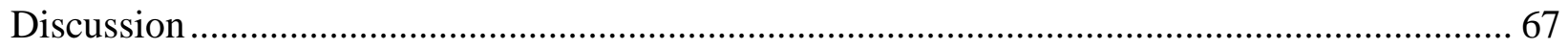

CHAPTER III: Alternative Mulches in Organic Vegetable Production.......................................... 74

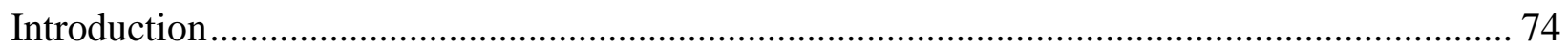

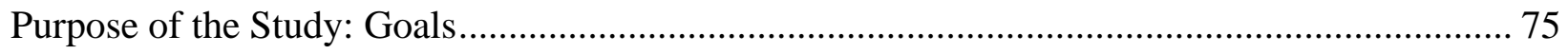

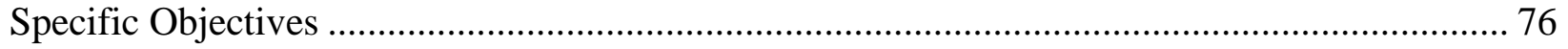




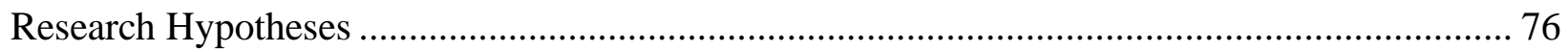

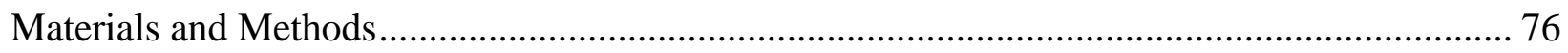

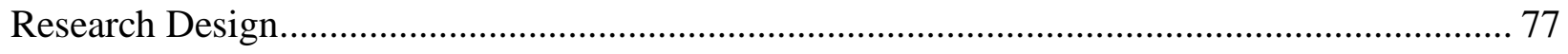

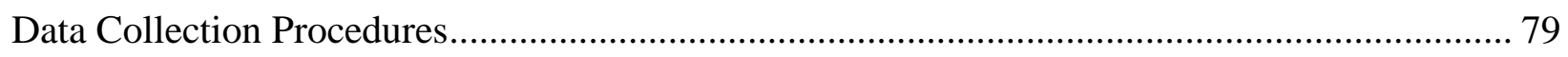

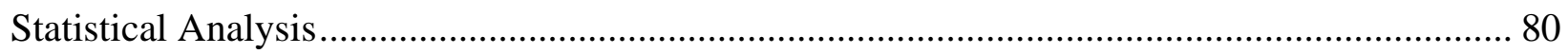

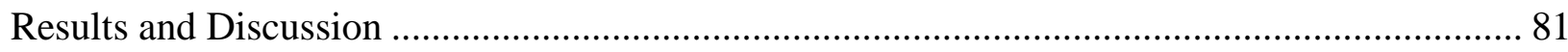

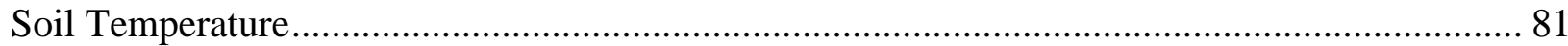

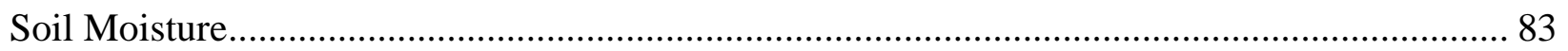

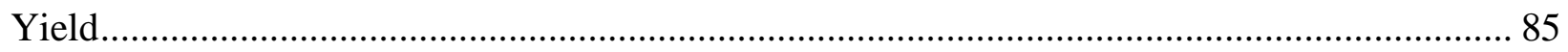

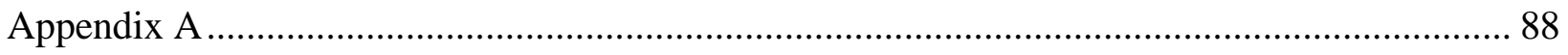

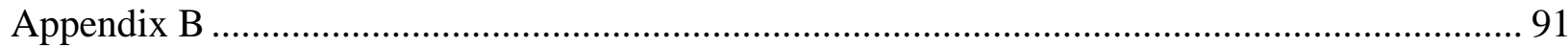

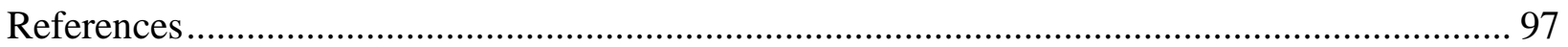




\section{LIST OF TABLES}

Table Title

Page

TABle 2.1. WATER VOlUMES USED to IRRIGATE TRANSPLANTS AT 80, 100, $120 \%$ VWC GROWN IN BLACK GOLD, FARM COMPOST, JOHNNY'S 512 MIX, AND SUNSHINE MIX (CONTROL) IN 2015 AND 2016.

TABLE 2.2. BULK DENSITY, CONTAINER CAPACITY, AERATION, EC, AND PH OF THE FOUR MEDIA USED TO GROW LETTUCE, TOMATO, AND PEPPER TRANSPLANTS IN 2015 AND 2016.

TABLE 2.3. STATISTICAL TEST FOR MAIN EFFECT OF MEDIA, IRRIGATION AND THEIR INTERACTION ON HEIGHT, LEAF COUNT, FRESH WEIGHT, DRY WEIGHT, EC AND PH THROUGH SIX WEEKS OF DATA COLLECTION FOR TOMATO 'WEST VIRGINIA '63' TRANSPLANTS.

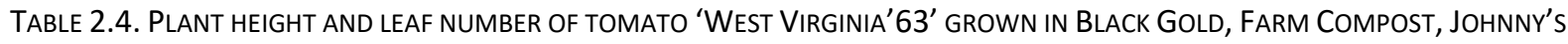
512 MIX, AND SUNSHINE MIX AND WATERED AT 80\%, 100\%, 120\% IRRIGATION AT WEEK 1 AND EC AND PH AT WEEK 2 FOR THOSE SAME MEDIA AND TREATMENTS. MEANS \pm STANDARD ERROR OF THE MEANS (SEM).

TAble 2.5. Plant height And leaf number of tomato ‘West Virginia’63’ grown in Black Gold, Farm Compost, Johnny’S 512 Mix, AND SUNSHINE Mix AND WATERED AT 80\%, 100\%, 120\% IRRIGATION AT WEEK 3 AND EC AND PH AT WEEK 4 FOR THOSE SAME MEDIA AND TREATMENTS. MEANS \pm STANDARD ERROR OF THE MEANS (SEM).

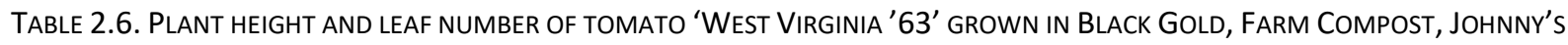
512 MIX, AND SUNSHINE MIX AND WATERED AT 80\%, 100\%, 120\% IRRIGATION AT WEEK 5 AND FRESH WEIGHT, DRY WEIGHT, EC AND PH AT WeEK 6 FOR THOSE SAME MEDIA AND TREATMENTS. MEANS \pm STANDARD ERROR OF THE MEANS (SEM).

TABLE 2.7. STATISTICAL TEST FOR MAIN EFFECT OF MEDIA, IRRIGATION AND THEIR INTERACTION ON VARIABLES. 34

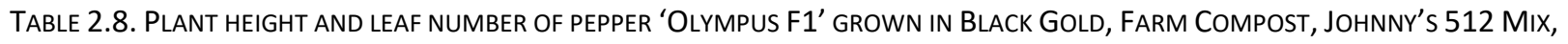
AND SUNSHINE Mix AND WATERED AT 80\%, 100\%, 120\% IRRIGATION AT WEEK 1 AND EC AND PH AT WEEK 2 FOR THOSE SAME MEDIA AND TREATMENTS. MEANS \pm STANDARD ERROR OF THE MEANS (SEM). 35

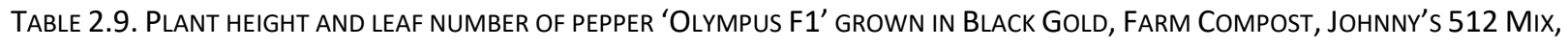
AND SUNSHINE Mix AND WATERED AT 80\%, 100\%, 120\% IRRIGATION AT WEEK 3 AND EC AND PH AT WEEK 4 FOR THOSE SAME MEDIA AND TREATMENTS. MEANS \pm STANDARD ERROR OF THE MEANS (SEM). 
TAble 2.10. Plant height And leaf number of Pepper ‘Olympus F1' GRoWn in Black Gold, Farm Compost, JohnNy’s 512 Mix, AND SUNSHINE MIX AND WATERED AT 80\%, 100\%, 120\% IRRIGATION AT WEEK 5 AND FRESH WEIGHT, DRY WEIGHT, EC AND PH AT WEEK 6 FOR THOSE SAME MEDIA AND TREATMENTS. MEANS \pm STANDARD ERROR OF THE MEANS (SEM). .41

TABLE 2.11. STATISTICAL TESTS FOR MAIN EFFECT OF MEDIA, IRRIGATION AND THEIR INTERACTIONS. . .45

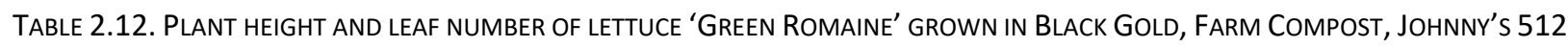
MIX, AND SUNSHINE MIX AND WATERED AT 80\%, 100\%, 120\% IRRIGATION AT WEEK 1 AND EC AND PH AT WEEK 2 FOR THOSE SAME MEDIA AND TREATMENTS. MEANS \pm STANDARD ERROR OF THE MEANS (SEM). . .46

Table 2.13. Plant height and leaf number of lettuce ‘Green Romaine' Grown in Black Gold, Farm Compost, JohnNy's 512 MIX, AND SUNSHINE Mix AND WATERED AT 80\%, 100\%, 120\% IRRIGATION AT WEEK 3 AND EC AND PH AT WEEK 4 FOR THOSE SAME MEDIA AND TREATMENTS. MEANS \pm STANDARD ERROR OF THE MEANS (SEM).

Table 2.14. Plant height and leaf number of lettuce 'Green Romaine’ Grown in Black Gold, Farm Compost, Johnny's 512 MIX, AND SUNSHINE MIX AND WATERED AT 80\%, 100\%, 120\% IRRIGATION AT WEEK 5 AND FRESH WEIGHT, DRY WEIGHT, EC AND PH AT WEEK 6 FOR THOSE SAME MEDIA AND TREATMENTS. MEANS \pm STANDARD ERROR OF THE MEANS (SEM). . .51

TABLE 2.15. RESULTS OF SATURATED REPEATED MEASURES ANOVA MODEL TESTS ASSESSING THE EFFECTS OF IRRIGATION, MEDIA AND WEEKS AND ALL INTERACTIONS ON EC, PH, PLANT HEIGHT AND LEAF NUMBER IN TOMATOES, PEPPERS AND LETTUCE. . .55

TABlE 2.16. ReSULTS OF SIMPLIFIED, REPEATEd MEASURES- ANOVA MODEL TESTS ASSESSING THE EFFECTS OF MEDIA AND WEEKS AND THEIR INTERACTION ON EC, PH, PLANT HEIGHT AND LEAF NUMBER IN TOMATOES, PEPPERS AND LETTUCE.

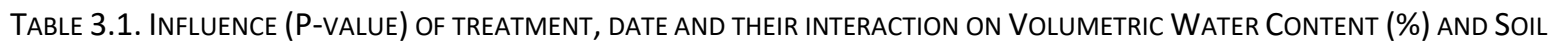
Temperature $\left({ }^{\circ} \mathrm{C}\right)$, AND THE EFFECT Of TREATMENT, HARVEST $\left(1^{\text {ST }}\right.$ AND $2^{\text {ND }}$ ) AND THEIR INTERACTION ON HARVEST WEIGHT (G).

TABLE 3.2. LeASt SQUARE MEANS AND StANDARD ERRORS OF THE MEANS (SEM) FOR SOIL TEMPERATURE $\left({ }^{\circ} \mathrm{C}\right)$. 


\section{LIST OF FIGURES}

Figure Title Page

FigURE 2.1. MAIN EFFECT OF MEDIA ON EC $\left(\mu \mathrm{S} \bullet \mathrm{CM}^{-1}\right)$ FOR TOMATO 'WeSt VIRGINIA '63' OVER THE COURSE OF THE STUDY (WEEKS 2-6). TOMATOES WERE GROWN IN THE GREENHOUSE USING FOUR LISTED MEDIA AND THREE LEVELS OF IRRIGATION. ELECTRICAL CONDUCTIVITY (EC) WAS RECORDED EVERY TWO WEEKS FOR SIX WEEKS AND THE EXPERIMENT WAS REPEATED THE FOLLOWING YEAR. ERROR BARS INDICATE THE STANDARD DEVIATION; JOHNNY'S 512 MIX IS SIGNIFICANTLY HIGHER THAN THE CONTROL........57

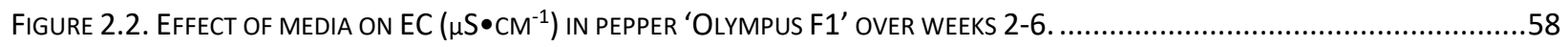

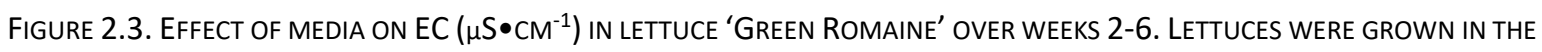
GREENHOUSE USING FOUR LISTED MEDIA AND THREE LEVELS OF IRRIGATION. ELECTRICAL CONDUCTIVITY (EC) OF LEACHATE WAS RECORDED EVERY TWO WEEKS FOR SIX WEEKS AND THE EXPERIMENT WAS REPEATED THE FOLLOWING YEAR. ASTERISKS INDICATE A LEAST SQUARE MEANS SIGNIFICANTLY DIFFERENT FROM CONTROL (SUNSHINE MIX) BEFORE ADJUSTING TO MULTIPLE COMPARISONS.

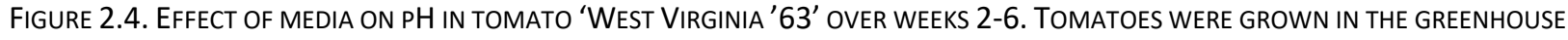
USING FOUR LISTED MEDIA AND THREE LEVELS OF IRRIGATION. PH WAS RECORDED EVERY TWO WEEKS FOR SIX WEEKS AND EXPERIMENT WAS REPEATED THE FOLLOWING YEAR. ASTERISKS INDICATE A LEAST SQUARE MEANS SIGNIFICANTLY DIFFERENT FROM CONTROL (SUNSHINE MIX) BEFORE ADJUSTING TO MULTIPLE COMPARISONS.

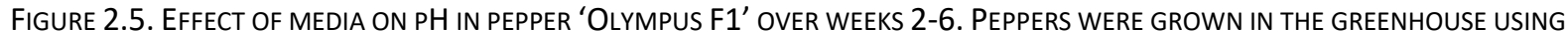
FOUR LISTED MEDIA AND THREE LEVELS OF IRRIGATION. PH WAS RECORDED EVERY TWO WEEKS FOR SIX WEEKS AND THE EXPERIMENT WAS REPEATED THE FOLLOWING YEAR. ASTERISKS INDICATE A LEAST SQUARE MEANS SIGNIFICANTLY DIFFERENT FROM CONTROL (SUNSHINE MIX) BEFORE ADJUSTING TO MULTIPLE COMPARISONS.

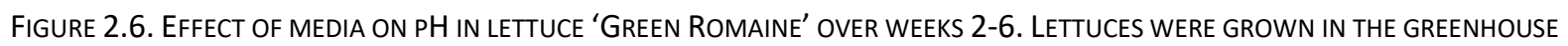
USING FOUR LISTED MEDIA AND THREE LEVELS OF IRRIGATION. PH WAS RECORDED EVERY TWO WEEKS FOR SIX WEEKS AND THE EXPERIMENT WAS REPEATED THE FOLLOWING YEAR. ASTERISKS INDICATE A LEAST SQUARE MEANS SIGNIFICANTLY DIFFERENT FROM CONTROL (SUNSHINE MIX) BEFORE ADJUSTING TO MULTIPLE COMPARISONS. 


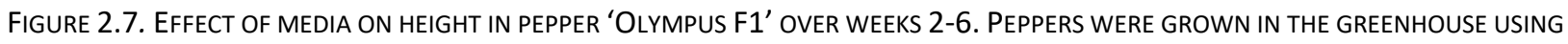
FOUR LISTED MEDIA AND THREE LEVELS OF IRRIGATION. HEIGHT WAS RECORDED EVERY TWO WEEKS FOR SIX WEEKS AND THE EXPERIMENT WAS REPEATED THE FOLLOWING YEAR. ASTERISKS INDICATE A LEAST SQUARE MEANS SIGNIFICANTLY DIFFERENT FROM CONTROL (SUNSHINE MIX) BEFORE ADJUSTING TO MULTIPLE COMPARISONS.

FigURE 2.8. EfFECT OF MEDIA ON LEAF NUMBER OF TOMATO 'WEST VIRGINIA '63' OVER WEeKS 2-6. 64

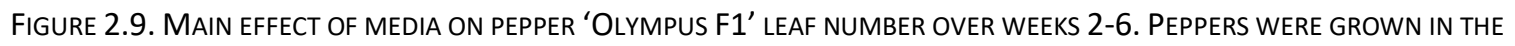
GREENHOUSE USING FOUR LISTED MEDIA AND THREE LEVELS OF IRRIGATION. LEAF NUMBER WAS RECORDED EVERY TWO WEEKS FOR SIX WEEKS AND THE EXPERIMENT WAS REPEATED THE FOLLOWING YEAR. ERROR BARS INDICATE STANDARD DEVIATION; ONLY PLANTS GROWN IN FARM COMPOST POSSESSED A SIGNIFICANTLY LOWER NUMBER OF LEAVES. 65

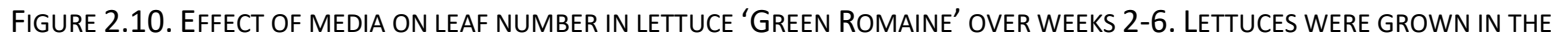
GREENHOUSE USING FOUR LISTED MEDIA AND THREE LEVELS OF IRRIGATION. LEAF NUMBER WAS RECORDED EVERY TWO WEEKS FOR SIX WEEKS AND THE EXPERIMENT WAS REPEATED THE FOLLOWING YEAR. ASTERISKS INDICATE A LEAST SQUARE MEANS SIGNIFICANTLY DIFFERENT FROM CONTROL (SUNSHINE MIX) BEFORE ADJUSTING TO MULTIPLE COMPARISONS.

FIGURE 3.1. 2016 PLOT LAYOUT. BLOCKS WERE LAID OUT IN TWO ROWS ACROSS THE SLOPE OF THE PLOT IN ORDER TO ACCOUNT FOR SMALL DIFFERENCES IN SOIL MOISTURE (FIG. 3.1).

Minimum daILY SOIL MOISTURE (\%VWC) UNDER EIGHT TREATMENTS FROM JUly 3 TO SEPT. 30, 2016. PePPER ‘OlyMPUS F1' WAS GROWN IN THE FIELD UNDER EIGHT SOIL TREATMENTS. LINES INDICATE A DAILY MAXIMUM SOIL TEMPERATURE OVER A 24-HOUR PERIOD AS RECORDED 5 CM BELOW THE SOIL SURFACE. BARS REPRESENT DAILY RAINFALL TOTALS AS RECORDED OVER A 24-HOUR PERIOD. REDUCTIONS IN SOIL TEMPERATURE CONCURRENT WITH INCREASES IN SOIL MOISTURE ARE A PRODUCT OF RAIN EVENTS. .94 MAXIMUM daILY SOIL MOISTURE (\%VWC) UNDER EIGHT TREATMENTS FROM JUly 3 TO SEPT. 30, 2016. PePPER 'OlympUs F1' WAS GROWN IN THE FIELD UNDER EIGHT SOIL TREATMENTS. LINES INDICATE A DAILY MAXIMUM SOIL TEMPERATURE OVER A 24-HOUR PERIOD AS RECORDED 5 CM BELOW THE SOIL SURFACE. BARS REPRESENT DAILY RAINFALL TOTALS AS RECORDED OVER A 24-HOUR PERIOD. REDUCTIONS IN SOIL TEMPERATURE CONCURRENT WITH INCREASES IN SOIL MOISTURE ARE A PRODUCT OF RAIN EVENTS. .96 


\section{CHAPTER I}

\section{Introduction}

\section{Organic Agriculture}

For approximately 10,000 years, humanity has relied on agriculture to supply most of its nutritional needs. For the majority of agricultural history, many of the tenets of organic agriculture were the only option, at least until the advent of biocides, synthetic fertilizers, fossil fuels, and other cornerstones of modern industrial agriculture. Up to the development of chemical fertilizers in the mid-19th century, the application of plant materials, human and animal waste and cultivation of leguminous plants were the primary methods by which nutrients could be returned to cultivated soil. In the era before pesticides, methods of pest control were limited. Therefore, the model of 'organic agriculture' that many may see as a novel concept is, in reality, more ancient than the conventional methods relied upon for the majority of the modern world's crop production.

Conventional agriculture as we know it today has its roots in the early 1800 s, when it was discovered that plants absorbed mineral salts, instead of organic matter as was then believed, in order to obtain necessary nutrients (Kristiansen, 2006). The first phosphate fertilizer, made from ground bones, was used widely in Europe in the first part of the $19^{\text {th }}$ century; and in the latter part of the $19^{\text {th }}$ century, ammonium sulfate was used as source of nitrogen (Hignett, 1985). Potash was sourced from unrefined ores such as kainite, and in 1844 it was discovered that chlorosis of some plants could be corrected by spraying them with iron salts (Hignett, 1985). The first chemical fertilizer produced was superphosphate, made by treating bones with sulfuric acid, and in 1861 the modern phosphorus fertilizer industry began in Germany (Russel and Williams, 1977). The Haber-Bosch synthesis of ammonia, discovered in 1909 and commercialized in 1913, 
allowed for the mass production of cheap nitrogenous fertilizers (Smil, 2011). However, conventional fertilizers did not come into widespread use until the beginning of World War Two. Yet even as conventional agriculture was gaining a foothold, concerned voices were speaking out against it. In 1924 Rudolf Steiner, a founder of the biodynamic method of agriculture, was speaking out in criticism of industrial agriculture, and the first organic labeling and certification system, known as Demeter, was founded in that same year. Many early proponents of organic agriculture recognized the connections between healthy soil, plants, and animals, including humans, that fed on those plants. Though organic agriculture progressed and evolved through the early decades of the 20th century, it was in 1960s that the modern organic agriculture movement as we know it began to take shape. Pivotal in this revolution was Rachel Carson's Silent Spring (Carson, 1962). Written in 1962, it opened the public's eyes to the damage being done to the global environment by pesticides and other toxins. This brought a barrage of new arguments against industrial agriculture, adding to the ones that the organic agriculture movement had been pushing for decades. In 1972 the International Federation of Organic Agriculture Movements (IFOAM) was formed. The organization aimed to lead, unite, and assist the organic movement through representing it at international policy-making forums, providing information about organic agriculture, and promoting its worldwide application, amongst other goals. The 1980s saw rapid growth in organic agriculture as it became a comforting alternative to the uncomfortable truths the public was discovering about conventional agriculture. This increased awareness continued through the 1990s and into the current century, causing exponential growth in demand and production of organic products and culminating in the Organic Foods Production Act (OFPA) of 1990 as well as the establishment of the National Organic Program (NOP) in 2000 (USDA-AMS, 2000). 
Today organic agriculture is widely recognized by individuals and governments as a valid alternative to conventional agriculture. However, organic agriculture still faces hurdles and limitations. In an age of industrialized agriculture dependent on high-yielding, often pesticideresistant hybrids and intensive production methods, organic farming is limited to few chemicals for pest management and subsequent yields may be lower, up to $34 \%$ in some cases (Seufert, 2012). The ban on application of synthetic chemical fertilizers limits organic producers to obtaining nutrients from mineral, plant, and animal sources. Weeds must be managed through physical measures such as mulching, grazing, tilling, or flame weeding, the use of biological controls, or the application of a limited number of chemicals such as vinegar. Plastic mulches are permitted in organic agriculture; however, their use presents several disadvantages which will be elaborated upon in this thesis.

This research compares the efficacy of using organic media versus conventional media in the production of organic vegetable transplants, as well as the performance of organic mulches versus conventional polyethylene mulch in the field production of sweet peppers.

\section{Review of Literature}

\section{I: Organic Transplant Production}

Growing plants in containers of soil dates to antiquity and the mythical hanging gardens of Babylon, Nineveh, and Egypt (Michael, 2017). Archaeologists and historians have discovered that the Romans used mobile containers of soil to enable year-round crop production by moving plants into shelter in times of need. Such methods are still widely used today in the production of transplants, and in particular organic transplants. Organic production of vegetable transplants is undertaken for several reasons. Due to the high cost of organic seed, transplants are often used instead of field sowing in order to reduce seed and seedling loss from pathogens, predators, or 
inclement weather. Transplants also produce seedlings of a more consistent quality, enable an earlier start to the growing season in some climates and subsequent earlier harvests, and allow for optimum field spacing of mature plants (Russo, 2005). Despite the higher production costs of this method, consumers are willing to pay a premium for a product they feel is environmentally friendly and sustainable, up to $25 \%$ more in some cases (Rippy et al., 2004). The organic industry is the fastest growing segment of US agriculture, with total sales of food and non-food products reaching \$47 billion in 2016 (USDA—National Institute of Food and Agriculture, n.d.).

Transplant size and quality influence plant establishment, initial growth, and subsequent yield (Orzolek, 2015). Signs to look for in quality transplants include proper leaf color, stem thickness, and root mass as well as appropriate age or stage of development (Orzolek, 2015). A quality organic transplant is one that performs comparably to a conventional transplant in terms of vigor and development and is equal or superior in terms of marketability. Under conventional transplant production methods, abundant amounts of both water and fertilizer are applied to transplants, ensuring satisfactory growth but also leading to large losses of water-soluble soil nutrients via leaching, not to mention waste of valuable water. If nutrients are not replenished by fertilizer application, or if the media nutrient charge is sufficiently depleted by leaching, deficiencies could occur.

Under the US Department of Agriculture's Agricultural Marketing Service (USDAAMS) National Organic Program (NOP) Final Rule (UDSA-AMS, 2000), transplants used in organic production must be produced using organic practices and materials. Peat is used as a major component of conventional media, and though it is considered organic, many consider peat to be a nonrenewable resource as it accumulates slowly, at a rate of roughly one millimeter per year (Keddy, 2010). Many organic media contain peat, as it is cheap, easily available, and 
effective in retaining moisture, but it is low in nutrients which must therefore be obtained from other organic ingredients or synthetic or organic fertilizers. Organic vegetable transplant production cannot rely upon synthetic ingredients or additives. To be approved for use in organic vegetable production, media, fertilizers, and fillers must be certified by agencies such as the Organic Materials Review Institute (OMRI) or the USDA's National Organic Program (NOP). Without these certifications, products cannot legally be labeled as organic by their producers. To combat this issue, organic producers frequently look to composts due to their inherent nutrient content, local availability, and as an alternative to peat. These composts can act as the main component of a medium or as an additive. Various types of compost have been used in vegetable production with generally successful results (Raviv et al., 1998). However, not all composts are created equal. A study by Clark and Cavigelli (2005) which utilized locally available compost made from used horse bedding found it to be entirely unsuitable for the production of lettuce (Lactuca sativa) and tatsoi (Brassica rapa var. rosularis) when grown from seed for transplant production. This was thought to be due to its inherent high salinity, as well as its inhibition of nitrogen mineralization, a crucial process by which organic nitrogen is converted to inorganic nitrogen forms that plants can utilize. Nitrogen availability is often the main aspect affecting plant growth in containers (Raviv et el.,1998) and is not always sufficient for production of potted or container-grown plants such as vegetable transplants due to its slow mineralization rate (Gravel et al., 2012). Organic fertilizers can circumvent the limitations of compost nutrient availability, but multiple studies have shown that up to eight times the label rate may need to be applied in order to produce transplants of comparable quality to those produced through conventional means (Murray \& Anderson, n.d.; Gravel et al., 2012; Russo, 2006). Producers must also carefully apply organic fertilizers in order to avoid possible phytotoxic effects of plant 
residues. For example, it has been shown that meal from ground field beans (Phaseolus vulgaris), when over-applied, can reduce transplant weight by $40 \%$ (Koller et al., 2004). In addition to media, abiotic factors such as water amount and fertilizer available can affect transplant development (Russo, 2006). For organic materials and practices to be accepted as commonplace in the industry, they must be compared to the existing conventional standards.

The experiments described herein subjected transplants grown in different organic media to varying levels of irrigation. The aim in evaluating organic transplant production was to determine whether limiting water inhibits transplant growth; these findings could enable producers to reduce water and fertilizer usage. Preliminary experimentation showed that transplants may be successfully grown when irrigated with only eighty percent of a medium's water holding capacity. Watering with 100 and 120 percent of water holding capacity resulted in plants that occasionally exhibited signs of nutrient deficiency or excess water stress, depending on the media. Therefore, it is a reasonable hypothesis that reducing the amount of water applied to transplants will result in a plant of comparable quality to one produced conventionally.

\section{II: Mulches}

Mulch has been used for over a thousand years in both the Old and New Worlds (Lightfoot, 1996). Using stones to concentrate and conserve soil moisture is the oldest recorded use of mulch and dates to at least 2000 BC (Lightfoot, 1996). Mulches may take myriad forms, from organic materials such as hay, wood chips, or grass clippings to inorganic materials such as carpet, chipped or ground tires, and plastic films. Before the advent of modern chemicals, mulches were a valuable means of returning nutrients to the soil. In some coastal areas, such as the British Isles, seaweed was commonly applied to fields as a form of fertilizer. In the 1800s, long before the advent of black plastic, tar-coated paper was used as a mulch (Rivise, 1929). 
Mulches are often used in both conventional and organic agriculture to fulfill many purposes. Agricultural uses include reducing weed competition, conserving soil moisture, affecting soil temperature by heating or cooling, and reducing insect damage, all of which may increase yields (Kasirajan and Ngouajio, 2012). Conventional mulches often consist of plastic films of various colors but can be materials as varied as shredded or chopped rubber, while organic mulches may consist of herbaceous plant matter, animal fibers, hard plant matter such as bark chips or nut hulls, or animal wastes such as poultry litter.

Today, one of the most common mulches used in agriculture is black plastic film. Black plastic is generally made of polyethylene. It is a common mulch in both conventional and organic production. First used in 1948 as a substitute for glass in greenhouses, plastic film in various colors has been used for commercial vegetable production since the 1960s (Emmert, 1957; Lamont, 2005). In 2004, 130,000 tons of plastic mulch were used in the United States alone (Kwabiah et al, 2006). Plastic mulch was initially noted in the 1950s for its ability to raise soil temperatures (Emmert, 1957). Lamont (2017) states that, in general, soil temperatures under black plastic mulch during the daytime are $5^{\circ} \mathrm{F}\left(2.8^{\circ} \mathrm{C}\right)$ higher at 2 in. $(5 \mathrm{~cm})$ beneath the soil surface and $3{ }^{\circ} \mathrm{F}\left(1.7^{\circ} \mathrm{C}\right)$ higher at 4 in $(10 \mathrm{~cm})$ depth than in bare soil. Use of plastic mulch can increase soil temperatures significantly: in spring in cool climates, plastic mulch can warm the soil by an average of $8-10{ }^{\circ} \mathrm{F}$ depending on sunlight, soil type, ambient air temperature, available soil moisture, and mulch color (Orzolek, 2017). Maximum soil temperatures under plastic have been reported at $7{ }^{\circ} \mathrm{C}$ higher than in bare soil in Canadian corn trials (Kwabiah, 2004). Higher soil temperatures promote increased growth and earlier yields, which can be an important factor in the successful production of food crops in areas with short growing seasons and cool soils. Increased temperatures also favor nitrogen mineralization and plant $\mathrm{N}$ uptake (Wilson and 
Jefferies, 1996). Plastic mulch also moderates fluctuations in soil water content by acting as an impermeable barrier; precipitation is prevented from saturating the soil and runs off, whereas moisture in the soil is prevented from evaporating as quickly as from bare soil. Such moderation can reduce the need for irrigation and help prevent physiological disorders resulting from wateror nutrient-related deficiencies, such as blossom-end rot (McCraw and Motes, 2007). Plastic mulch can protect a soil from erosion caused by wind and water (Garnaud,1974). It can also prevent weed competition, reducing weed emergence by $64 \%$ to $98 \%$ over the course of a growing season in one study (Egley, 1983). Plants and their associated produce can be protected from pests and spoilage by mulches through elimination of pest habitat and reduced contact with the soil and its associated risks, such as fungal or pathogenic contamination of produce. In organic agriculture, with its heavy reliance on non-chemical means of pest control, black plastic could seem like a key factor in the economic viability of organic production methods due to a decreased reliance on chemical controls such as herbicides. However, there are also key disadvantages that illustrate a need for viable alternatives in organic production.

Black plastic mulch does not degrade and therefore poses a disposal issue. Covering 1 acre of soil uses 100 to $120 \mathrm{lb}$ of black plastic which must often be removed at the end of each growing season (McCraw and Motes, 2007). Due to the high costs related to the regular process of gathering and discarding plastic film mulches and the recycling process, black plastic is often discarded in a dump or burned, with the subsequent emission of toxic substances both to the atmosphere and to the soil (De Prisco et al, 2002). Improperly disposed-of plastics are a significant source of environmental pollution that may be harmful to life (Kasirajan and Ngouajio, 2012). The low amount of agricultural plastic mulch recycled is due to its high amount of contaminants, which has been found to be $36 \%$ moisture and soil in one study (Kasirajan and 
Ngouajio, 2012; Brooks, 1996). In addition, most plastic that has spent a growing season exposed to UV radiation is too photodegraded to be used as a recycling feedstock, regardless of economic concerns (Levitan and Barro, 2003). Recycling concerns aside, covering a field in black plastic renders $50-70 \%$ of its surface impermeable to water, which can increase runoff by 40\% (Rice et al, 2007). Rice et al. (2001) compared the off-site translocation of agrichemicals between tomato grown on polyethylene mulch and a residue mulch of hairy vetch (Vicia villosa) and found significantly greater amounts of pesticide runoff with the polyethylene mulch. That impermeability could also result in the prevention of organic matter accumulation when crop residues are removed with the plastic; Lee et al. (2018) found that maize plots mulched with plastic film lost greater amounts of carbon from the soil than non-film-mulched plots. Additionally, the increase in temperature under black plastic, while potentially valuable in terms of promoting plant growth, has been found to alter microbial communities which can result in microbial stress (Almeida et al., 2011). Finally, there are financial costs associated with the purchase, installation, removal, and disposal of black plastic mulch. While biodegradable plastics may seem like a viable alternative to conventional black plastic film, no currently available biodegradable plastic mulch is approved for use in organic cropping systems in the U.S. (USDA-AMS, n.d.). This is because currently available mulches are not completely 'biobased', i.e. 'composed in whole, or in significant part, of biological products or renewable domestic agricultural materials (including plant, animal, or marine materials) or forestry materials' (U.S. Congress, 2002). Additionally, the use of genetically-modified organisms is prohibited in biodegradable plastic mulch feedstocks and in the production of mulch (7 CFR 205.601; USDA-AMS, 2000). Many of these disadvantages, though perhaps not all, may be eliminated through the implementation of other organic mulches. 
Organic mulches are those which originate from a natural source. These can consist of byproducts of animal husbandry such as waste wool or unneeded hay, natural materials collected from surrounding areas, such as hardwood leaf litter, or byproducts of commercial processing, such as nut hulls, wood chips, or other materials. Organic mulches, by nature, are almost always permeable. Organic mulches typically do not need to be removed at the end of the growing season; additionally, their decomposition will return vital nutrients to the soil. The second part of this study will investigate the effects of wool, hay, and leaf litter mulch on soil temperature and moisture while using black polyethylene mulch as a control. Taken together, the individual parts of this proposed research aim to simplify and streamline the production of organic produce from seed to harvest. 


\section{CHAPTER II: MEDIA MOISTURE EFFECT ON ORGANIC TRANSPLANT PRODUCTION}

\section{Introduction}

Fertilizer runoff is a major component of water pollution. The EPA's 2000 National Water Quality Inventory report states that "pollution from urban and agricultural land that is transported by precipitation and runoff (called nonpoint source or NPS pollution) is the leading source of impairment" of U.S. waterways (U.S. EPA, 2002). A later EPA report listed nutrients "among the top ten pollutants preventing lakes, estuaries, and streams from meeting their designated uses in 2004" (Wilson, 2011). This runoff may arise from application of fertilizers to soil in excess, erosion of fertilized soil, improper recycling of greenhouse wastewater, and other sources.

Conventional greenhouse production of transplants often relies on abundant fertigation which produces large amounts of polluted runoff; Yeager et al. (1993) found that $\mathrm{NO}_{3}-\mathrm{N}_{\text {levels }}$ could be as high as $135 \mathrm{mg} \cdot \mathrm{L}^{-1}$ in collection ponds that held runoff from nursery production beds fertilized with a combination of controlled-release and soluble fertilizers. Wilson and Albano (2011) discovered that replacing soluble fertilizer applied as an additive to irrigation water with controlled-release fertilizer applied to the soil as a solid reduced median nitrate-nitrogen levels in greenhouse waste water from $31.2 \mathrm{mg} \cdot \mathrm{L}^{-1}$ to $0.9 \mathrm{mg} \cdot \mathrm{L}^{-1}$ in the production of large potted lady palms (Raphis excelsa). In contrast, Cox (1994) showed that even carefully-timed applications of controlled-release fertilizer resulted in losses of roughly $70 \%$ added nitrogen after 30 days when marigolds (Tagetes spp.) were grown in 10-cm pots. Though recycling systems in some greenhouses allow for reuse of wastewater, this water must be treated to avoid excess fertilization of crops and transmission of plant pathogens and the resulting concentrated waste subsequently disposed of. Given a target leaching value of approximately $20 \%$ container 
capacity (Wilson and Albano, 2011), the conclusion that conventional greenhouse production of transplants can cause water pollution is a valid one.

Limiting irrigation can reduce the amount of nutrients leached from media. Stowe et al. (2010) have shown that decreased irrigation of containerized white spruce seedlings from 55\% $\mathrm{V} / \mathrm{V}$ (volume percent) to $30 \% \mathrm{~V} / \mathrm{V}$ resulted in reduced levels of lost nutrients, especially mineral $\mathrm{N}$, without impact on seedling development. It is rational that limiting water could negatively impact plant growth and development. Kang et al. (2001) found that using alternate drip irrigation, where only half of a root mass is irrigated at a time, on containerized hot peppers (Capsicum anuиm) resulted in a comparable fruit yield to a fully irrigated control while using $40 \%$ less water. Studies with bald cypress (Taxodium distichum) in containers have shown that even under $60 \%$ water capacity plants were not placed under water stress (Sammons and Struve, 2008). Under this study, only plants watered in excess of container capacity produced any leachate. However, limiting leaching must be done while keeping in mind fertilization schedules and methods so that elevated electrical conductivity levels (beyond those required for optimal growth) can be avoided. Elevated electrical conductivity can cause a decrease in nutrient availability; these salts would theoretically be leached out under higher levels of irrigation. The cypress study relied on frequent rains in order to compensate for any salt buildup in soil as a result of fertilizer accumulation (Sammons and Struve, 2008). Savic et al. (2012) have shown that deficit irrigation regulated at $21 \%$ volumetric soil water content produced a tomato yield comparable to that from a freely irrigated field; these plants were reliant on native soil for nutrients and were not fertilized. In the greenhouse, however, transplants are reliant on artificially supplied irrigation and nutrients either present in the media or supplied in the form of fertilizer. 
Organic horticulture is based on an integrated production system using organic fertilizer inputs. This contrasts with conventional production systems, in which plant nutrition is based on using well-balanced, synthetic fertilizers in excess of plant uptake (Dorais, 2007). Organic media often include composts or other organic components to supply nutrients on which transplants can rely. Watering at the industry standard volume of $120 \%$ could result in the loss of these nutrients due to leaching. Gravel et al. (2012) have shown that sweet pepper transplants provided with only a solid organic fertilizer at the time of potting performed less favorably than those fertilized with an organic fertilizer throughout the experiment. The lack of availability of literature references for greenhouse production which did not use additional fertilizer suggests that relying solely on nutrients in the medium is an uncommon practice.

\section{Purpose of the Study: Goals}

The purpose of this study is to determine if organic transplants can be successfully produced in a greenhouse under reduced soil moisture in order to reduce leaching of nutrients and potential pollution of surface waters. A second and more detailed aspect of our study aims to investigate the influence of irrigation levels on nutrient changes in the media throughout transplant production. This research aims to clarify the effect of varying levels of irrigation on both retention of nutrients and the potential for increased electrical conductivity due to buildup of salts in the media under lower levels of water availability.

\section{Specific Objectives}

The first objective is to determine if organic media can produce a quality transplant without the addition of liquid or solid fertilizers other than the nutrient charges present in the media when purchased or formulated. To test this, we compared treatments to a conventional medium which was fertilized with every irrigation, which is the standard conventional industry 
practice. Second, we wanted to determine if organic transplants can be grown successfully under limited leaching conditions. Third, we wanted to determine the effect of these irrigation regimens on transplant production of three vegetables with varying production times: lettuce, tomato and bell peppers.

\section{Research Hypotheses}

\section{Objective 1:}

Hypothesis: Height, leaf number, fresh weight, and dry weight of transplants grown in organic media will be comparable to, or of higher quality, than transplants produced with conventional media and fertilization methods.

\section{Objective 2:}

Hypothesis: Reduced irrigation of 80 and $100 \%$ container capacity will produce transplants of equal or greater quality than those grown with traditional leaching irrigation regimens (120\%).

\section{Objective 3:}

Hypothesis: EC and pH will remain at adequate levels in all media throughout transplant production and produce quality transplants of lettuce, tomato and bell pepper, three vegetables with varying production times and cultural requirements.

\section{Research Design}

Three concurrent experiments were carried out on lettuce, tomato and pepper transplants. Each species was grown in a separate trial consisting of a two-factor experiment in a completely randomized design. Four media treatments: Sunshine Mix \#1 (control), Johnny’s 512 Mix, Black Gold Natural and Organic Potting Soil, and farm compost, were each subjected to one of three watering regimes: $80 \%, 100 \%$, or $120 \%$ of each individual medium's container capacity for a 
total of 12 treatment combinations. Each treatment combination was replicated ten times

(Appendix A). The experiment was repeated in 2015 and 2016.

\section{Materials and Methods}

\section{Location and environmental conditions}

Experiments were conducted in the West Virginia University Greenhouses, located in Morgantown, West Virginia $\left(39^{\circ} 38^{\prime} \mathrm{N} / 79^{\circ} 58^{\prime} \mathrm{W}\right)$. Greenhouse temperature from 23 February to 1 April 2015 averaged $23.8{ }^{\circ} \mathrm{C}$ day $\pm 5.8{ }^{\circ} \mathrm{C} / 22.5{ }^{\circ} \mathrm{C} \pm 3.9{ }^{\circ} \mathrm{C}$; temperature records for 2016 were unavailable. Relative humidity ranged widely, from $6 \% \mathrm{RH}$ to $61 \% \mathrm{RH}$, with an average of 25.4 \% RH. Peppers and tomatoes received supplemental bottom heat while germinating; lettuce did not. The experiments were carried out under natural irradiance from February to April in 2015 and April to June in 2016; no supplemental lighting was provided.

\section{Plant Material}

Three concurrent experiments with 120 plants each of pepper (Capsicum anuum) 'Olympus F1', tomato (Solanum lycopersicum) 'West Virginia '63', and lettuce (Lactuca sativa L.) 'Green Romaine’ were conducted. Pepper and lettuce seeds were sourced from Johnny’s Selected Seeds (Johnny's Selected Seeds, Winslow, ME) and tomato seeds were sourced from West Virginia University's 'West Virginia '63' development program.

Seeds were sown in 288-cell plug trays and grown to transplanting size in the greenhouse. Transplanting size in this experiment was indicated by the seedlings' second set of true leaves expanding. Seeds were sown in Sunshine Mix \#1 (Sun Gro Horticulture, Agawam, MA) and lightly covered with fine vermiculite to conserve moisture. Plug trays were placed on a mist bench; peppers and tomatoes received supplemental bottom heat, lettuce did not. Plants were randomly divided into four treatments of 30 plants each at the plug stage and transplanted 
into $10-\mathrm{cm}$ pots filled with four media, described below. There were 10 replications for each treatment, for a total of 120 plants per species used. Plants were spaced pot-to-pot on a single greenhouse bench. A randomized design was used, where plants are grouped by species but treatments are assigned and arranged randomly on the greenhouse bench. The bench layout was generated using Excel's random number generator for 120 numbers, corresponding to 120 spots on the grid of the bench (Appendix A). Boundary plants were used to reduce edge effects in plants at the perimeters of the $10 \times 12$ blocks. The boundary plants were WV' 63 tomatoes planted in Sunshine Mix and watered as needed.

Watering regime was determined by obtaining the container capacity of each medium at the beginning of the experiment and adding or subtracting $20 \%$ of the total volume of water contained in the media (Table 2.1). Plant height and leaf number as well as leachate $\mathrm{pH}$ and EC were determined bi-weekly, and the plant fresh and dry weight were determined at the conclusion of the study.

Table 2.1. Water volumes used to irrigate transplants at 80, 100, $120 \%$ VWC grown in Black Gold, Farm Compost, Johnny's 512 Mix, and Sunshine mix (control) in 2015 and 2016.

\section{Water applied $(\mathrm{mL})$}

\begin{tabular}{ccccccc}
\hline Medium & $\mathbf{8 0 \%}$ Container & \multicolumn{2}{c}{$\mathbf{1 0 0 \%}$ Container } & \multicolumn{2}{c}{ 120\% Container } \\
& \multicolumn{2}{c}{ Capacity } & \multicolumn{2}{c}{ Capacity } & \multicolumn{2}{c}{ Capacity } \\
\hline Year & $\mathbf{2 0 1 5}$ & $\mathbf{2 0 1 6}$ & $\mathbf{2 0 1 5}$ & $\mathbf{2 0 1 6}$ & $\mathbf{2 0 1 5}$ & $\mathbf{2 0 1 6}$ \\
\hline Black Gold & 154 & 149 & 193 & 186 & 232 & 223 \\
\hline Farm Compost & 56 & 121 & 70 & 151 & 84 & 181 \\
\hline Johnny's 512 Mix & 75 & 129 & 94 & 161 & 113 & 193 \\
\hline Sunshine Mix & 133 & 140 & 166 & 175 & 199 & 210 \\
\hline
\end{tabular}




\section{Media}

Four media were used over the course of this experiment. The commercially available conventional medium Sunshine Mix \#1 (Sun Gro Horticulture Canada Ltd.) was used as a control. This medium was fertigated according to conventional production practices; therefore, water containing 150 ppm nitrogen from Peter's Professional Peat-Lite Special (Everris NA, Inc.), a 20-10-20 fertilizer, was applied at treatment volumes. The two other commercial media used in the experiment were OMRI (Organic Materials Review Institute) certified and were chosen due to their commercial availability. Johnny’s 512 Mix (Johnny’s Selected Seeds, Winslow, ME) is composed of sedge and sphagnum peat mosses, compost, and perlite. Black Gold Natural \& Organic Potting Soil (Sun Gro Horticulture Canada Ltd.) is composed of 4555\% Canadian sphagnum peat moss, perlite, composted worm castings, and a blend that includes one or more of the following: compost, composted peanut hulls, composted rice hulls, forest products, pumice or cinders. The fourth medium used for the experiment was obtained from the market garden at the West Virginia University Plant and Soil Sciences Farm, a certified organic property located in Morgantown, West Virginia. This medium was derived from the WVU Animal Science Farm and consisted of wood chips, dairy manure, leaf litter, crop residues, and other organic matter. The medium was aged in a windrow for a minimum of 6 months before use, but was not composted according to USDA-NOP composting protocols and therefore was autoclaved to eliminate any pests or viable weed seeds (7 CFR 205.303; USDA-AMS, 2000).

\section{Irrigation}

Based on preliminary work, plants were watered at 80,100 , and $120 \%$ container capacity when volumetric water content was at $40 \%$ in the $80 \%$ treatment of Sunshine Mix, Johnny's 512 Mix, and Black Gold and at $50 \%$ in the $80 \%$ treatment of farm compost due to its lack of water- 
retaining peat moss. These thresholds avoided visible wilting in all three species, media and irrigation combinations. Forty percent VWC was determined with a FieldScout Soil Sensor Reader and a WaterScout SM 100 Soil Moisture Sensor inserted into the media (Spectrum Technologies, Inc, Aurora, IL). Sensors were new and were found to read true to factory calibration in distilled water. To determine container capacity, a $10-\mathrm{cm}$ pot was filled to within $2.5 \mathrm{~cm}$ of the rim with the selected oven-dried medium. Peat-based media were mixed thoroughly before being removed from the bag to prevent separation of ingredients. The medium was removed, weighed dry and returned to the pot. Water was applied until the medium was fully saturated and allowed to stop dripping before the wet soil was weighed again. The weight

gained was that of the water, which was then converted from grams to milliliters to obtain $100 \%$ container capacity. Eighty and $120 \%$ container capacity were calculated from this value (Table 2.1).

\section{Fertigation}

The conventional treatment was fertilized with Peter's Professional 20-10-20 Peat-Lite Special water-soluble fertilizer at $150 \mathrm{ppm}$ N. Fertilizer was stored as a 1:100 concentrated solution in the greenhouse and supplied to irrigation water via Dosatron D14MZ2 (Dosatron International, Inc.) fertilizer injectors. The conventional treatment was watered with this solution daily or as needed at the same percentages as the organic treatments $(80 \%, 100 \%$, and $120 \%$ ). The control was intended to emulate commercial conventional transplant production as closely as possible. No other treatments received additional liquid or dry fertilizer to supplement the nutrients present in the media at the start of the experiment.

The experiments described above were repeated twice, once in the spring of 2015 and once in the spring of 2016. The 2015 trial was initiated on 16 January with the planting of pepper 
seeds; tomato and lettuce seeds were planted in succession both years so that all plants were of transplanting size simultaneously. Transplanting took place on February 23, 2015, and the experiment was concluded on 15 April with the harvest, weight collection, and drying of all experimental plants. The 2016 trial was initiated on 16 March with sowing of peppers, transplanting of all study plants took place April 23, and the experiment was concluded on 1 June. The 2016 study was concluded somewhat earlier than anticipated due to drought stress experienced by the study plants under the experimental watering regime.

\section{Data Collection Procedures}

\section{Media characteristics}

Data on media physical and chemical characteristics were collected before the experiment. The characteristics measured before the start of the experiment were: wet and dry bulk density, container capacity, aeration. EC, and pH (Table 2.2). Bulk density is the dry weight of the medium divided by its total volume and is used as an indicator of compaction and in this case, container capacity. Container capacity was determined by saturating a known volume of oven dried medium with a known volume of water and then draining the excess water and weighing the remaining medium. Aeration refers to the amount of air spaces or pores in a medium; an aerated medium is less compacted and therefore would have a lower bulk density. Aeration was calculated by subtracting the weight of a drained medium from the combined weight of that oven dried medium and a known volume of water, then dividing the resulting amount by the volume of the medium. EC is a measure of the conductivity of a medium; higher solute concentration indicates a higher EC. $\mathrm{pH}$ is a measure of the acidity or basicity of a solution and an indicator of nutrient availability. Both EC and $\mathrm{pH}$ were measured using the pourthrough method (Wright, 1986). 
Table 2.2. Bulk density, container capacity, aeration, EC, and $\mathrm{pH}$ of the four media used to grow lettuce, tomato, and pepper transplants in 2015 and 2016

\begin{tabular}{|c|c|c|c|c|c|c|c|c|c|c|c|c|}
\hline \multirow[b]{2}{*}{ Year } & \multicolumn{2}{|c|}{$\begin{array}{l}\text { Oven Dry } \\
\text { Bulk } \\
\text { Density } \\
\text { (g/L) } \\
\end{array}$} & \multicolumn{2}{|c|}{$\begin{array}{l}\text { Wet Bulk } \\
\text { Density } \\
\text { (g/L) }\end{array}$} & \multicolumn{2}{|c|}{$\begin{array}{l}\text { Container } \\
\text { Capacity } \\
\text { (g/L) }\end{array}$} & \multicolumn{2}{|c|}{$\begin{array}{c}\text { Aeration } \\
(\%)\end{array}$} & \multicolumn{2}{|c|}{$\begin{array}{c}\text { EC } \\
\left(\mu S \bullet \mathrm{cm}^{-1}\right) \\
(\text { Week } 0)\end{array}$} & \multicolumn{2}{|c|}{$\begin{array}{c}\text { pH } \\
(\text { Week 0) }\end{array}$} \\
\hline & 2015 & 2016 & 2015 & 2016 & 2015 & 2016 & 2015 & 2016 & 2015 & 2016 & 2015 & 2016 \\
\hline Medium & & & & & & & & & & & & \\
\hline $\begin{array}{l}\text { Black } \\
\text { Gold }\end{array}$ & 190 & 120 & 640 & 670 & 490 & 540 & 13.3 & 8.2 & 3990 & 2747 & 6.1 & 4.2 \\
\hline $\begin{array}{c}\text { Farm } \\
\text { Compost }\end{array}$ & 460 & 540 & 830 & 940 & 410 & 490 & 22.3 & 19.7 & 4040 & 1270 & 7.9 & 7.5 \\
\hline $\begin{array}{l}\text { Johnny's } \\
512 \text { Mix }\end{array}$ & 320 & 350 & 890 & 640 & 580 & 680 & 12.5 & 6.5 & 7762 & 5923 & 7 & 7.7 \\
\hline $\begin{array}{c}\text { Sunshine } \\
\text { Mix }\end{array}$ & & 100 & & 680 & & 600 & & 12.6 & & 1584 & & 6 \\
\hline
\end{tabular}

\section{EC and pH}

EC and pH were measured at transplant (Week 0) with a Myron L model 6PFC Ultrameter II (Myron L ${ }^{\circledR}$ Company). Soil electrical conductivity (EC) was measured in microSiemens per square centimeter. Subsequent EC and pH measurements took place 2 weeks, 4 weeks, and 6 weeks after transplanting. For these measurements, leachate was collected using the pour-through method (Wright, 1986); in lieu of daily watering, where leachate was allowed to run freely onto the floor, pots were placed above clean containers and leachate collected in order to measure EC and $\mathrm{pH}$. All plants were watered at $120 \%$ container capacity for leachate collection purposes.

\section{Plant Measurements}

Plant height and leaf number were also measured every 2 weeks during the experiment, alternating weeks (Weeks 1, 3, and 5) with EC and $\mathrm{pH}$ data collection (Weeks 2, 4, and 6). This method of data collection was used due to time constraints experienced by data collectors. 
Measurements started 1 week after transplanting to allow for transplant establishment. At the conclusion of the experiment plants were harvested, their fresh shoot weight recorded, dried at $75^{\circ} \mathrm{C}$ for 48 hours, and weighed again.

\section{Statistical Analysis}

Data (pH, EC, fresh weight, dry weight, leaf count and plant height) were analyzed separately for each species (lettuce, tomato, and pepper) and week (1-6), while years (2015, 2016) were used as a random effect in the model used to analyze the data. Data for fresh weight and dry weight were collected at the end of the experiment each year $(2015,2016)$ and were also analyzed separately for each species. Normality of distribution of all response variables $(\mathrm{pH}, \mathrm{EC}$, fresh weight, dry weight, leaf count and plant height) was inspected by Shapiro-Wilk-W goodness of fit test. Variables that deviated from normality were transformed. Specifically, data for EC for lettuce and tomatoes were heavily skewed to the right, therefore a Ln transformation was applied. Normally distributed and transformed data were analyzed by factorial (two-way) ANOVA with fixed effects of media (Sunshine Mix \#1, Johnny's 512 Mix, Black Gold, and farm compost), irrigation ( $80 \%, 100 \%$, and $120 \%$ container capacity) and random effect of year $(2015,2016)$ separately for weeks 1 and 2,3 and 4 , and 5 and 6 . This ANOVA enabled us to test the main effects of media and irrigation and interaction of the two effects. ANOVA was followed by multiple comparisons, comparing each group to the control (Sunshine Mix at 120\% container capacity irrigation) with Dunnett's adjustment. Variables that deviated from normality and that transformation did not correct (leaf count and $\mathrm{pH}$ for all species) were analyzed by KruskalWallis test on all 12 treatment combinations, again separately for weeks 1 and 2, 3 and 4 and 5 and 6. Kruskal-Wallis is the nonparametric equivalent to a one-way ANOVA. Kruskal-Wallis 
was followed by the Steel test (nonparametric multiple comparison where all groups were compared to control: Sunshine Mix at $120 \%$ container capacity irrigation).

Even though treatments (media and irrigation) were applied to individual pots, no data were recorded on individual pots over time; therefore, repeated measures ANOVA was not possible when considering pots as experimental units. However, since the whole study was repeated a second year, another replicate was available and the results from each group of treatments could be averaged and used in repeated measures across weeks with the two subsequent years considered as replications. Thus, two experimental units were used for each group combination. A full, saturated model included seven terms; the main effects of media (4 categories), and irrigation (3 categories) and repeated effect of week (1 and 2, 3 and 4, and 5 and 6), three two-way interactions (media*irrigation, media*week, irrigation*week) and the threeway interaction (media*irrigation*week) was used.

Data were analyzed using JMP and SAS software (SAS Institute, 2015). Significance criterion alpha for all tests was 0.05 . 


\section{Results}

\section{Tomatoes}

At week 1, there were no significant effects of media, irrigation, or their interaction on height or leaf number of tomato plants (Table 2.3). However, by week 3 main effects of media and irrigation on height, as well as a difference among treatments in leaf number, were observed. Differences in leaf number among the treatments were significant only at week 3 . At weeks 2 and 4, there were significant effects of media, irrigation, and their interaction on EC; at week 6 only a main effect of media was discernible from leachate. A significant difference in $\mathrm{pH}$ among treatments was present throughout the course of the experiment. Fresh and dry weights differed significantly among media; irrigation levels had no effect on final plant weights.

Table 2.3. Statistical test for main effect of media, irrigation and their interaction on height, leaf count, fresh weight, dry weight, EC and pH through six weeks of data collection for tomato 'West Virginia '63' transplants.

\begin{tabular}{|c|c|c|c|c|}
\hline \multirow{2}{*}{$\frac{\text { Tomatoes }}{\text { Variable }}$} & \multirow[b]{2}{*}{$\begin{array}{c}\text { Time } \\
\text { (Week) }\end{array}$} & \multicolumn{3}{|c|}{ Effect tests (Two-way ANOVA $P$-value) } \\
\hline & & Media & Irrigation & Media $x$ Irrigation \\
\hline \multirow[t]{3}{*}{ Height (cm) } & 1 & 0.4819 & 0.1399 & 0.2307 \\
\hline & 3 & $0.0101 *$ & $0.033^{*}$ & 0.4826 \\
\hline & 5 & 0.101 & 0.3687 & 0.6812 \\
\hline \multirow[t]{3}{*}{$\mathrm{EC}\left(\boldsymbol{\mu S} \bullet \mathrm{cm}^{-1}\right)$} & 2 & $0.0137 *$ & $0.002 *$ & $0.0214 *$ \\
\hline & 4 & $0.0014 *$ & $<0.0001 *$ & $0.0466 *$ \\
\hline & 6 & $0.0055^{*}$ & 0.4995 & 0.1417 \\
\hline Fresh Weight (g) & 6 & $<0.0001 *$ & 0.1616 & 0.6108 \\
\hline \multirow[t]{2}{*}{ Dry Weight (g) } & 6 & $<0.0001^{*}$ & 0.3075 & 0.7839 \\
\hline & & \multicolumn{3}{|c|}{ Kruskal-Wallis (One-way analysis $P$-value) } \\
\hline \multirow[t]{3}{*}{ Leaf count } & 1 & \multicolumn{3}{|c|}{0.8943} \\
\hline & 3 & \multicolumn{3}{|c|}{$0.0014 *$} \\
\hline & 5 & \multicolumn{3}{|c|}{0.1497} \\
\hline \multirow[t]{3}{*}{ pH } & 2 & \multicolumn{3}{|c|}{$<0.0001 *$} \\
\hline & 4 & \multicolumn{3}{|c|}{$<0.0001 *$} \\
\hline & 6 & \multicolumn{3}{|c|}{$<0.0001 *$} \\
\hline
\end{tabular}

* indicates the significant effect at $P \leq 0.05$. 


\section{Tomatoes, Week 1-2 from the start of experiment}

At week 2, Kruskal-Wallis results indicated a significant difference in $\mathrm{pH}$ among the 12 treatments $(P<0.0001$, Table 2.3). This was expected due to the inherent differences in composition between the media (Table 2.2). Farm compost and Johnny's 512 Mix across all irrigation levels possessed a much higher leachate $\mathrm{pH}$ (Table 2.4) than the control (Sunshine $120 \%$ VWC). Dunnett's comparison to Sunshine at 120\% VWC irrigation (Control) detected significant main effects of media $(P=0.0137)$ and irrigation $(P=0.002)$ as well as their interaction $(P=0.0214)$ (Table 2.3) on the EC of media leachate.

Table 2.4. Plant height and leaf number of tomato 'West Virginia'63' grown in Black Gold, Farm Compost, Johnny's 512 Mix, and Sunshine Mix and watered at 80\%, 100\%, 120\% irrigation at week 1 and $E C$ and $\mathrm{pH}$ at week 2 for those same media and treatments. Means \pm standard error of the means (SEM).

\begin{tabular}{cccccc}
\hline \multicolumn{2}{c}{ Tomatoes } & \multicolumn{2}{c}{ Week 1 } & \multicolumn{2}{c}{ Week 2 } \\
\hline Medium & $\begin{array}{c}\text { Irrigation } \\
(\% \text { VWC })\end{array}$ & $\begin{array}{c}\text { Height } \\
(\mathrm{cm}) \pm \\
\text { SEM }\end{array}$ & $\begin{array}{c}\text { Leaf } \\
\text { Number } \pm \\
\text { SEM }\end{array}$ & $\begin{array}{c}\text { EC }\left(\mu \mathrm{S}^{\bullet} \mathrm{cm}^{-1}\right) \\
\pm \text { SEM }\end{array}$ & $\mathrm{pH} \pm$ SEM \\
\hline Black & 80 & $6.9 \pm 0.8$ & $3.7 \pm 0.2$ & $1491 \pm 188$ & $5.77 \pm 0.33$ \\
\cline { 2 - 6 } Gold & 100 & $7.1 \pm 0.8$ & $3.5 \pm 0.4$ & $1088 \pm 201$ & $5.82 \pm 0.31$ \\
\cline { 2 - 6 } & 120 & $7.6 \pm 0.8$ & $3.6 \pm 0.2$ & $1050 \pm 254$ & $5.92 \pm 0.24$ \\
\hline Farm & 80 & $7.4 \pm 0.6$ & $3.5 \pm 0.2$ & $2403 \pm 146^{*}$ & $7.97 \pm 0.11^{*}$ \\
\cline { 2 - 6 } Compost & 100 & $7.5 \pm 0.6$ & $3.6 \pm 0.3$ & $2205 \pm 355$ & $8.08 \pm 0.09^{*}$ \\
\cline { 2 - 6 } & 120 & $8.3 \pm 0.5$ & $3.7 \pm 0.2$ & $2426 \pm 318^{*}$ & $8.01 \pm 0.08^{*}$ \\
\hline Johnny's & 80 & $7.3 \pm 0.7$ & $3.6 \pm 0.3$ & $2919 \pm 507^{*}$ & $7.25 \pm 0.05^{*}$ \\
\cline { 2 - 6 } 512 Mix & 100 & $6.9 \pm 0.6$ & $3.4 \pm 0.2$ & $3916 \pm 312^{*}$ & $7.15 \pm 0.09^{*}$ \\
\cline { 2 - 6 } & 120 & $7.8 \pm 0.5$ & $3.7 \pm 0.2$ & $2632 \pm 490^{*}$ & $7.37 \pm 0.05^{*}$ \\
\hline Sunshine & 80 & $7.8 \pm 0.4$ & $3.8 \pm 0.2$ & $2557 \pm 409^{*}$ & $6.34 \pm 0.05$ \\
\cline { 2 - 6 } Mix & 100 & $7.2 \pm 0.7$ & $3.9 \pm 0.2$ & $1534 \pm 272$ & $6.35 \pm 0.06$ \\
& $\mathbf{1 2 0}$ & $\mathbf{7 . 7} \pm \mathbf{0 . 6}$ & $\mathbf{3 . 9} \pm \mathbf{0 . 1}$ & $\mathbf{1 4 2 7} \pm \mathbf{2 9 9}$ & $\mathbf{6 . 2 1} \pm \mathbf{0 . 0 7}$ \\
\hline
\end{tabular}

* Indicates the mean for the variable differed significantly $(P \leq 0.05)$ from the control group (Sunshine 120\% VWC) detected by Dunnett's test or Steel Method following Kruskal-Wallis, when appropriate. 


\section{EC (Week 2)}

EC of media leachate differed significantly at week 2 among media $(P=0.0137)$, irrigation $(P=0.002)$ and their interaction $(P=0.0214)$ (Table 2.3). According to Dunnett's comparison, EC was significantly higher in farm compost at 80\% and 120\%, Johnny's 512 Mix at $80 \%, 100 \%$, and $120 \%$, and Sunshine Mix at $80 \%$ VWC irrigation than in Sunshine at $120 \%$ VWC irrigation (Control) (Table 2.4).

\section{pH (Week 2)}

Kruskal-Wallis analysis for week 2 indicated significant differences in $\mathrm{pH}$ among the 12 treatment combinations ( $P=0.0001$, Table 2.3). Specifically, the Steel test detected that leachate from farm compost at $80 \%, 100 \%$, and $120 \%$ VWC irrigation as well as Johnny's 512 Mix at $80 \%, 100 \%$, and $120 \%$ VWC irrigation possessed significantly higher $\mathrm{pH}$ than Sunshine Mix at 120\% VWC irrigation (Table 2.4). 


\section{Tomatoes, Weeks 3-4 from the start of experiment}

Plant height in week 3 differed significantly among media $(P=0.0101)$ and irrigation levels $(P=0.033)$, however, interaction of media and irrigation was not significant (Table 2.3). Plant height at $80 \%$ was significantly lower than at $120 \%$ (Control). Leaf number in week 3 differed significantly among the 12 treatment combinations $(P=0.0014$, Table 2.3$)$, with several treatments possessing significantly fewer leaves than the control. By week 4 EC dropped across all irrigation levels and media when compared to week 2. Differences in $\mathrm{pH}$ were smaller than those at week 2, with only farm compost across all irrigations and Black Gold at 80\% exhibiting a $\mathrm{pH}$ significantly different from the control. 
Table 2.5. Plant height and leaf number of tomato 'West Virginia'63' grown in Black Gold, Farm Compost, Johnny's 512 Mix, and Sunshine Mix and watered at 80\%, 100\%, 120\% irrigation at week 3 and $E C$ and $p H$ at week 4 for those same media and treatments. Means \pm standard error of the means (SEM).

\begin{tabular}{llllll}
\hline \multicolumn{1}{c}{ Tomatoes } & \multicolumn{2}{c}{ Week 3 } & \multicolumn{2}{c}{ Week 4 } \\
\hline Medium & $\begin{array}{l}\text { Irrigation } \\
(\boldsymbol{\%} \text { VWC })\end{array}$ & $\begin{array}{l}\text { Height }(\mathbf{c m}) \\
\pm \text { SEM }\end{array}$ & $\begin{array}{l}\text { Leaf } \\
\text { Number } \\
\pm \text { SEM }\end{array}$ & $\begin{array}{c}\text { EC }\left(\boldsymbol{\mu S} \bullet \mathbf{c m}^{-1}\right) \\
\pm \text { SEM }\end{array}$ & $\begin{array}{l}\text { pH } \pm \\
\text { SEM }\end{array}$ \\
\hline Black & 80 & $29.3 \pm 1.8^{\mathrm{z}}$ & $8.9 \pm 0.3$ & $889 \pm 232$ & $5.9 \pm 0.3^{*}$ \\
\cline { 2 - 6 } Gold & 100 & $28 \pm 2.1$ & $8.8 \pm 0.2^{*}$ & $413 \pm 102$ & $6.6 \pm 0.3$ \\
\cline { 2 - 6 } & 120 & $29.9 \pm 3.3$ & $8.2 \pm 0.3^{*}$ & $285 \pm 79$ & $6.5 \pm 0.3$ \\
\hline Farm & 80 & $24.8 \pm 1.7^{\mathrm{y}}$ & $8.7 \pm 0.3^{*}$ & $1769 \pm 305^{*}$ & $7.8 \pm 0.1^{*}$ \\
Compost & 100 & $25.9 \pm 1^{\mathrm{y}}$ & $8.9 \pm 0.2^{*}$ & $1592 \pm 343^{*}$ & $7.7 \pm 0.1^{*}$ \\
\cline { 2 - 6 } & 120 & $29.7 \pm 1.5^{\mathrm{y}}$ & $9.3 \pm 0.2$ & $455 \pm 83$ & $8 \pm 0.1^{*}$ \\
\hline Johnny's & 80 & $29.7 \pm 1.5^{\mathrm{z}}$ & $8.7 \pm 0.3^{*}$ & $1721 \pm 358^{*}$ & $7.3 \pm 0.1$ \\
\cline { 2 - 6 } 512 Mix & 100 & $31 \pm 1.7$ & $9.3 \pm 0.3$ & $1849 \pm 229^{*}$ & $7.5 \pm 0.1$ \\
\cline { 2 - 6 } & 120 & $30.8 \pm 2.5$ & $8.9 \pm 0.3$ & $1268 \pm 214^{*}$ & $7.5 \pm 0.1$ \\
\hline Sunshine & 80 & $30.5 \pm 2^{\mathrm{z}}$ & $9.4 \pm 0.3$ & $786 \pm 178^{*}$ & $6.8 \pm 0.1$ \\
\cline { 2 - 6 } Mix & 100 & $30.5 \pm 2.2$ & $10 \pm 0.2$ & $455 \pm 138$ & $7 \pm 0.1$ \\
\cline { 2 - 6 } & $\mathbf{1 2 0}$ & $\mathbf{3 2 . 3} \pm \mathbf{2 . 4}$ & $\mathbf{9 . 7} \pm \mathbf{0 . 2}$ & $\mathbf{3 9 0} \pm \mathbf{1 0 6}$ & $\mathbf{7 . 1} \pm \mathbf{0 . 1}$ \\
\hline
\end{tabular}

* indicates the mean for the variable significantly differed from the control group (Sunshine 120\% VWC) detected by Dunnett's test or Steel Method following Kruskal-Wallis, when appropriate. ${ }^{\mathrm{z}}$ indicates the significant difference of the entire irrigation group (main effect, across all 4 media treatments) from the control group (120\% VWC, across all 4 media treatments).

$\mathrm{y}$ indicates the significant difference of the entire media group (main effect, across all 3 irrigation levels) from the control group (Sunshine Mix, across all 3 irrigation levels).

\section{Height (Week 3)}

Farm compost- treated tomatoes [average across all three (80, 100 and 120) irrigation levels] had significantly lower height than Sunshine-mix treated plants. Irrigation also had a statistically significant main effect on plant height; overall height at $80 \%$ was significantly lower than Control (120\%). Therefore, tomatoes could be grown in Black Gold, Johnny's 512 Mix, or Sunshine Mix at 100\% VWC irrigation and serve as substitutes for those grown in Sunshine Mix at $120 \%$ VWC. 


\section{Leaf Number (Week 3)}

Leaf number at week 3 differed significantly among the 12 treatment combinations $(P<$ 0.0014, Table 2.3). Plants grown in Sunshine Mix at 120\% VWC irrigation possessed significantly more leaves than plants grown in Black Gold at 100\% and 120\% VWC irrigation, farm compost at $80 \%$ and $100 \%$ VWC, and Johnny's 512 Mix at $80 \%$ VWC irrigation (Table 2.5). However, a similar number of leaves to the control was observed in Black Gold at $80 \%$, farm compost at $120 \%$, Johnny's 512 Mix at $100 \%$ and $120 \%$, and Sunshine Mix at $100 \%$ and $120 \%$ (Table 2.5).

\section{pH (Week 4)}

From week 2 to week 4, leachate $\mathrm{pH}$ rose in Black Gold, Johnny's 512 Mix, and Sunshine Mix, while $\mathrm{pH}$ of leachates from farm compost decreased (Tables 2.4 and 2.5). Specifically, pH of leachate from Black Gold at $80 \%$ VWC irrigation (lower than control) and farm compost at $80 \%, 100 \%$, and $120 \%$ VWC irrigation (higher) differed significantly from Sunshine Mix at 120\% VWC irrigation (Table 2.5). Black Gold at 100 and 120\% VWC irrigation, as well as Johnny's 512 Mix and Sunshine Mix across all irrigations all had similar pH as the control.

\section{EC (Week 4)}

Media $(P=0.0014)$, irrigation $(P<0.0001)$ and the interaction of media with irrigation $(P=0.0466)$, had significant effects on leachate EC at week 4 (Table 2.3). Specifically, the EC was the highest in Johnny's 512 Mix media at $100 \%$ VWC irrigation and lowest in Black Gold at 120\% VWC irrigation (Table 2.5). Dunnett's comparison to Sunshine Mix at 120\% VWC irrigation (Control) detected significant differences between control and farm compost at $80 \%$ and 100\% VWC irrigation, Johnny's 512 Mix at 80\%, 100\% and 120\% VWC irrigation, and Sunshine Mix at 80\% VWC irrigation. (Table 2.5) Statistically speaking, Black Gold across all 
irrigation levels as well as farm compost at 120\% VWC and Sunshine Mix at 100\% VWC irrigation were similar to the control. 


\section{Tomatoes, Weeks 5-6 from the start of experiment}

By weeks 5 and 6 many of the statistically significant differences present amongst treatment plants earlier in the study had disappeared. Two-way ANOVA detected no significant differences in height due to main effect of media (NS), effect of irrigation (NS), nor an interaction between media and irrigation at week 5 (NS). Kruskal-Wallis analysis for week 5 did not indicate significant differences in leaf number among the 12 treatment combinations (NS, Table 2.3). Despite the lack of significant differences in height and leaf number, a significant main effect of media was detected for fresh and dried shoot weights of tomato plants at 6 weeks $(\mathrm{p}<0.0001)$. However, neither the effects of irrigation nor the interaction were significant. Twoway ANOVA at week 6 indicated a significant effect of media $(\mathrm{p}=0.0055)$, but neither irrigation (NS) nor interaction of media with irrigation (NS) on EC (Table 2.3). Kruskal-Wallis analysis for week 6 indicated a significant difference in $\mathrm{pH}$ among the 12 treatment combinations $(\mathrm{p}<0.0001$, Table 2.3). 
Table 2.6. Plant height and leaf number of tomato 'West Virginia '63' grown in Black Gold, Farm Compost, Johnny's 512 Mix, and Sunshine Mix and watered at 80\%, 100\%, 120\% irrigation at week 5 and fresh weight, dry weight, EC and pH at week 6 for those same media and treatments. Means \pm standard error of the means (SEM).

\begin{tabular}{|c|c|c|c|c|c|c|c|}
\hline \multirow{2}{*}{$\begin{array}{l}\text { Tomatoes } \\
\text { Medium }\end{array}$} & \multicolumn{3}{|c|}{ Week 5} & \multicolumn{4}{|c|}{ Week 6} \\
\hline & $\begin{array}{l}\text { Irrigation } \\
\text { (\%VWC) }\end{array}$ & $\begin{array}{l}\text { Height } \\
(\mathrm{cm}) \pm \\
\text { SEM }\end{array}$ & $\begin{array}{l}\text { Leaf Number } \\
\pm \text { SEM }\end{array}$ & $\begin{array}{l}\text { Fresh } \\
\text { Weight } \\
\pm \text { SEM }\end{array}$ & $\begin{array}{l}\text { Dry Weight } \\
\text { 土 SEM }\end{array}$ & $\begin{array}{l}\mathrm{EC}\left(\mu \mathrm{\mu S} \mathrm{cm}^{-1}\right) \\
\pm \mathrm{SEM}\end{array}$ & $\begin{array}{l}\text { pH } \\
\pm \text { SEM }\end{array}$ \\
\hline \multirow[t]{3}{*}{ Black Gold } & 80 & $38.1 \pm 1.9$ & $9.3 \pm 0.5$ & $25 \pm 3.2^{y}$ & $3.1 \pm 0.5^{y}$ & $213 \pm 39.9$ & $6.4 \pm 0.1$ \\
\hline & 100 & $34.9 \pm 2$ & $8.1 \pm 0.4$ & $23.6 \pm 3.1^{\mathrm{y}}$ & $3 \pm 0.4^{y}$ & $243 \pm 90$ & $6.6 \pm 0.1$ \\
\hline & 120 & $38.6 \pm 2.2$ & $8.8 \pm 0.4$ & $24.3 \pm 3.6^{y}$ & $3 \pm 0.6^{y}$ & $301 \pm 106$ & $6.7 \pm 0.1$ \\
\hline \multirow{3}{*}{$\begin{array}{l}\text { Farm } \\
\text { Compost }\end{array}$} & 80 & $42.6 \pm 2.8$ & $9.4 \pm 0.5$ & $20.9 \pm 1.9^{y}$ & $1.9 \pm 0.2^{y}$ & $886 \pm 378$ & $7.8 \pm 0.1$ \\
\hline & 100 & $43 \pm 2.3$ & $7.6 \pm 0.5$ & $27.6 \pm 2.9^{y}$ & $2.8 \pm 0.4^{\mathrm{y}}$ & $333 \pm 77$ & $8.0 \pm 0.0$ \\
\hline & 120 & $45.4 \pm 2.6$ & $7.8 \pm 1.9$ & $24.6 \pm 2.3^{y}$ & $2.5 \pm 0.2^{y}$ & $522 \pm 107$ & $7.8 \pm 0.1$ \\
\hline \multirow{3}{*}{$\begin{array}{l}\text { Johnny's } 512 \\
\text { Mix }\end{array}$} & 80 & $42.3 \pm 1.1$ & $8.7 \pm 0.5$ & $32.1 \pm 3.7$ & $3.9 \pm 0.4$ & $749 \pm 256$ & $6.9 \pm 0.1$ \\
\hline & 100 & $41.9 \pm 2.3$ & $9 \pm 0.6$ & $38.2 \pm 1.6$ & $4.3 \pm 0.3$ & $1398 \pm 362$ & $7.0 \pm 0.2$ \\
\hline & 120 & $40.6 \pm 2.5$ & $9.2 \pm 0.5$ & $32.8 \pm 4.2$ & $4.6 \pm 0.4$ & $838 \pm 207$ & $7.2 \pm 0.1 *$ \\
\hline \multirow{3}{*}{$\begin{array}{l}\text { Sunshine } \\
\text { Mix }\end{array}$} & 80 & $47.3 \pm 3$ & $7.8 \pm 0.4$ & $39.8 \pm 2.8$ & $4.7 \pm 0.4$ & $959 \pm 180$ & $6.5 \pm 0.0$ \\
\hline & 100 & $45.6 \pm 2.2$ & $7.4 \pm 0.4$ & $40.9 \pm 2.5$ & $4.8 \pm 0.3$ & $889 \pm 289$ & $6.5 \pm 0.0$ \\
\hline & 120 & $48 \pm 2.9$ & $8.2 \pm 0.4$ & $39.1 \pm 3.9$ & $5.1 \pm 0.5$ & $789 \pm 198$ & $6.5 \pm 0.0$ \\
\hline
\end{tabular}

* indicates the mean for the variable significantly differed from the control group (Sunshine 120\% VWC) detected by Dunnett's test or Steel Method following Kruskal-Wallis, when appropriate.

$\mathrm{y}$ indicates the significant difference of the entire media group (main effect, across all 3 irrigation levels) from the control group (Sunshine Mix, across all 3 irrigation levels). 


\section{pH (Week 6)}

pH differed significantly among the 12 treatment combinations $(P<0.0001$, Table 2.3$)$. Specifically, the Steel test detected that Johnny's 512 Mix at 120\% VWC irrigation differed from Sunshine Mix at 120\% VWC irrigation (Table 2.3). $\mathrm{pH}$ was highest in farm compost at 100\% VWC irrigation and lowest in Black Gold at 80\% VWC irrigation (Table 2.6).

\section{Fresh Weight (Week 6)}

A significant main effect of media was detected for fresh weight of tomato plants at 6 weeks $(P<0.0001)$, but the effect of irrigation or the interaction were not significant. Dunnett's comparison of each medium to Sunshine (across all irrigations) detected a significantly lower fresh weight than control in Black Gold and farm compost across all irrigations (Table 2.6) Johnny’s 512 Mix across all irrigations was comparable to the control.

\section{Dry Weight (Week 6)}

Only the main effect of media was significant for dry weight of tomato plants at 6 weeks $(P<0.0001)$. The largest average dry weight was $5.1 \pm 0.5 \mathrm{~g}$ using Sunshine mix at $120 \% \mathrm{VWC}$ irrigation, the smallest was for farm compost at $80 \%$ VWC irrigation $(1.9 \pm 0.2 \mathrm{~g})$. Dry weight of tomato in both Black Gold $(P<0.0053)$ and farm compost $(P<0.0001)$ differed significantly from the Sunshine mix, across all irrigations (Table 2.6). Again, Johnny's 512 Mix across all irrigation levels was statistically similar to the control.

\section{EC (Week 6)}

Two-way ANOVA at week 6 results indicate significant effects of media $(P=0.0055)$, but neither irrigation (NS) nor interaction (NS) on EC (Table 2.3). Specifically, the EC was the highest at Johnny's 512 Mix (across all irrigations) and lowest in Black Gold. However, 
Dunnett's comparison of each medium to Sunshine (across all irrigations) did not detect significant differences between the control and any organic medium. 


\section{Peppers}

No significant effect of irrigation or the interaction of media and irrigation was detected on height throughout the course of the experiment (Table 2.7). A significant difference in leaf number among the 12 treatments was not detectable at week 1, but was apparent at weeks 3 and 5. A significant difference amongst the treatments with regards to $\mathrm{pH}$ was detectable throughout the course of the experiment. At week 2 a main effect of media on the EC of leachate was apparent; weeks 4 and 6 exhibited main effects of media and irrigation, but a significant effect of their interaction was not detected at any time. Only a main effect of media was observed with regards to fresh and dry weights.

Table 2.7. Statistical test for main effect of media, irrigation and their interaction on variables.

\begin{tabular}{|c|c|c|c|c|}
\hline \multicolumn{2}{|l|}{ Pepper } & \multicolumn{3}{|c|}{ Effect tests (2-way ANOVA • p-value) } \\
\hline Variable & $\begin{array}{l}\text { Time } \\
\text { (Week) }\end{array}$ & Media & Irrigation & Media x Irrigation \\
\hline \multirow[t]{3}{*}{ Height $(\mathrm{cm})$} & 1 & $0.036 *$ & 0.1186 & 0.8092 \\
\hline & 3 & $0.0422 *$ & 0.458 & 0.4001 \\
\hline & 5 & $<.0001^{*}$ & 0.1692 & 0.1166 \\
\hline \multirow[t]{3}{*}{$\mathrm{EC}\left(\mu \mathrm{S} \cdot \mathrm{cm}^{-1}\right)$} & 2 & $<.0001 *$ & 0.3815 & 0.0824 \\
\hline & 4 & $<.0001 *$ & $0.0366^{*}$ & 0.9164 \\
\hline & 6 & $<.0001 *$ & $0.0033 *$ & 0.1165 \\
\hline Fresh Weight (g) & 6 & $0.0009 *$ & 0.7484 & 0.5098 \\
\hline \multirow[t]{2}{*}{ Dry Weight (g) } & 6 & $0.0018^{*}$ & 0.4895 & 0.5775 \\
\hline & & \multicolumn{3}{|c|}{ Kruskal-Wallis (1-way analysis p-value) } \\
\hline \multirow[t]{3}{*}{ Leaf count } & 1 & \multicolumn{3}{|c|}{0.3574} \\
\hline & 3 & \multicolumn{3}{|c|}{$0.0199 *$} \\
\hline & 5 & \multicolumn{3}{|c|}{$<.0001 *$} \\
\hline \multirow[t]{3}{*}{$\mathrm{pH}$} & 2 & \multicolumn{3}{|c|}{$<.0001 *$} \\
\hline & 4 & \multicolumn{3}{|c|}{$<.0001 *$} \\
\hline & 6 & \multicolumn{3}{|c|}{$<.0001 *$} \\
\hline
\end{tabular}

* Indicates the significant effect at 0.05 .

\section{Peppers, Weeks 1-2 from the start of experiment}

At week 1, no significant differences in height or leaf number were found when comparing treatments to the control (Sunshine $120 \%$ VWC). At this early stage, a significant 
effect of media on EC was detected ( $\mathrm{p}<.0001)$, which is understandable and perhaps expected, though no effect of irrigation or interaction was discernible (Table 2.8). With regards to $\mathrm{pH}$, farm compost and Johnny's 512 Mix possessed a significantly higher $\mathrm{pH}$ across all irrigation levels than Sunshine Mix and Black Gold.

Table 2.8. Plant height and leaf number of pepper 'Olympus F1' grown in Black Gold, Farm Compost, Johnny's 512 Mix, and Sunshine Mix and watered at 80\%, 100\%, 120\% irrigation at week 1 and $\mathrm{EC}$ and $\mathrm{pH}$ at week 2 for those same media and treatments. Means \pm standard error of the means (SEM).
Peppers
Week 1
Week 2

\begin{tabular}{llllll}
\hline Medium & $\begin{array}{l}\text { Irrigation } \\
(\% \text { VWC })\end{array}$ & $\begin{array}{l}\text { Height }(\mathbf{c m}) \\
\pm \text { SEM }\end{array}$ & $\begin{array}{l}\text { Leaf } \\
\text { Number } \pm \\
\text { SEM }\end{array}$ & $\begin{array}{c}\left.\text { EC( } \boldsymbol{\mu S \bullet c m}^{-1}\right) \\
\pm \text { SEM }\end{array}$ & $\begin{array}{l}\text { pH } \pm \\
\text { SEM }\end{array}$ \\
\hline Black & 80 & $12.2 \pm 2.8$ & $2.9 \pm 0.3$ & $1906 \pm 316^{\mathrm{y}}$ & $5.6 \pm 0.3$ \\
Gold & 100 & $10.2 \pm 2$ & $3 \pm 0.3$ & $2140 \pm 545^{\mathrm{y}}$ & $5.6 \pm 0.2$ \\
\cline { 2 - 6 } & 120 & $13.1 \pm 3.1$ & $2.8 \pm 0.3$ & $1964 \pm 310^{\mathrm{y}}$ & $5.6 \pm 0.3$ \\
\hline Farm & 80 & $12.7 \pm 3.4$ & $2.8 \pm 0.3$ & $1755 \pm 371^{\mathrm{y}}$ & $8.1 \pm 0.1^{*}$ \\
\cline { 2 - 6 } Compost & 100 & $11.7 \pm 2.4$ & $2.9 \pm 0.3$ & $1721 \pm 388^{\mathrm{y}}$ & $8.1 \pm 0.1^{*}$ \\
\cline { 2 - 6 } & 120 & $11.4 \pm 2.9$ & $3 \pm 0.3$ & $2464 \pm 208^{\mathrm{y}}$ & $8.2 \pm 0.1^{*}$ \\
\hline Johnny's & 80 & $18 \pm 3.9$ & $3.4 \pm 0.4$ & $4124 \pm 682^{\mathrm{y}}$ & $7 \pm 0 *$ \\
\cline { 2 - 6 } 512 Mix & 100 & $14.1 \pm 2.8$ & $3.1 \pm 0.4$ & $4463 \pm 772^{\mathrm{y}}$ & $7.1 \pm 0.1^{*}$ \\
\cline { 2 - 6 } & 120 & $16 \pm 3.7$ & $3.2 \pm 0.4$ & $5157 \pm 414^{\mathrm{y}}$ & $7 \pm 0.1^{*}$ \\
\hline Sunshine & 80 & $14.9 \pm 3.3$ & $3.1 \pm 0.3$ & $3064 \pm 363$ & $6.1 \pm 0$ \\
\cline { 2 - 6 } Mix & 100 & $14.7 \pm 2.9$ & $3.6 \pm 0.5$ & $2777 \pm 453$ & $6.1 \pm 0$ \\
\cline { 2 - 6 } & $\mathbf{1 2 0}$ & $\mathbf{1 4 . 5} \pm \mathbf{2 . 6}$ & $\mathbf{3 . 7} \pm \mathbf{0 . 5}$ & $\mathbf{2 4 3 7} \pm \mathbf{3 5 5}$ & $\mathbf{6 . 1} \pm \mathbf{0}$ \\
\hline
\end{tabular}

* indicates the mean for the variable significantly differed from the control group (Sunshine 120\% VWC) detected by Dunnett's test or Steel Method following Kruskal-Wallis, when appropriate. ${ }^{\mathrm{y}}$ indicates the significant difference of the entire media group (main effect, across all 3 irrigation levels) from the control group (Sunshine Mix, across all 3 irrigation levels).

\section{Height (Week 1)}

Two-way ANOVA detected a significant difference due to main effect of media $(P<$ 0.0001); however, no effect of irrigation (NS), or interaction (NS), was detected. Plant height was highest in Johnny's 512 Mix at 80\% VWC irrigation and lowest in Black Gold at 100\% 
VWC irrigation, Table 2.7; however, no significant differences were detected comparing each media to Sunshine Mix using Dunnett's test.

\section{EC (Week 2)}

Two-way ANOVA results indicate significant effect of media $(P<0.0001)$, though no effect of irrigation or interaction (Table 2.7). Specifically, the EC was lower in Black Gold and farm compost, but higher in Johnny's 512 Mix when each was compared to Sunshine Mix (Control) across all irrigation levels (Table 2.8).

\section{pH (Week 2)}

Kruskal-Wallis analysis for week 2 indicate significant difference among the 12 treatment combinations $(P<0.0001$, Table 2.7). Specifically, the Steel test detected that Farm compost at $80 \%, 100 \%$, and 120\% VWC irrigation as well as Johnny's 512 Mix at 80\%, 100\%, and $120 \%$ VWC irrigation each differed from Sunshine Mix at 120\% VWC irrigation (Table 2.6). $\mathrm{pH}$ was highest in farm compost at $120 \%$ VWC irrigation $(8.2 \pm 0.1)$ and lowest in Black Gold at 100\%VWC irrigation (5.6 \pm 0.2) (Table 2.7). 


\section{Peppers, Weeks 3-4 from start of experiment}

With regards to leaf number, Kruskal-Wallis analysis for week 4 was initially done on all 12 treatment combinations, but the sample size for each group was too small to do the nonparametric multiple comparisons. Therefore, only the main effect of media (4 groups) across all irrigation levels was analyzed and significant effect of media was found $(\mathrm{p}<0.0199)$. Twoway ANOVA EC results indicate significant effect of media $(P<0.0001)$ and irrigation $(P=$ 0.0366), however no effect of interaction (NS), Table 2.9.

Table 2.9. Plant height and leaf number of pepper 'Olympus F1' grown in Black Gold, Farm Compost, Johnny's 512 Mix, and Sunshine Mix and watered at 80\%, 100\%, 120\% irrigation at week 3 and $E C$ and $p H$ at week 4 for those same media and treatments. Means \pm standard error of the means (SEM).

\begin{tabular}{|c|c|c|c|c|c|}
\hline \multirow[b]{2}{*}{ Medium } & \multirow{2}{*}{$\begin{array}{l}\text { Peppers } \\
\text { Irrigation } \\
(\% \\
\text { VWC) }\end{array}$} & \multicolumn{2}{|c|}{ Week 3} & \multicolumn{2}{|c|}{ Week 4} \\
\hline & & $\begin{array}{l}\text { Height }(\mathrm{cm}) \\
\pm \text { SEM }\end{array}$ & $\begin{array}{l}\text { Leaf } \\
\text { Number } \\
\pm \text { SEM }\end{array}$ & $\begin{array}{c}\mathrm{EC}\left(\mu \mathrm{S} \cdot \mathrm{cm}^{-1}\right) \\
\pm \mathrm{SEM}\end{array}$ & $\begin{array}{l}\text { pH } \pm \\
\text { SEM }\end{array}$ \\
\hline \multirow[t]{3}{*}{ Black Gold } & 80 & $28 \pm 3.3$ & $8.9 \pm 1.4$ & $891 \pm 192^{z}$ & $6.1 \pm 0.3$ \\
\hline & 100 & $26.4 \pm 3.6$ & $8.2 \pm 1.3$ & $865 \pm 158$ & $6 \pm 0.3$ \\
\hline & 120 & $28.1 \pm 3.1$ & $9.1 \pm 1.3$ & $698 \pm 154$ & $6.2 \pm 0.3$ \\
\hline \multirow{3}{*}{$\begin{array}{l}\text { Farm } \\
\text { Compost }\end{array}$} & 80 & $18.9 \pm 2^{y}$ & $6.9 \pm 1.3^{y}$ & $2014 \pm 447^{z}$ & $7.4 \pm 0.1 *$ \\
\hline & 100 & $22.9 \pm 3.1^{\mathrm{y}}$ & $8.3 \pm 1.3^{y}$ & $1597 \pm 292$ & $7.6 \pm 0 *$ \\
\hline & 120 & $17.8 \pm 2.6^{y}$ & $5.8 \pm 1.1^{y}$ & $1690 \pm 201$ & $7.4 \pm 0.1^{*}$ \\
\hline \multirow{3}{*}{$\begin{array}{l}\text { Johnny's } \\
512 \text { Mix }\end{array}$} & 80 & $26.4 \pm 2.3$ & $7.3 \pm 1.4$ & $2728 \pm 427^{y z}$ & $7.2 \pm 0.1^{*}$ \\
\hline & 100 & $29.8 \pm 3.9$ & $8 \pm 1.3$ & $2460 \pm 633^{y}$ & $7.3 \pm 0^{*}$ \\
\hline & 120 & $30.8 \pm 4.9$ & $8.7 \pm 1.3$ & $2146 \pm 253^{y}$ & $7.2 \pm 0.1^{*}$ \\
\hline \multirow{3}{*}{$\begin{array}{l}\text { Sunshine } \\
\text { Mix }\end{array}$} & 80 & $31.6 \pm 4.4$ & $10.4 \pm 1.4$ & $1427 \pm 239^{z}$ & $6.4 \pm 0.1$ \\
\hline & 100 & $30.6 \pm 3.5$ & $9.8 \pm 1.5$ & $1014 \pm 124$ & $6.5 \pm 0$ \\
\hline & 120 & $37.1 \pm 5.9$ & $11.3 \pm 1.3$ & $991 \pm 118$ & $6.4 \pm 0$ \\
\hline
\end{tabular}

* indicates the mean for the variable significantly differed from the control group (Sunshine 120\% VWC) detected by Dunnett's test or Steel Method following Kruskal-Wallis, when appropriate. ${ }^{\mathrm{z}}$ indicates the significant difference of the entire irrigation group (main effect, across all 4 media treatments) from the control group (120\% VWC, across all 4 media treatments).

$\mathrm{y}$ indicates the significant difference of the entire media group (main effect, across all 3 irrigation levels) from the control group (Sunshine Mix, across all 3 irrigation levels). 


\section{Height (Week 3)}

Media had significant effect on plant height at week $3(P<0.0422)$, however no main effect of irrigation or interaction (NS) was present. Among media, height of peppers was significantly lower in plants grown in farm compost than those grown in Sunshine Mix.

\section{Leaf Number (Week 3)}

Kruskal-Wallis analysis for week 4 was initially done on all 12 treatment combinations, but the sample size for each group was too small to do the nonparametric multiple comparisons. Therefore, only main effect of media (4 groups) across all irrigation levels was analyzed using Kruskal-Wallis and significant effect of media was found $(P<0.0199)$. Similarly to height, peppers grown in farm compost possessed significantly fewer leaves than plants grown in Sunshine Mix as well as the other commercial mixes. It is possible that this could be due to farm compost's lack of water-retaining peat limiting nutrient availability to plants grown in that medium.

\section{EC (Week 4)}

Media $(P<0.0001)$ and irrigation $(P=0.0366)$ had significant effects on leachate $\mathrm{EC}$ at week 4; however, no effect of interaction was present (NS, Table 2.7). Specifically, the EC was the highest at Johnny's 512 (across all irrigation levels) and lowest at Black Gold. The EC in Johnny's 512 Mix was significantly higher than Sunshine using Dunnett's test. EC from plants irrigated at $80 \%$ VWC (across all media) compared to $120 \%$ was significantly higher.

\section{pH (Week 4)}

$\mathrm{pH}$ changes from week 2 to week 4 were similar to those of tomatoes, with Black Gold, Johnny's 512 Mix, and Sunshine Mix rising and farm compost decreasing. The Steel test detected that both farm compost and Johnny's 512 Mix at 80\%, 100\%, and 120\% VWC 
irrigation possessed a significantly higher $\mathrm{pH}$ than Sunshine Mix at 120\% VWC irrigation (Table 2.9). 


\section{Peppers, Weeks 5-6 from start of experiment}

With regards to leaf number (week 5) and pH (week 6), due to the small sample size, multiple comparisons on all 12 treatment combinations were not reliable. Therefore, only the main effects of media and irrigation were examined. We found main effect of media on $\mathrm{pH}$ (Kruskal-Wallis, $P \leq 0.0001$ ) as well as leaf number (Kruskal-Wallis, $P \leq 0.0001$ ), but no effect of irrigation was found for either variable. Two-way ANOVA results indicated a significant effect of media on height at week $5(P \leq 0.0001)$, however no effect of irrigation or interaction was detected. At week 6, two-way ANOVA results indicated significant effects of media ( $P \leq$ 0.0001) and irrigation $(P=0.0033)$ on $\mathrm{EC}$, however no effect of interaction (NS), Table 2.7. A significant main effect of media was detected in terms of fresh and dry weights; Black Gold and farm compost both possessed significantly lower fresh weights than control, while farm compost possessed a significantly lower dry weight. 
Table 2.10. Plant height and leaf number of pepper 'Olympus F1' grown in Black Gold, Farm Compost, Johnny's 512 Mix, and Sunshine Mix and watered at 80\%, 100\%, 120\% irrigation at week 5 and fresh weight, dry weight, EC and pH at week 6 for those same media and treatments. Means \pm standard error of the means (SEM).

\begin{tabular}{|c|c|c|c|c|c|c|c|}
\hline \multicolumn{2}{|c|}{ Peppers } & \multicolumn{2}{|c|}{ Week 5} & \multicolumn{4}{|c|}{ Week 6} \\
\hline Medium & $\begin{array}{l}\text { Irrigation } \\
\text { (\% VWC) }\end{array}$ & $\begin{array}{c}\text { Height (cm) } \\
\pm \text { SEM }\end{array}$ & $\begin{array}{c}\text { Leaf } \\
\text { Number } \pm \\
\text { SEM }\end{array}$ & $\begin{array}{l}\text { Fresh } \\
\text { Weight (g) } \\
\pm \text { SEM }\end{array}$ & $\begin{array}{c}\text { Dry Weight } \\
\text { (g) } \pm \text { SEM }\end{array}$ & $\begin{array}{c}\mathrm{EC}\left(\boldsymbol{\mu S \bullet \mathrm { cm } ^ { - 1 } )}\right. \\
\pm \mathrm{SEM}\end{array}$ & $\mathrm{pH} \pm \mathrm{SEM}$ \\
\hline \multirow[t]{3}{*}{ Black Gold } & 80 & $25.7 \pm 1$ & $13.2 \pm 0.7^{\mathrm{y}}$ & $7.7 \pm 1.9^{y}$ & $1.1 \pm 0.2$ & $859 \pm 201^{z}$ & $6.8 \pm 0.1^{y}$ \\
\hline & 100 & $24.9 \pm 1.2$ & $13.6 \pm 0.9^{\mathrm{y}}$ & $7.5 \pm 1.8^{y}$ & $0.8 \pm 0.2$ & $723 \pm 80$ & $6.8 \pm 0.1^{\mathrm{y}}$ \\
\hline & 120 & $25.4 \pm 1.2$ & $12.8 \pm 0.5^{\mathrm{y}}$ & $7.8 \pm 1.9^{y}$ & $0.9 \pm 0.2$ & $637 \pm 41$ & $6.7 \pm 0.1^{y}$ \\
\hline \multirow{3}{*}{$\begin{array}{c}\text { Farm } \\
\text { Compost }\end{array}$} & 80 & $22.7 \pm 1.7^{y}$ & $8.4 \pm 2^{y}$ & $7 \pm 1.8^{y}$ & $0.7 \pm 0.2^{y}$ & $2295 \pm 121^{\mathrm{yz}}$ & $7.6 \pm 0^{y}$ \\
\hline & 100 & $20.7 \pm 1.6^{y}$ & $9 \pm 0.9^{y}$ & $7.8 \pm 1.9^{y}$ & $0.8 \pm 0.2^{y}$ & $1257 \pm 332^{y}$ & $7.7 \pm 0.1^{y}$ \\
\hline & 120 & $22.8 \pm 2.3^{y}$ & $9.8 \pm 0.8^{y}$ & $6 \pm 1.8^{y}$ & $0.6 \pm 0.2^{y}$ & $1239 \pm 291^{y}$ & $7.7 \pm 0^{y}$ \\
\hline \multirow{3}{*}{$\begin{array}{c}\text { Johnny's } 512 \\
\text { Mix }\end{array}$} & 80 & $33 \pm 0.8$ & $13.8 \pm 0.7^{y}$ & $9.7 \pm 2.4$ & $1.1 \pm 0.3$ & $2643 \pm 484^{\mathrm{yz}}$ & $7 \pm 0.4^{y}$ \\
\hline & 100 & $26.4 \pm 1.5$ & $12.2 \pm 1.1^{\mathrm{y}}$ & $7.5 \pm 1.4$ & $0.7 \pm 0.1$ & $1571 \pm 275^{y}$ & $7.5 \pm 0^{y}$ \\
\hline & 120 & $28.6 \pm 1.7$ & $11.2 \pm 2.5^{y}$ & $9.4 \pm 1.5$ & $1 \pm 0.2$ & $1562 \pm 286^{y}$ & $7.4 \pm 0^{y}$ \\
\hline \multirow{3}{*}{$\begin{array}{c}\text { Sunshine } \\
\text { Mix }\end{array}$} & 80 & $28.6 \pm 0.9$ & $16.2 \pm 1.4$ & $12.2 \pm 3.2$ & $1.5 \pm 0.4$ & $1061 \pm 196^{z}$ & $6.6 \pm 0$ \\
\hline & 100 & $30.5 \pm 0.4$ & $18.4 \pm 0.7$ & $12.5 \pm 3.4$ & $1.4 \pm 0.4$ & $1328 \pm 341$ & $6.7 \pm 0$ \\
\hline & 120 & $30.4 \pm 1.3$ & $18 \pm 1.9$ & $14.6 \pm 3$ & $1.7 \pm 0.4$ & $897 \pm 120$ & $6.3 \pm 0$ \\
\hline
\end{tabular}

* indicates the mean for the variable significantly differed from the control group (Sunshine 120\% VWC) detected by Dunnett's test or Steel Method following Kruskal-Wallis, when appropriate.

${ }^{\mathrm{z}}$ indicates the significant difference of the entire irrigation group (main effect, across all 4 media treatments) from the control group (120\% VWC, across all 4 media treatments).

$\mathrm{y}$ indicates the significant difference of the entire media group (main effect, across all 3 irrigation levels) from the control group (Sunshine Mix, across all 3 irrigation levels). 


\section{Leaf Number (Week 5)}

Due to the small sample size ( $\mathrm{n}=5$; human error) multiple comparisons on all 12 treatment combinations were not reliable thus only the main effects of media and irrigation were examined at week 5 and only a main effect of media was apparent (Kruskal-Wallis, $P \leq 0.0001$ ). The three groups of peppers using experimental media had on average four to eight leaves less at week 5 than peppers in the Sunshine Mix and were each significantly different compared to Sunshine Mix. Specific leaf counts' means \pm SEM were $17.3 \pm 0.8$ in Sunshine Mix, $13.2 \pm 0.4$ in Black Gold $(P=0.0016), 9.1 \pm 0.7$ in farm compost $(P<0.0001)$, and $12.4 \pm 0.9$ in Johnny's 512 Mix peppers $(P=0.0011)$.

\section{Height (Week 5)}

Two-way ANOVA results indicate a significant effect of media $(P<0.0001)$, however no effect of irrigation or interaction. Only heights of pepper plants grown in farm compost were significantly lower than control.

\section{Fresh Weight (Week 6)}

Significant main effect of media was detected for fresh weight of pepper plants at 6 weeks $(P=0.0009)$, without effect of irrigation (NS) or interaction (NS). The largest average fresh weight was $13.13 \pm 1.8 \mathrm{~g}$ using Sunshine Mix, which was significantly higher than farm compost as well as Black Gold across all irrigations (Table 2.10). Similarly to tomatoes, the fresh weight of pepper shoots grown in Johnny's 512 Mix across all irrigations was statistically similar to the control.

\section{Dry Weight (Week 6)}

Significant main effect of media was detected for dry weight of pepper plants at 6 weeks (P < 0.0018), without effect of irrigation (NS) or interaction (NS). Dunnett's comparison of each 
media to Sunshine Mix detected a dry weight of pepper plants in farm compost being significantly lower. Dry weights of plants grown in Black Gold and Johnny's 512 Mix were comparable to the control.

\section{pH (Week 6)}

Due to the small sample size, multiple comparisons on all 12 treatment combinations were not reliable thus only the main effects of media and irrigation were examined at week 6 . We found main effect of media (Kruskal-Wallis, $P \leq 0.0001)$. All three media had significantly higher $\mathrm{pH}$ when compared to $\mathrm{pH}$ of Sunshine mix. There were no significant differences in $\mathrm{pH}$ among the three irrigation levels.

\section{EC (Week 6)}

Media $P \leq 0.0001)$ and irrigation $(P=0.0033)$ had significant effects on leachate EC at week 6; however, no effect of interaction was present (NS, Table 2.7). Specifically, the EC across all irrigation levels was higher for farm compost and Johnny's 512 Mix than in Sunshine Mix. Leachate EC across all media was significantly higher in plants irrigated at $80 \% \mathrm{VWC}$ than those irrigated at $120 \%$ VWC. 


\section{Lettuce}

At week 1 from the start of the experiment, only a main effect of media on plant height was detectable and there were no significant differences amongst the 12 treatments in regards to leaf count. At week 2 a significant difference amongst the 12 treatments was detectable with regards to $\mathrm{pH}$; this difference remained significant throughout the course of the experiment. Significant effects of media, irrigation, and their interaction on EC were detectable in leachate at week 2; Johnny’s 512 Mix yielded a significantly higher EC across all irrigation levels. Main effects of media and irrigation on EC were significant at week 4, but the interaction present at week 2 was no longer significant. Significant main effects of media on height as well as a significant difference amongst treatments with regards to leaf count were present at week 5. At week 6 a main effect of media on fresh weight, dry weight, and leachate EC was significant. 
Table 2.11. Statistical tests for main effect of media, irrigation and their interactions.

\begin{tabular}{|c|c|c|c|c|}
\hline Lettuce & \multicolumn{4}{|c|}{ Effect tests (2-way Anova $\bullet P$-value) } \\
\hline Variable & $\begin{array}{l}\text { Time } \\
\text { (Week) }\end{array}$ & Media & Irrigation & $\begin{array}{l}\text { Media } \mathrm{x} \\
\text { Irrigation }\end{array}$ \\
\hline \multirow[t]{3}{*}{ Height } & 1 & $0.0284 *$ & 0.3867 & 0.1694 \\
\hline & 3 & 0.9070 & 0.7496 & 0.1531 \\
\hline & 5 & $0.0107 *$ & 0.1874 & 0.6765 \\
\hline \multirow[t]{3}{*}{$\mathrm{EC}\left(\mu \mathrm{S} \bullet \mathrm{cm}-^{1}\right)$} & 2 & $0.0044 *$ & $0.0045^{*}$ & $0.0481 *$ \\
\hline & 4 & $0.0339 *$ & $<0.0001 *$ & 0.456 \\
\hline & 6 & $0.0022 *$ & 0.7143 & 0.7632 \\
\hline Fresh Weight & 6 & $<0.0001 *$ & 0.6653 & 0.555 \\
\hline \multirow[t]{2}{*}{ Dry Weight } & 6 & $<0.0001 *$ & 0.5143 & 0.6553 \\
\hline & & \multicolumn{3}{|c|}{ Kruskal-Wallis (1-way analysis $P$-value) } \\
\hline \multirow[t]{3}{*}{ Leaf count } & 1 & & 0.9801 & \\
\hline & 3 & & 0.2023 & \\
\hline & 5 & & $<0.0001 *$ & \\
\hline \multirow[t]{3}{*}{ pH } & 2 & & $<0.0001^{*}$ & \\
\hline & 4 & & $<0.0001 *$ & \\
\hline & 6 & & $<0.0001^{*}$ & \\
\hline
\end{tabular}

* Indicates the significant effect at 0.05 .

\section{Lettuce, Weeks 1-2 from start of experiment}

Kruskal-Wallis analysis for week 1 does not indicate significant differences in leaf number among the 12 treatment combinations (NS, Table 2.12). Two-way ANOVA results at week 1 indicate a significant effect of media on height $(P=.0011)$, however no effect of irrigation or interaction. At week 2, two-way ANOVA results indicate significant effect of media $(P \leq 0.0001)$, irrigation $(P=0.0045)$ and their interaction $(P=0.0481)$ on leachate EC, Table 2.12. With regards to $\mathrm{pH}$, Kruskal-Wallis analyses for week 2 indicate significant differences among the 12 treatment combinations $(P<0.0001$, Table 2.11). 
Table 2.12. Plant height and leaf number of lettuce 'Green Romaine' grown in Black Gold, Farm Compost, Johnny's 512 Mix, and Sunshine Mix and watered at 80\%, 100\%, 120\% irrigation at week 1 and $E C$ and $\mathrm{pH}$ at week 2 for those same media and treatments. Means \pm standard error of the means (SEM).

\begin{tabular}{|c|c|c|c|c|c|}
\hline \multicolumn{2}{|l|}{ Lettuce } & \multicolumn{2}{|c|}{ Week 1} & \multicolumn{2}{|c|}{ Week 2} \\
\hline Medium & $\begin{array}{l}\text { Irrigation } \\
(\% \\
\text { VWC) }\end{array}$ & $\begin{array}{l}\text { Height (cm) } \\
\pm \text { SEM }\end{array}$ & $\begin{array}{l}\text { Leaf } \\
\text { Number } \pm \\
\text { SEM }\end{array}$ & $\begin{array}{c}\mathrm{EC}\left(\mu \mathrm{S} \bullet \mathrm{cm}^{-1}\right) \\
\pm \mathrm{SEM}\end{array}$ & $\mathrm{pH} \pm \mathrm{SEM}$ \\
\hline \multirow{3}{*}{$\begin{array}{l}\text { Black } \\
\text { Gold }\end{array}$} & 80 & $5.9 \pm 1.1$ & $4.8 \pm 0.3$ & $1617 \pm 231$ & $5.8 \pm 0.3$ \\
\hline & 100 & $5.8 \pm 1.1$ & $4.5 \pm 0.3$ & $1319 \pm 278$ & $5.8 \pm 0.3$ \\
\hline & 120 & $6.2 \pm 0.9$ & $4.4 \pm 0.3$ & $1233 \pm 314$ & $6 \pm 0.3$ \\
\hline \multirow{3}{*}{$\begin{array}{l}\text { Farm } \\
\text { Compost }\end{array}$} & 80 & $4.7 \pm 0.8^{y}$ & $4.9 \pm 0.3$ & $2847 \pm 160^{*}$ & $7.9 \pm 0.1^{*}$ \\
\hline & 100 & $5.3 \pm 0.8^{y}$ & $4.9 \pm 0.4$ & $2930 \pm 395^{*}$ & $7.8 \pm 0.2 *$ \\
\hline & 120 & $4.7 \pm 0.7^{y}$ & $4.9 \pm 0.4$ & $2760 \pm 306^{*}$ & $7.9 \pm 0.1 *$ \\
\hline \multirow{3}{*}{$\begin{array}{l}\text { Johnny's } \\
512 \text { Mix }\end{array}$} & 80 & $5.2 \pm 0.5$ & $4.6 \pm 0.3$ & $3233 \pm 759 *$ & $7 \pm 0.1^{*}$ \\
\hline & 100 & $4.9 \pm 0.6$ & $4.5 \pm 0.3$ & $4479 \pm 494 *$ & $7 \pm 0 *$ \\
\hline & 120 & $5.1 \pm 0.6$ & $4.6 \pm 0.4$ & $3211 \pm 639 *$ & $7.2 \pm 0^{*}$ \\
\hline \multirow{3}{*}{$\begin{array}{l}\text { Sunshine } \\
\text { Mix }\end{array}$} & 80 & $6.1 \pm 1$ & $5.1 \pm 0.4$ & $2308 \pm 255$ & $6.1 \pm 0^{*}$ \\
\hline & 100 & $4.7 \pm 0.9$ & $4.9 \pm 0.4$ & $1862 \pm 307$ & $6.2 \pm 0$ \\
\hline & 120 & $6 \pm 1.1$ & $4.6 \pm 0.3$ & $1583 \pm 305$ & $6.3 \pm 0$ \\
\hline
\end{tabular}

* indicates the mean for the variable significantly differed from the control group (Sunshine 120\% VWC) detected by Dunnett's test or Steel Method following Kruskal-Wallis, when appropriate. $\mathrm{y}$ indicates the significant difference of the entire media group (main effect, across all 3 irrigation levels) from the control group (Sunshine Mix, across all 3 irrigation levels).

\section{Height (Week 1)}

Media $(P=0.0011)$ had a significant effect on height at week 1 ; however, there was no significant effect of irrigation or interaction. Dunnett's test detected that plants grown in farm compost across all irrigations $(P=0.022)$ were significantly shorter than the control (Sunshine Mix at $120 \%$ VWC irrigation).

\section{EC (Week 2)}

Media $(P \leq 0.0044)$, irrigation $(P=0.0045)$ and their interaction $(P=0.0481)$ had significant effects on leachate EC (Table 2.11). Specifically, the EC was the highest at Johnny's 
512 Mix at $100 \%$ irrigation and lowest at Black Gold at $120 \%$ irrigation. Dunnett's comparison to Sunshine at $120 \%$ (Control) detected significantly higher EC than the control in farm compost at $80 \%, 100 \%$, and $120 \%$, as well as Johnny's $512 \mathrm{Mix}$ at $80 \%, 100 \%$, and $120 \%$ VWC irrigation.

\section{pH (Week 2)}

$\mathrm{pH}$ at week 2 differed significantly among the 12 treatment combinations $(P<0.0001$, Table 2.11). Specifically, the Steel test detected that Farm compost at 80\%, 100\%, and $120 \%$ VWC irrigation as well as Johnny's 512 Mix at $80 \%, 100 \%$, and 120\% VWC irrigation each had higher $\mathrm{pH}$ compared to Sunshine Mix at 120\% VWC irrigation (Table 2.12). 


\section{Lettuce, Weeks 3-4 from the start of experiment}

No significant effect of media, irrigation, or interaction was present on height at week 3

(Table 2.13). Nor were any significant differences in leaf number present among the 12 treatment combinations (Table 2.13). Media $(P=0.0339)$ and irrigation $(P<0.0001)$ had significant

effects on leachate EC at week 4; however, no interaction was present (Table 2.13).

Table 2.13. Plant height and leaf number of lettuce 'Green Romaine' grown in Black Gold, Farm Compost, Johnny's 512 Mix, and Sunshine Mix and watered at 80\%, 100\%, 120\% irrigation at week 3 and $E C$ and $\mathrm{pH}$ at week 4 for those same media and treatments. Means \pm standard error of the means (SEM).

\begin{tabular}{|c|c|c|c|c|c|}
\hline \multicolumn{2}{|c|}{ Lettuce } & \multicolumn{2}{|c|}{ Week 3} & \multicolumn{2}{|c|}{ Week 4} \\
\hline Medium & $\begin{array}{l}\text { Irrigation } \\
(\% \\
\text { VWC) }\end{array}$ & $\begin{array}{l}\text { Height (cm) } \\
\pm \text { SEM }\end{array}$ & $\begin{array}{l}\text { Leaf } \\
\text { Number } \pm \\
\text { SEM }\end{array}$ & $\begin{array}{c}\mathrm{EC}\left(\mu \mathrm{S} \bullet \mathrm{cm}^{-1}\right) \\
\pm \mathrm{SEM}\end{array}$ & $\overline{\mathrm{pH}} \pm \mathrm{SEM}$ \\
\hline \multirow{3}{*}{$\begin{array}{l}\text { Black } \\
\text { Gold }\end{array}$} & 80 & $14.5 \pm 2.9$ & $12.7 \pm 0.5$ & $872 \pm 175^{z}$ & $5.7 \pm 0.4$ \\
\hline & 100 & $14.3 \pm 3.1$ & $12.6 \pm 0.4$ & $688 \pm 117^{z}$ & $5.8 \pm 0.4$ \\
\hline & 120 & $13.7 \pm 2.6$ & $11.9 \pm 0.5$ & $390 \pm 105$ & $6 \pm 0.3$ \\
\hline \multirow{3}{*}{$\begin{array}{l}\text { Farm } \\
\text { Compost }\end{array}$} & 80 & $14 \pm 3$ & $11.6 \pm 0.6$ & $1345 \pm 424^{z}$ & $7.6 \pm 0.1^{y}$ \\
\hline & 100 & $14.5 \pm 3.1$ & $11.6 \pm 0.7$ & $1273 \pm 324^{z}$ & $7.7 \pm 0.1^{y}$ \\
\hline & 120 & $12.9 \pm 2.8$ & $11.7 \pm 0.6$ & $681 \pm 190$ & $7.6 \pm 0.1^{y}$ \\
\hline \multirow{3}{*}{$\begin{array}{l}\text { Johnny's } \\
512 \text { Mix }\end{array}$} & 80 & $13.8 \pm 2.1$ & $11.7 \pm 0.3$ & $2049 \pm 532^{z y}$ & $7.4 \pm 0.1^{y}$ \\
\hline & 100 & $13.5 \pm 2.2$ & $11.5 \pm 0.4$ & $1401 \pm 325^{\mathrm{zy}}$ & $7.5 \pm 0.1^{y}$ \\
\hline & 120 & $15.3 \pm 2.6$ & $11.4 \pm 0.5$ & $894 \pm 193^{y}$ & $7.6 \pm 0^{y}$ \\
\hline \multirow{3}{*}{$\begin{array}{l}\text { Sunshine } \\
\text { Mix }\end{array}$} & 80 & $14.3 \pm 2.8$ & $12.9 \pm 0.8$ & $1072 \pm 266^{z}$ & $6.8 \pm 0.1$ \\
\hline & 100 & $15.6 \pm 2.9$ & $13.2 \pm 0.7$ & $1147 \pm 301^{z}$ & $6.8 \pm 0.1$ \\
\hline & 120 & $16.1 \pm 2.9$ & $12.6 \pm 0.8$ & $758 \pm 192$ & $6.8 \pm 0.1$ \\
\hline
\end{tabular}

${ }^{\mathrm{z}}$ indicates the significant difference of the entire irrigation group (main effect, across all 4 media treatments) from the control group ( $120 \%$ VWC, across all 4 media treatments).

${ }^{\mathrm{y}}$ indicates the significant difference of the entire media group (main effect, across all 3 irrigation levels) from the control group (Sunshine Mix, across all 3 irrigation levels).

\section{EC (Week 4)}

Media $(P=0.0339)$ and irrigation $(P<0.0001)$ had a significant effect on EC at week 4; however, no significant effect of interaction was present (NS, Table 2.11). Specifically, the EC 
was the highest in Johnny's 512 Mix and lowest at Black Gold. Dunnett's comparison to Sunshine (Control) detected that EC in Johnny's was significantly higher. EC of leachate from pots with irrigation at $80 \%$ and $100 \%$ VWC were both significantly greater than that at $120 \%$ VWC (Table 2.13).

\section{pH (Week 4)}

Kruskal-Wallis analysis for week 4 indicates significant differences in $\mathrm{pH}$ among the 12 treatment combinations $(P<0.0001$, Table 2.11). Specifically, the Steel test detected that leachate $\mathrm{pH}$ from both farm compost and Johnny's 512 Mix at 80\%, 100\%, and 120\% VWC irrigation were significantly higher than Sunshine Mix at 120\% VWC irrigation (Table 2.13). 


\section{Lettuce, Weeks 5-6 from the start of experiment}

At week 5, Two-way ANOVA results indicate a significant effect of media $(P<0.0107)$ on plant height, however no effect of irrigation or interaction, Table 2.11. Kruskal-Wallis analysis for week 5 indicates significant difference among the 12 treatment combinations with regards to leaf number $(P<0.001)$, Table 2.11. At week 6, Two-way ANOVA results indicate a significant effect of media $(P<0.001)$ on both fresh and dry shoot weights, however, there was no effect of irrigation (NS) or an interaction (NS) for either, Table 2.11. Two-way ANOVA results indicate a significant effect of media on EC $(P=0.0022)$, however no effect of irrigation (NS) or interaction (NS), Table 2.11. Kruskal-Wallis analysis for week 6 indicates significant differences in $\mathrm{pH}$ among the 12 treatment combinations $(P<0.0001$, Table 2.11). 
Table 2.14. Plant height and leaf number of lettuce 'Green Romaine' grown in Black Gold, Farm Compost, Johnny's 512 Mix, and Sunshine Mix and watered at 80\%, 100\%, 120\% irrigation at week 5 and fresh weight, dry weight, EC and pH at week 6 for those same media and treatments. Means \pm standard error of the means (SEM).

\begin{tabular}{|c|c|c|c|c|c|c|c|}
\hline \multicolumn{2}{|r|}{ Lettuce } & \multicolumn{2}{|c|}{ Week 5} & \multicolumn{4}{|c|}{ Week 6} \\
\hline Medium & $\begin{array}{l}\text { Irrigation } \\
\text { (\% VWC) }\end{array}$ & $\begin{array}{l}\text { Height }(\mathrm{cm}) \pm \\
\text { SEM }\end{array}$ & $\begin{array}{l}\text { Leaf Number } \\
\pm \text { SEM }\end{array}$ & $\begin{array}{l}\text { Fresh Weight } \\
\text { (g) } \pm \text { SEM }\end{array}$ & $\begin{array}{l}\text { Dry Weight } \\
\text { (g) } \pm \text { SEM }\end{array}$ & $\begin{array}{c}\text { EC } \\
\left(\mu \mathrm{S} \bullet \mathrm{cm}^{-1}\right) \\
\pm \mathrm{SEM}\end{array}$ & $\begin{array}{l}\text { pH } \pm \\
\text { SEM }\end{array}$ \\
\hline \multirow{3}{*}{$\begin{array}{l}\text { Black } \\
\text { Gold }\end{array}$} & 80 & $20.7 \pm 0.9^{\mathrm{y}}$ & $16.9 \pm 0.5$ & $19.8 \pm 0.9^{y}$ & $2.1 \pm 0.2^{y}$ & $332 \pm 83$ & $5.7 \pm 0.4$ \\
\hline & 100 & $20.5 \pm 0.8^{y}$ & $16.3 \pm 0.4$ & $18.6 \pm 1.4^{y}$ & $2 \pm 0.1^{y}$ & $473 \pm 159$ & $5.9 \pm 0.4$ \\
\hline & 120 & $21.1 \pm 0.6^{\mathrm{y}}$ & $14.8 \pm 0.6^{y}$ & $17 \pm 0.5^{y}$ & $2.2 \pm 0.2^{y}$ & $311 \pm 96$ & $6.1 \pm 0.3$ \\
\hline \multirow{3}{*}{$\begin{array}{l}\text { Farm } \\
\text { Compost }\end{array}$} & 80 & $20.5 \pm 0.8^{y}$ & $12.9 \pm 0.4^{\mathrm{y}}$ & $14.8 \pm 1.8^{y}$ & $1.3 \pm 0.2^{y}$ & $1282 \pm 361$ & $7.6 \pm 0.1^{y}$ \\
\hline & 100 & $20.7 \pm 1.2^{\mathrm{y}}$ & $13.9 \pm 0.7^{\mathrm{y}}$ & $14.7 \pm 1.8^{y}$ & $1.5 \pm 0.2^{y}$ & $968 \pm 291$ & $7.6 \pm 0.1^{y}$ \\
\hline & 120 & $23.4 \pm 1^{y}$ & $14.6 \pm 0.7^{\mathrm{y}}$ & $18.4 \pm 1.8^{y}$ & $1.7 \pm 0.2^{y}$ & $715 \pm 245$ & $7.6 \pm 0.1^{y}$ \\
\hline \multirow{3}{*}{$\begin{array}{l}\text { Johnny's } \\
512 \mathrm{Mix}\end{array}$} & 80 & $20.2 \pm 0.7^{y}$ & $15.6 \pm 0.4$ & $26.6 \pm 1.9^{y}$ & $2.7 \pm 0.2$ & $910 \pm 221^{\mathrm{y}}$ & $7.2 \pm 0.1^{\mathrm{y}}$ \\
\hline & 100 & $21 \pm 0.9^{y}$ & $16.5 \pm 0.8$ & $29.2 \pm 1.8^{y}$ & $3.1 \pm 0.2$ & $1118 \pm 284^{y}$ & $7.1 \pm 0.1^{y}$ \\
\hline & 120 & $20.7 \pm 0.8^{y}$ & $15.9 \pm 0.8$ & $27.4 \pm 1.1^{\mathrm{y}}$ & $2.7 \pm 0.2$ & $1222 \pm 309^{y}$ & $7.2 \pm 0.1^{\mathrm{y}}$ \\
\hline \multirow{3}{*}{$\begin{array}{l}\text { Sunshine } \\
\text { Mix }\end{array}$} & 80 & $24 \pm 1.4$ & $19.8 \pm 1.1$ & $33.6 \pm 3.5$ & $2.9 \pm 0.3$ & $619 \pm 194$ & $6.4 \pm 0$ \\
\hline & 100 & $24.1 \pm 0.9$ & $19.5 \pm 0.8$ & $36.2 \pm 2.9$ & $3.1 \pm 0.3$ & $671 \pm 223$ & $6.4 \pm 0$ \\
\hline & 120 & $24.6 \pm 0.9$ & $19 \pm 0.9$ & $37.6 \pm 2.7$ & $3 \pm 0.2$ & $812 \pm 235$ & $6.5 \pm 0$ \\
\hline
\end{tabular}

$\mathrm{y}$ indicates the significant difference of the entire media group (main effect, across all 3 irrigation levels) from the control group (Sunshine Mix, across all 3 irrigation levels). 


\section{Height (Week 5)}

Two-way ANOVA results indicate a significant effect of media on plant height $(P<$ 0.001), however no effect of irrigation (NS) or interaction (NS), (Table 2.11). Lettuce plants grown in Black Gold, farm compost and Johnny’s 512 Mix were all significantly shorter than those grown in Sunshine Mix (Table 2.14).

\section{Leaf Number (Week 5)}

Kruskal-Wallis analysis for week 5 indicates significant difference among the 12 treatment combinations $(P<0.0001)$ (Table 2.11). Plants grown in farm compost at $80 \%, 100 \%$, and $120 \%$, Black Gold at 100 and 120\% and Johnny's 512 Mix at 80\% VWC each had fewer leaves than plants grown in Sunshine Mix at 120\% VWC. Statistically speaking, plants grown in Black Gold at 80\% and 100\% VWC as well as Johnny’s 512 Mix at all irrigation levels and Sunshine Mix at $80 \%$ and $100 \%$ were similar to the control.

\section{Fresh Weight (Week 6)}

Two-way ANOVA results indicate a significant effect of media on fresh weight $(P<$ 0.001), however no effect of irrigation or interaction (Table 2.11). The largest average fresh weight (across all irrigations) was achieved using Sunshine mix, while the smallest was for farm compost. All test media produced plants of significantly lower fresh weight than Sunshine Mix.

\section{Dry Weight (Week 6)}

Media had a significant effect on dry shoot weight of lettuce $(P<0.001)$, however no effect of irrigation or interaction was present (Table 2.11). Dunnett's comparison of each medium to Sunshine (across all irrigations) detected a significantly smaller dry weight than control in farm compost and Black Gold (Table 2.14); however, dry weights of plants grown in Johnny's 512 Mix and Sunshine Mix were comparable to the control. 


\section{EC (Week 6)}

Media had a significant effect on EC of lettuce $(P<0.0022)$, however no effect of irrigation or interaction was present, (Table 2.11). Specifically, the EC was the highest in Johnny’s 512 Mix and lowest at Black Gold.

pH (Week 6)

Kruskal-Wallis analysis for week 6 indicates a significant difference in $\mathrm{pH}$ among the 12 treatment combinations $(P<0.0001$, Table 2.11). Specifically, the Steel test detected that leachate $\mathrm{pH}$ from farm compost at $80 \%, 100 \%$, and $120 \%$ VWC irrigation as well as Johnny's 512 Mix at $80 \%, 100 \%$, and $120 \%$ VWC irrigation was significantly higher than leachate $\mathrm{pH}$ from Sunshine Mix at 100\% VWC irrigation (Table 2.14). 


\section{Repeated Measures ANOVA}

In this secondary analysis, two Repeated-measures ANOVA models were considered, and the average of all five randomly selected plants for measurements at three time points were used as an experimental unit. First, the saturated model included seven terms, such as the main effect of media (4 categories), irrigation (3 categories) and repeated effect of week $(2,4,6)$, three two-way interactions (media*irrigation, media*week, irrigation*week) and the three-way interaction (media*irrigation*week). We found that the EC was affected by the interaction of media and week in peppers and lettuce (Table 2.15). In tomato, the $\mathrm{pH}$ was affected by media, while in peppers and lettuce an interaction of media and week was significant (Table 2.15). Leaf number in lettuce was affected by the interaction of media and week (Table 2.15).

The second repeated measures ANOVA model was simplified after observing that neither interaction of media, irrigation and week, nor the main effect of irrigation were significant. Therefore irrigation was omitted from the model. The second model had three terms: main effect of media, main effect of week, and interaction of the two. We found that in tomato, EC was affected solely by media (Table 2.16, Fig 2.1). However, an interaction of media and week was significant in peppers, where leachate EC from Johnny’s 512 Mix, Sunshine Mix and Black Gold decreased over the 6 weeks, but farm compost did not significantly decrease (Table 2.16, Fig 2.2). In lettuce, where leachate EC decreased across all treatments, Johnny's 512 Mix saw the greatest decrease (Table 2.16, Fig 2.3). $\mathrm{pH}$ was affected by the interaction of media and week across all species: tomato (Table 2.16, Fig 2.4), pepper (Table 2.16, Fig 2.5), and lettuce (Table 2.16, Fig 2.6). Pepper height was also affected by the interaction of media and week, with an increase in height occurring over time (Table 2.16, Fig 2.7). Leaf number in tomato (Table 2.16, Fig 2.8) and lettuce (Table 2.16, Fig 2.10) was affected by the interaction of media and week, 
while a main effect of media was observed in regards to pepper leaf number (Table 2.16, Fig 2.9). Changes in $\mathrm{EC}$ and $\mathrm{pH}$ differed between species and were gradual, be they increases or decreases.

Table 2.15. Results of saturated repeated measures ANOVA model tests assessing the effects of Irrigation, Media and Weeks and all interactions on EC, pH, plant height and leaf number in tomatoes, peppers and lettuce.

\begin{tabular}{|c|c|c|c|c|c|c|c|c|}
\hline \multirow[b]{2}{*}{ Species } & \multirow[b]{2}{*}{$\begin{array}{l}\text { Response } \\
\text { Variable }\end{array}$} & \multicolumn{7}{|c|}{ Effect tests (Three-way ANOVA $P$-value) } \\
\hline & & $\begin{array}{l}\text { Irrigation } \\
\text { (I) }\end{array}$ & $\begin{array}{l}\text { Media } \\
\text { (M) }\end{array}$ & $\mathbf{I} * \mathbf{M}$ & $\begin{array}{l}\text { Week } \\
(\mathbf{W})\end{array}$ & $\mathbf{I} * \mathbf{W}$ & $\mathbf{M} * \mathbf{W}$ & $\begin{array}{l}\mathbf{I} * \mathbf{M} * \\
\mathbf{W}\end{array}$ \\
\hline \multirow[t]{4}{*}{ Tomato } & $\mathrm{EC}\left(\mu \mathrm{S} \bullet \mathrm{cm}^{-1}\right)$ & 0.510 & 0.070 & 0.970 & $<.0001 *$ & 0.720 & 0.210 & 0.640 \\
\hline & $\mathrm{pH}$ & 0.650 & $0.0001 *$ & 0.998 & $0.043^{*}$ & 0.908 & 0.064 & 0.996 \\
\hline & Height $(\mathrm{cm})$ & 0.874 & 0.785 & 0.999 & $<.0001 *$ & 0.883 & 0.277 & 1.000 \\
\hline & Leaf number & 0.680 & 0.750 & 0.750 & $<.0001 *$ & 0.450 & 0.120 & 0.940 \\
\hline \multirow[t]{4}{*}{ Pepper } & $\mathrm{EC}\left(\mu \mathrm{S} \bullet \mathrm{cm}^{-1}\right)$ & 0.935 & 0.252 & 0.999 & $<.0001 *$ & 0.603 & $0.021 *$ & 0.894 \\
\hline & $\mathrm{pH}$ & 0.907 & $0.001^{*}$ & 1.000 & 0.515 & 0.947 & $0.0004 *$ & 0.993 \\
\hline & Height (cm) & 0.967 & 0.579 & 1.000 & $<.0001 *$ & 0.688 & 0.095 & 0.927 \\
\hline & Leaf number & 0.977 & 0.157 & 1.000 & $<.0001 *$ & 1.000 & 0.511 & 0.999 \\
\hline \multirow[t]{4}{*}{ Lettuce } & $\mathrm{EC}\left(\mu \mathrm{S} \cdot \mathrm{cm}^{-1}\right)$ & 0.779 & 0.229 & 1.000 & $<.0001 *$ & 0.374 & $0.025 *$ & 0.773 \\
\hline & $\mathrm{pH}$ & 0.935 & $0.004 *$ & 1.000 & $0.017 *$ & 0.999 & $0.021 *$ & 1.000 \\
\hline & Height $(\mathrm{cm})$ & 0.977 & 0.911 & 1.000 & $<.0001 *$ & 0.999 & 0.996 & 1.000 \\
\hline & Leaf number & 0.777 & $0.008^{*}$ & 0.941 & $<.0001 *$ & 0.994 & $0.002 *$ & 0.998 \\
\hline
\end{tabular}

* Indicates the significant effect at 0.05 . 
Table 2.16. Results of simplified, repeated measures-ANOVA model tests assessing the effects of Media and Weeks and their interaction on EC, pH, plant height and leaf number in tomatoes, peppers and lettuce.

\begin{tabular}{|c|c|c|c|c|}
\hline \multirow{2}{*}{ Species } & \multirow{2}{*}{$\begin{array}{l}\text { Response } \\
\text { Variable }\end{array}$} & \multicolumn{3}{|c|}{$\begin{array}{c}\text { Effect tests (Two-way ANOVA } P \text { - } \\
\text { value) }\end{array}$} \\
\hline & & $\begin{array}{l}\text { Media } \\
\text { (M) }\end{array}$ & Week (W) & $\mathbf{M} * \mathbf{W}$ \\
\hline \multirow[t]{4}{*}{ Tomato } & $\mathrm{EC}\left(\mu \mathrm{S} \bullet \mathrm{cm}^{-1}\right)$ & $0.0186^{*}$ & $<0.0001 *$ & 0.1312 \\
\hline & $\mathrm{pH}$ & $<0.0001 *$ & $0.0067 *$ & $0.0046 *$ \\
\hline & Height $(\mathrm{cm})$ & 0.6304 & $<0.0001 *$ & 0.0587 \\
\hline & Leaf number & 0.6727 & $<0.0001 *$ & $0.0354 *$ \\
\hline \multirow[t]{4}{*}{ Pepper } & $\mathrm{EC}\left(\mu \mathrm{S} \bullet \mathrm{cm}^{-1}\right)$ & 0.0740 & $<0.0001 *$ & $0.0012 *$ \\
\hline & $\mathrm{pH}$ & $<0.0001 *$ & 0.2942 & $<0.0001 *$ \\
\hline & Height $(\mathrm{cm})$ & 0.3590 & $<0.0001 *$ & $0.0124 *$ \\
\hline & Leaf number & $0.0284 *$ & $<0.0001 *$ & 0.1425 \\
\hline \multirow[t]{4}{*}{ Lettuce } & $\mathrm{EC}\left(\mu \mathrm{S} \cdot \mathrm{cm}^{-1}\right)$ & 0.0719 & $<0.0001 *$ & $0.0093 *$ \\
\hline & $\mathrm{pH}$ & $<0.0001 *$ & $0.0011 *$ & $0.0005 *$ \\
\hline & Height $(\mathrm{cm})$ & 0.8337 & $<0.0001 *$ & 0.9852 \\
\hline & Leaf number & 0.0007 & $<0.0001 *$ & $0.0354 *$ \\
\hline
\end{tabular}




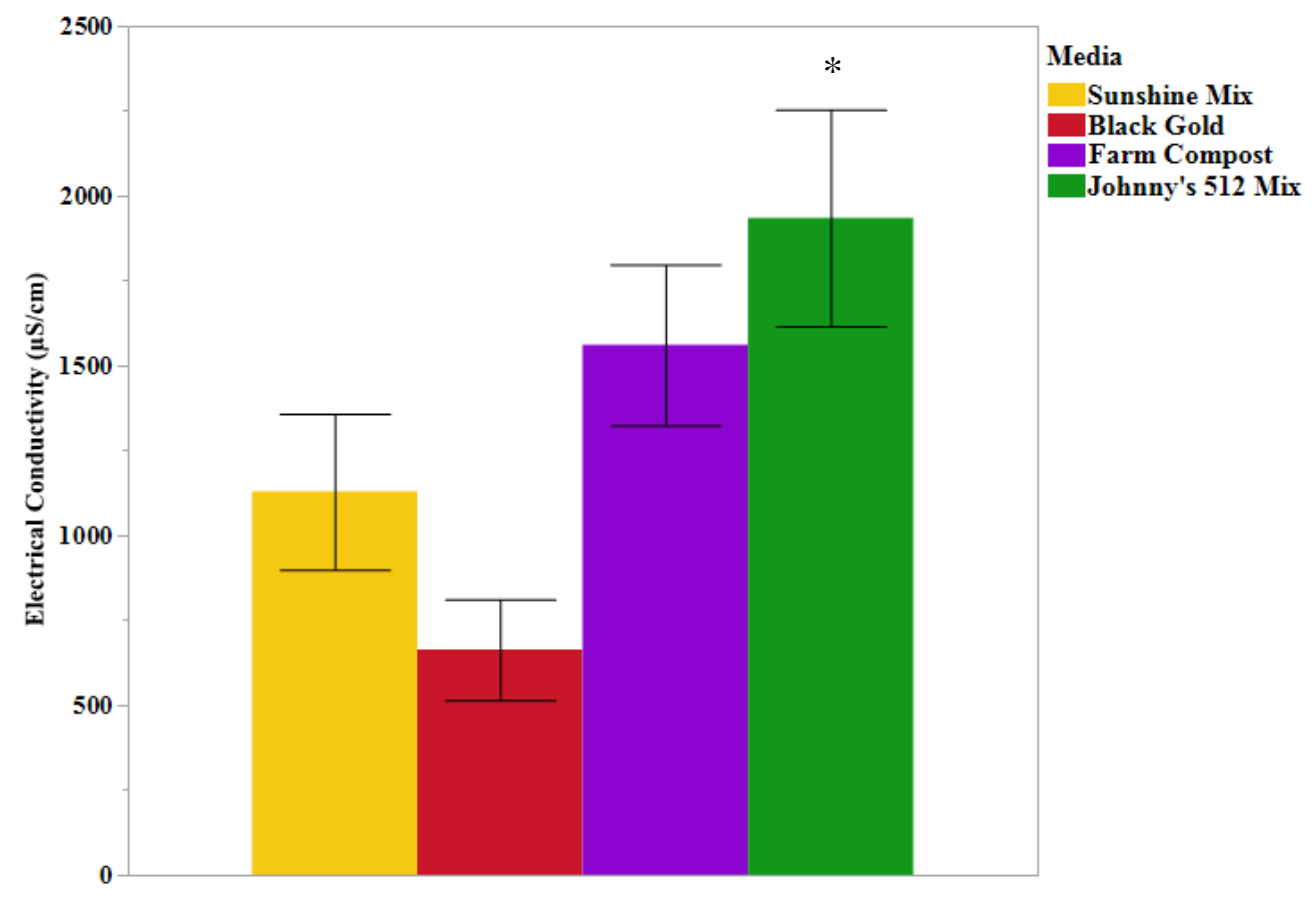

Figure 2.1. Main effect of media on EC $\left(\mu \mathrm{S} \cdot \mathrm{cm}^{-1}\right)$ for tomato 'West Virginia '63' over the course of the study (weeks 2-6). Tomatoes were grown in the greenhouse using four listed media and three levels of irrigation. Electrical conductivity (EC) was recorded every two weeks for six weeks and the experiment was repeated the following year. Error bars indicate the standard deviation; Johnny's 512 Mix is significantly higher than the control. 


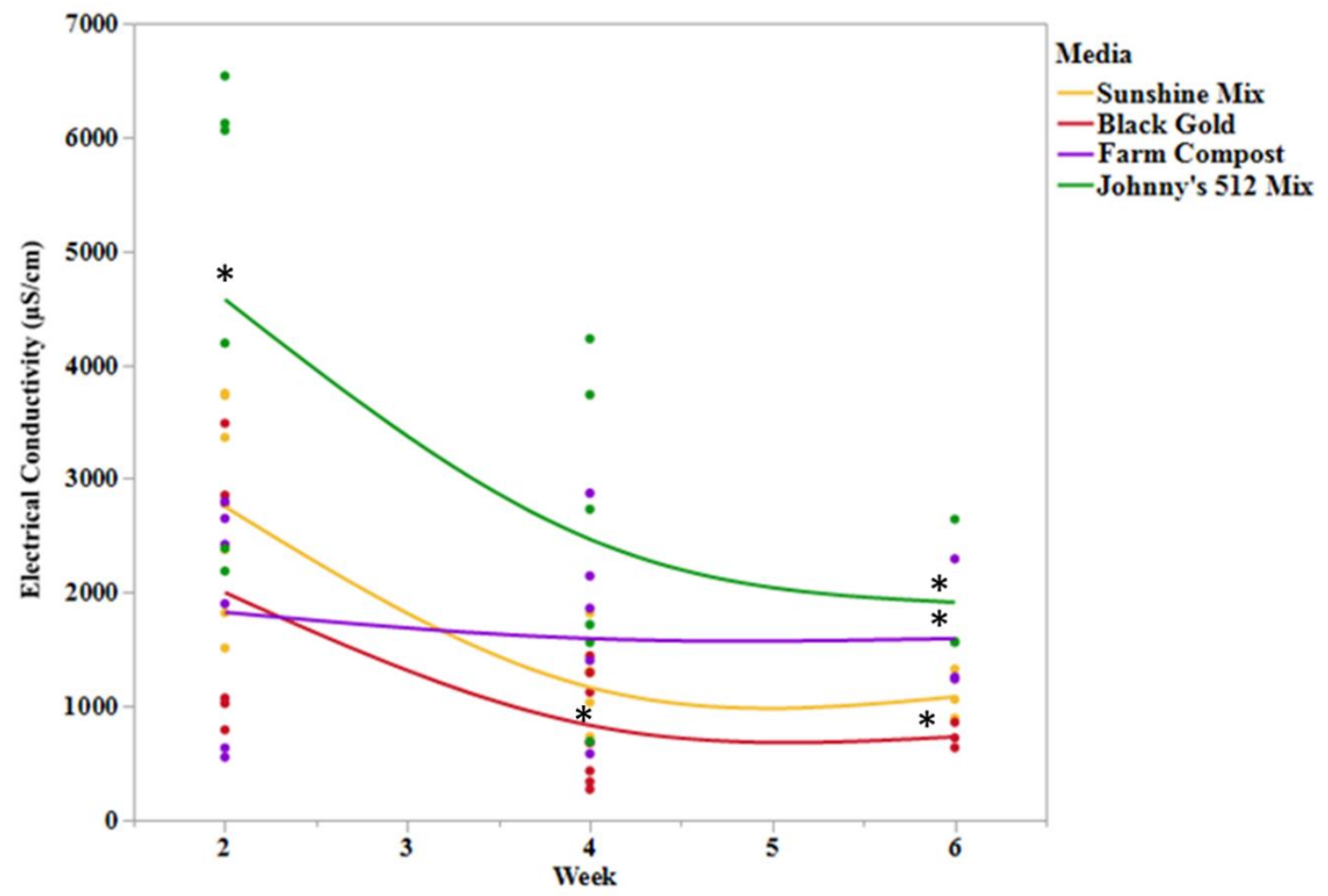

Figure 2.2. Effect of media on EC $\left(\mu \mathrm{S} \bullet \mathrm{cm}^{-1}\right)$ in pepper 'Olympus F1' over weeks 2-6. Peppers were grown in the greenhouse using four listed media and three levels of irrigation. Electrical conductivity (EC) of leachate was recorded every two weeks for six weeks and the experiment was repeated the following year. Asterisks indicate a least square means significantly different from control (Sunshine Mix) before adjusting to multiple comparisons. 


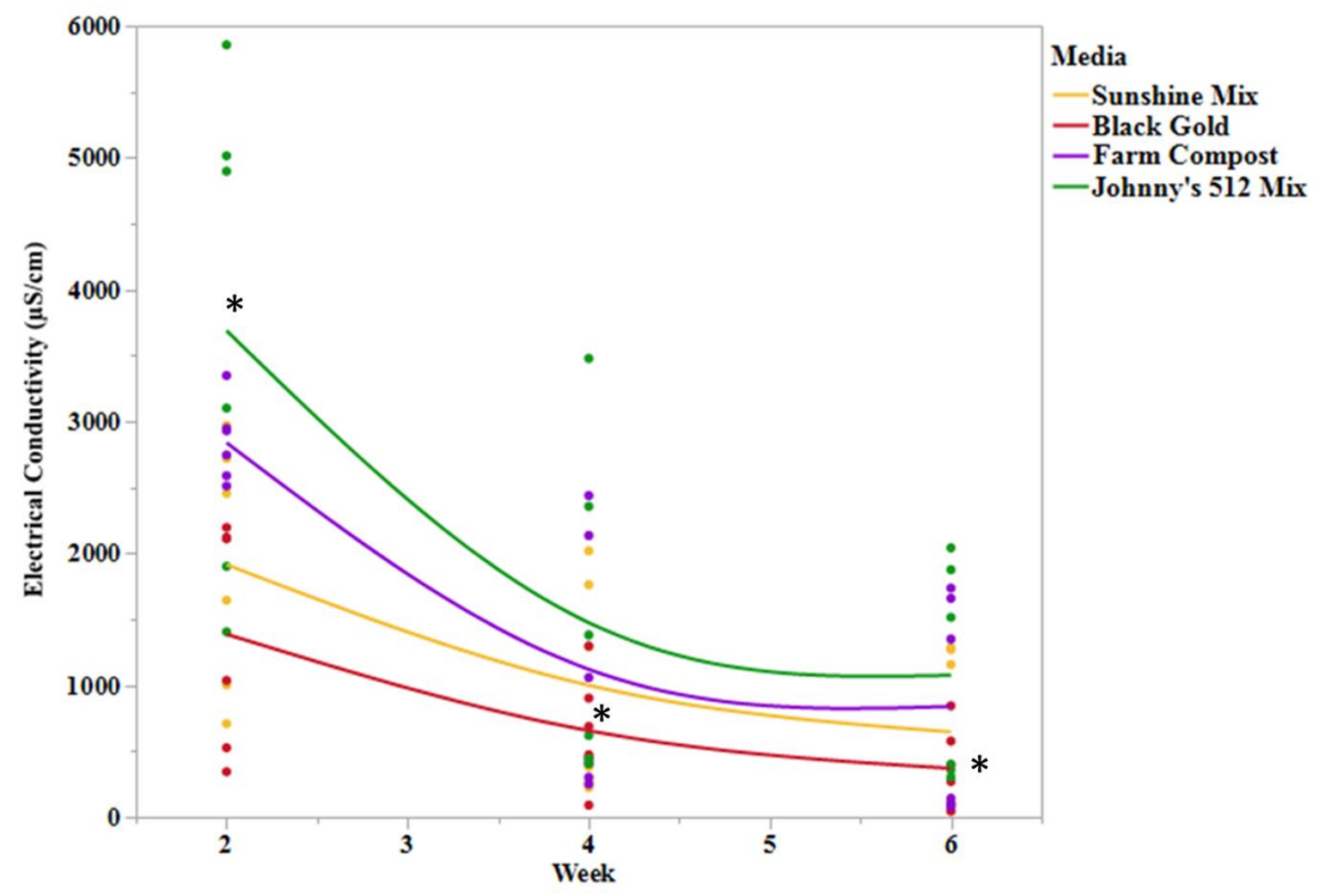

Figure 2.3. Effect of media on EC $\left(\mu \mathrm{S} \bullet \mathrm{cm}^{-1}\right)$ in lettuce 'Green Romaine' over weeks 2-6. Lettuces were grown in the greenhouse using four listed media and three levels of irrigation. Electrical conductivity (EC) of leachate was recorded every two weeks for six weeks and the experiment was repeated the following year. Asterisks indicate a least square means significantly different from control (Sunshine Mix) before adjusting to multiple comparisons. 


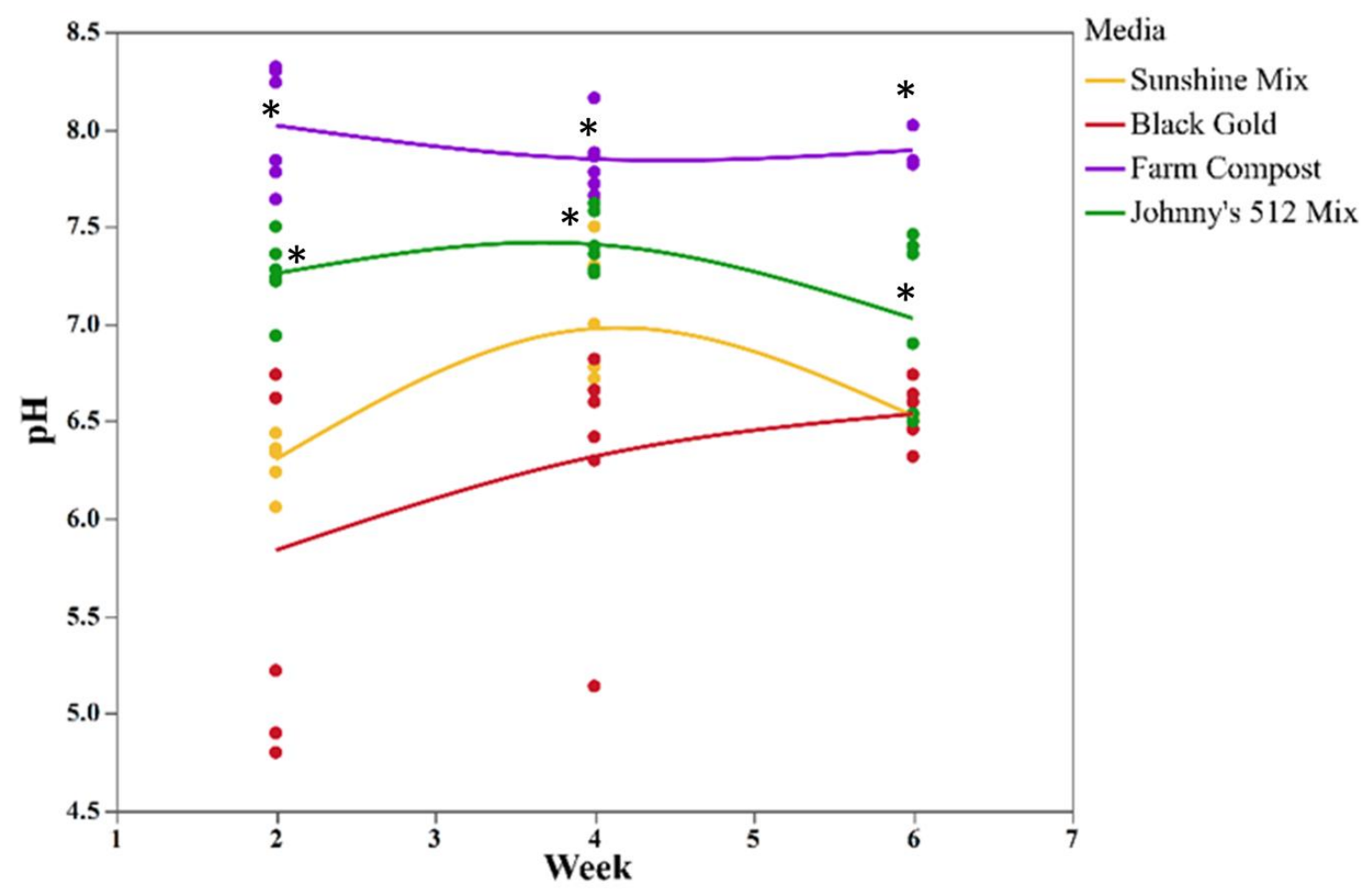

Figure 2.4. Effect of media on $\mathrm{pH}$ in tomato 'West Virginia '63' over weeks 2-6. Tomatoes were grown in the greenhouse using four listed media and three levels of irrigation. $\mathrm{pH}$ was recorded every two weeks for six weeks and experiment was repeated the following year. Asterisks indicate a least square means significantly different from control (Sunshine Mix) before adjusting to multiple comparisons. 


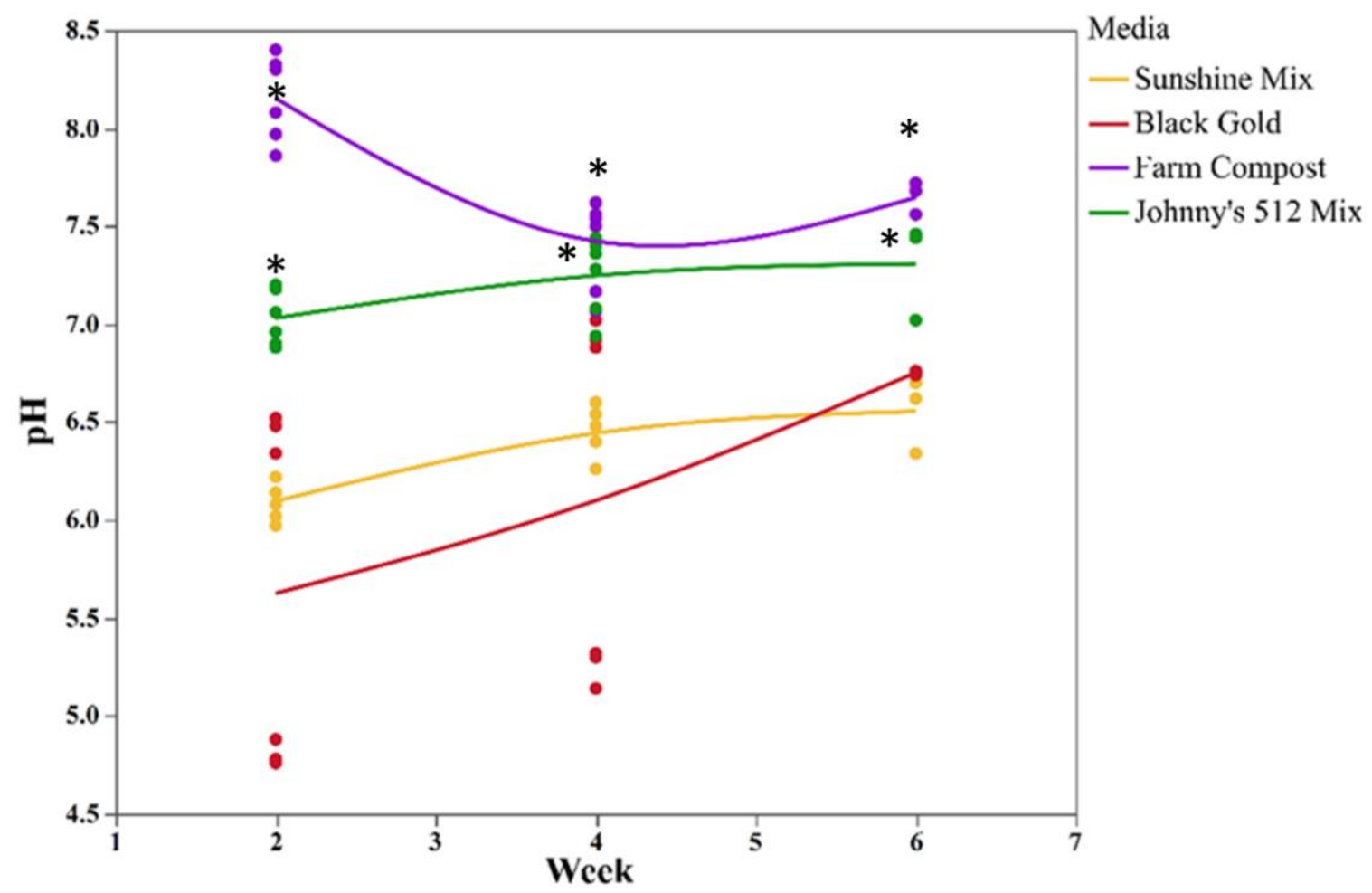

Figure 2.5. Effect of media on $\mathrm{pH}$ in pepper 'Olympus F1' over weeks 2-6. Peppers were grown in the greenhouse using four listed media and three levels of irrigation. $\mathrm{pH}$ was recorded every two weeks for six weeks and the experiment was repeated the following year. Asterisks indicate a least square means significantly different from control (Sunshine Mix) before adjusting to multiple comparisons. 


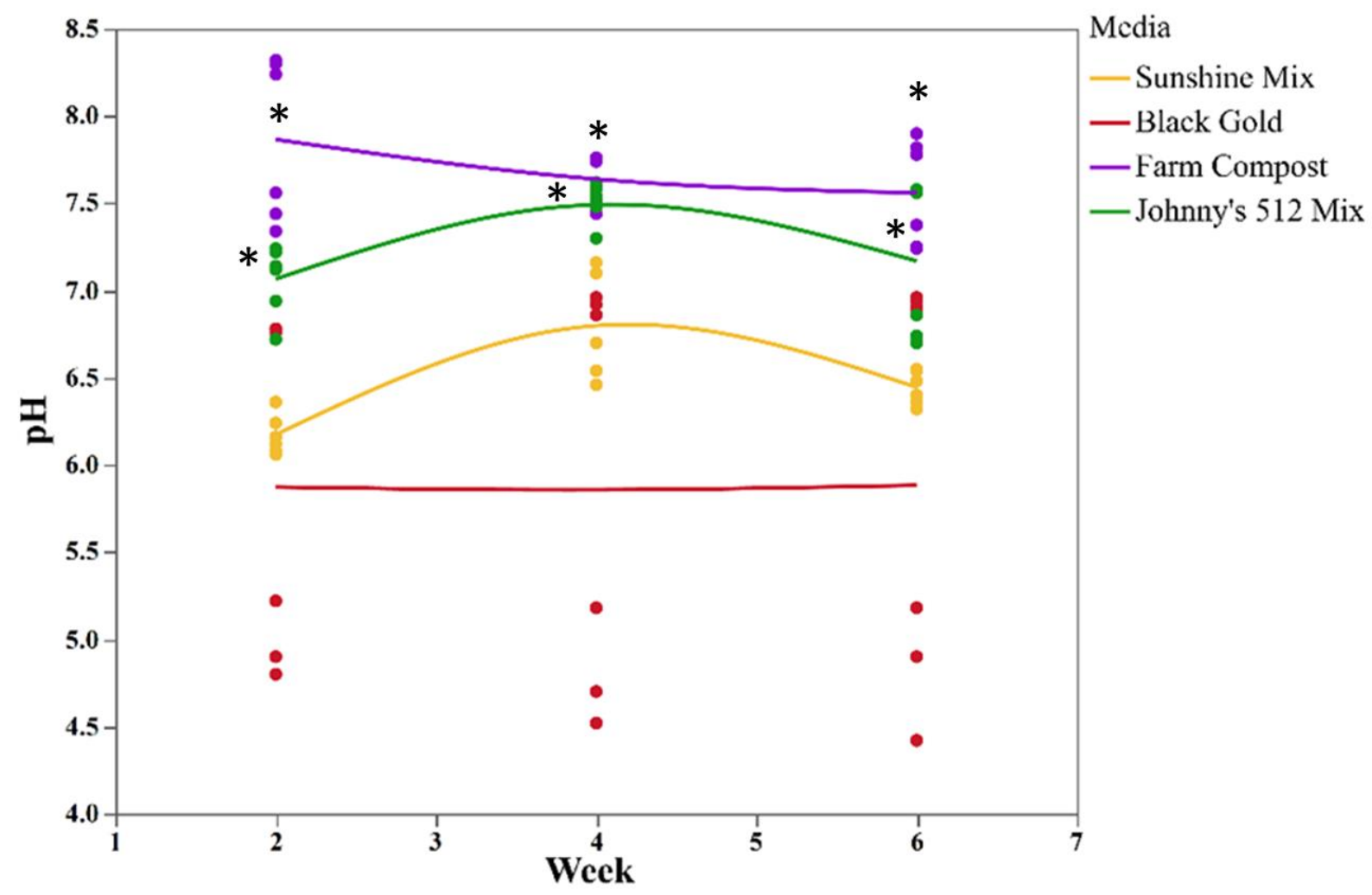

Figure 2.6. Effect of media on $\mathrm{pH}$ in lettuce 'Green Romaine' over weeks 2-6. Lettuces were grown in the greenhouse using four listed media and three levels of irrigation. $\mathrm{pH}$ was recorded every two weeks for six weeks and the experiment was repeated the following year. Asterisks indicate a least square means significantly different from control (Sunshine Mix) before adjusting to multiple comparisons. 


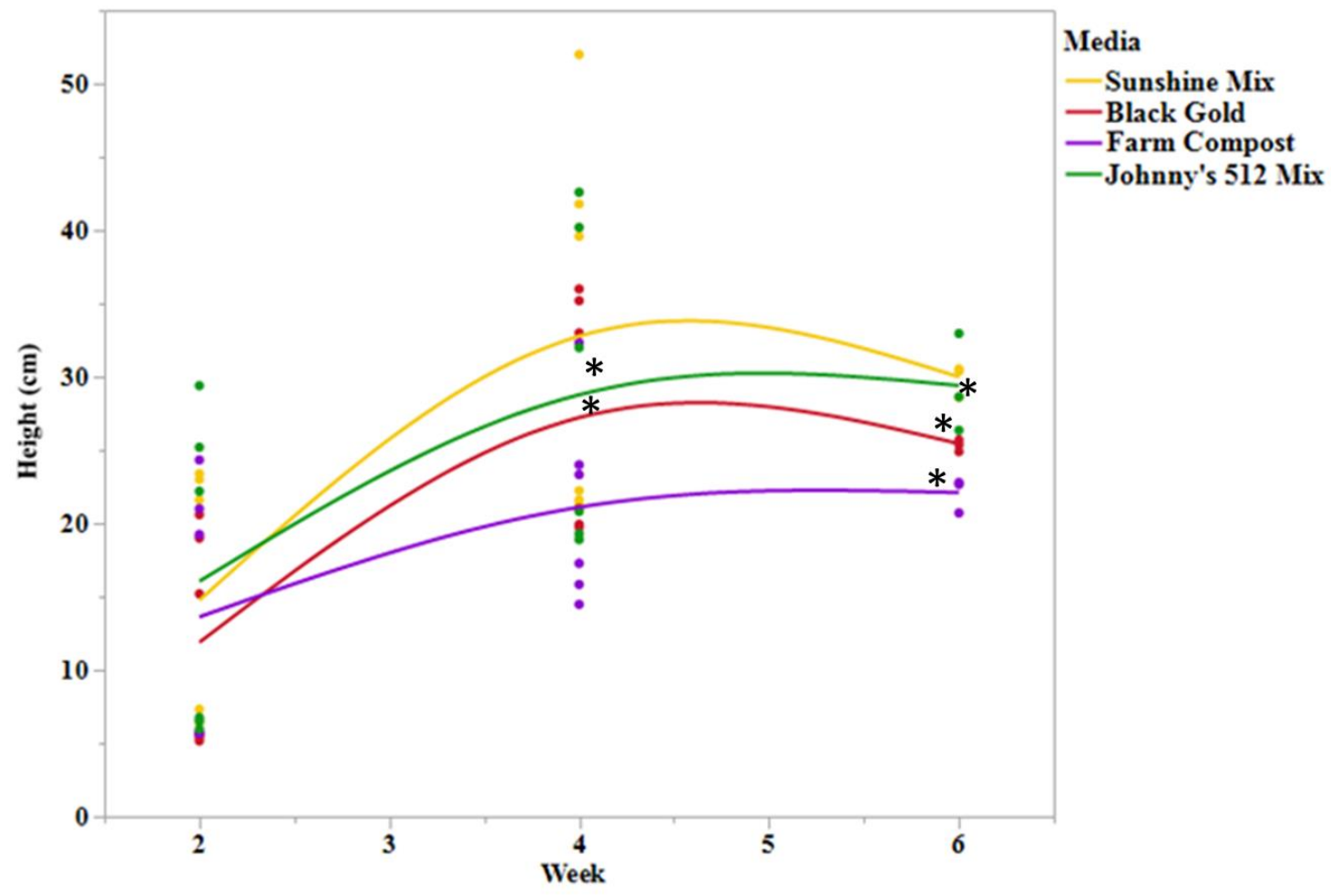

Figure 2.7. Effect of media on height in pepper 'Olympus F1' over weeks 2-6. Peppers were grown in the greenhouse using four listed media and three levels of irrigation. Height was recorded every two weeks for six weeks and the experiment was repeated the following year. Asterisks indicate a least square means significantly different from control (Sunshine Mix) before adjusting to multiple comparisons. 


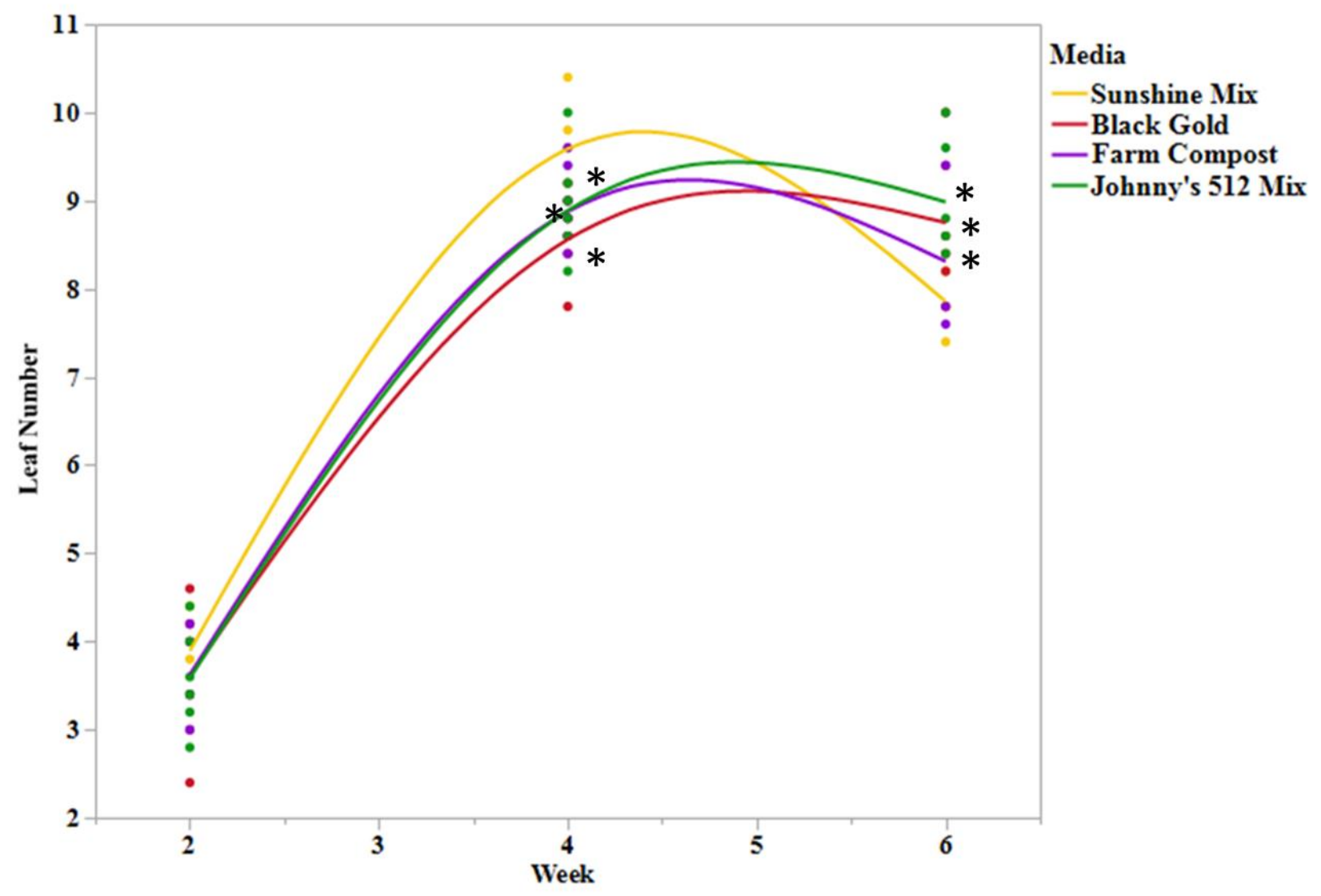

Figure 2.8. Effect of media on leaf number of tomato 'West Virginia '63' over weeks 2-6. Tomatoes were grown in the greenhouse using four listed media and three levels of irrigation. Height was recorded every two weeks for six weeks and the experiment was repeated the following year. Asterisks indicate a least square means significantly different from control (Sunshine Mix) before adjusting to multiple comparisons. 


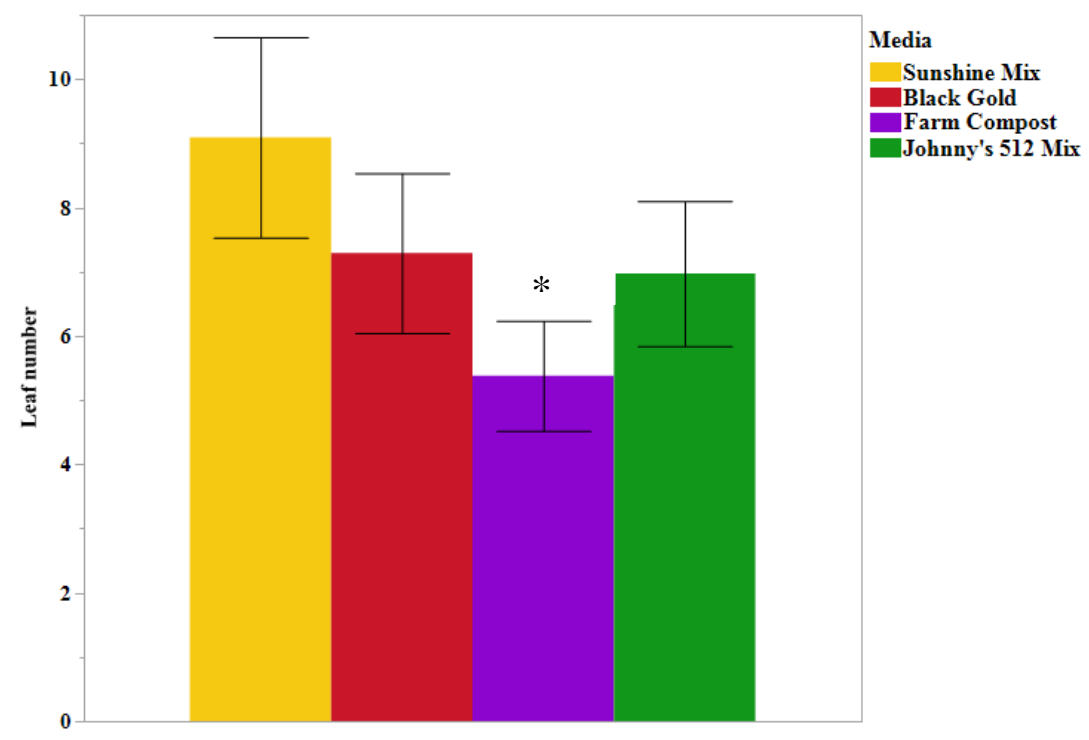

Figure 2.9. Main effect of media on pepper 'Olympus F1' leaf number over weeks 2-6. Peppers were grown in the greenhouse using four listed media and three levels of irrigation. Leaf number was recorded every two weeks for six weeks and the experiment was repeated the following year. Error bars indicate standard deviation; only plants grown in farm compost possessed a significantly lower number of leaves. 


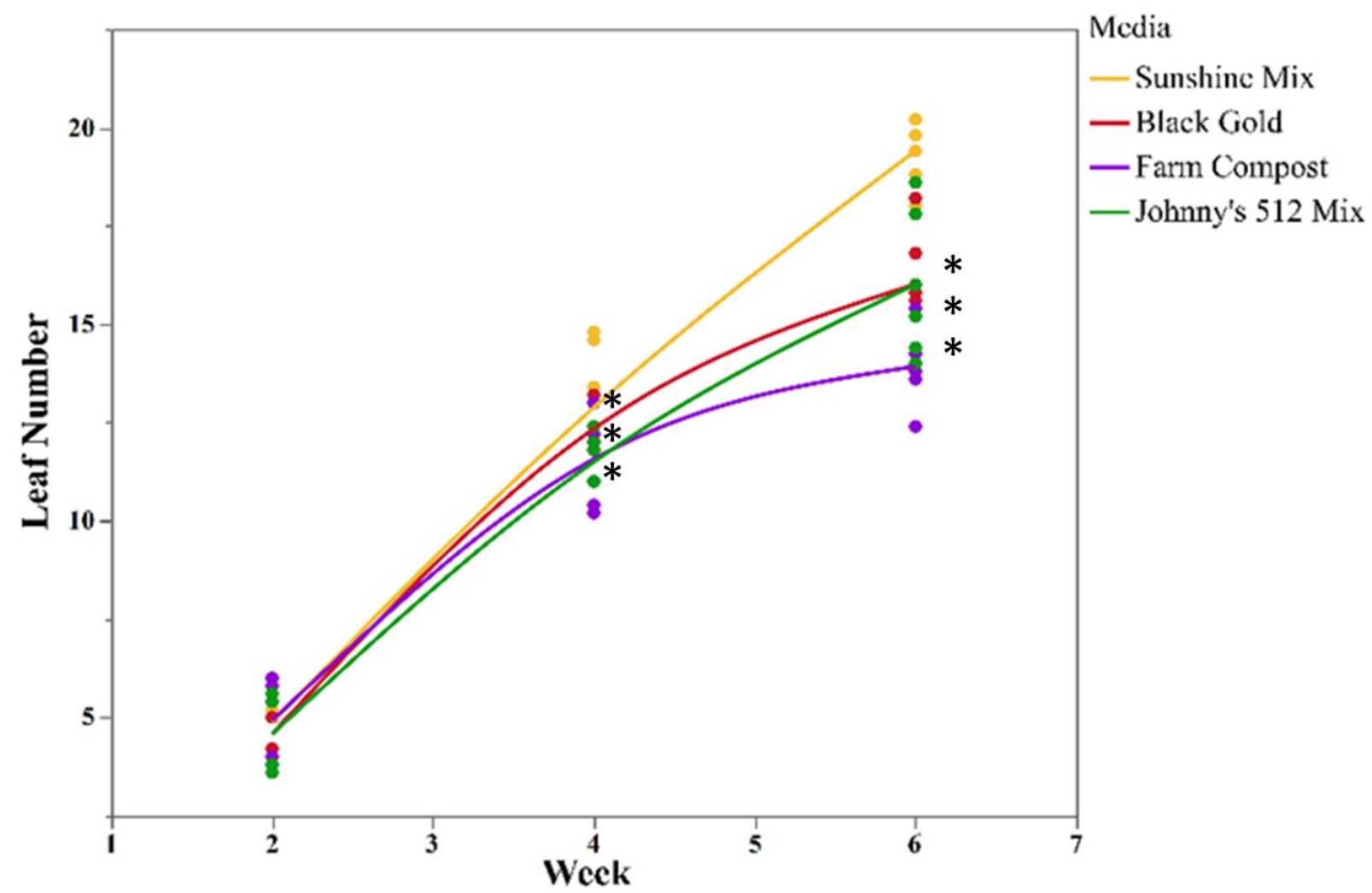

Figure 2.10. Effect of media on leaf number in lettuce 'Green Romaine' over weeks 2-6. Lettuces were grown in the greenhouse using four listed media and three levels of irrigation. Leaf number was recorded every two weeks for six weeks and the experiment was repeated the following year. Asterisks indicate a least square means significantly different from control (Sunshine Mix) before adjusting to multiple comparisons. 


\section{Discussion}

The first objective was to determine if organic media can produce a quality transplant without the addition of liquid or solid fertilizers other than the nutrient charge present in the media when purchased or formulated. We hypothesized that organic media can produce transplants of tomato, pepper, and lettuce of comparable quality to transplants produced with conventional media and fertilization methods. Quality was assessed in terms of plant vigor, which was quantified by plant height and leaf number throughout the experiment, and fresh and dry weight of organically versus conventionally produced transplants at the conclusion of the experiment. Many promising media were excluded due to the prohibitive cost of their acquisition; shipping was prohibitively expensive in some cases, while other media were only available in amounts far in excess of experimental need.

At the end of the experiment at week 6, differences in tomato height and leaf number were not significant across all treatments, with each treatment possessing 7 to 9 leaves (Table 2.6). The presence or absence of flowers was not recorded; however, studies have shown that indeterminate tomatoes initiate flowering after the presence of approximately 9 leaves (Thouet et al., 2008). Overall, Johnny's 512 Mix was comparable to conventional media, except at the condition with low irrigation $(80 \%)$, when lower leaf number occurred. The fresh aboveground shoot weight was lower in Black Gold and farm compost across all irrigations; however, Johnny's shoot weight was comparable to Sunshine Mix (Table 2.6). A similar pattern was observed in dry weights (Table 2.6). Only tomato plants measured at week 4 showed any main effect of irrigation in regards to leaf number. At week two we found the height and leaf number were comparable across all media, as plants may not yet be sufficiently established to display differences in vigor. Dry and Loveys (1998) found that deficit irrigation resulted in reduced 
shoot growth of grape (Vitis vinifera). However, in only one instance, in tomato at week 4, did we find a separate significant effect of irrigation on plant height. Stowe et al. (2010) have shown that decreased irrigation of containerized white spruce seedlings from 55\% V/V (volume percent) to $30 \% \mathrm{~V} / \mathrm{V}$ resulted in reduced levels of lost nutrients, especially mineral N, without impact on seedling development.

Similarly to tomatoes at week 6, peppers grown in Johnny's 512 Mix were physically comparable to those grown in Sunshine Mix. All pepper plants grown in test media exhibited a significantly lower leaf count than control plants (Sunshine Mix at 120\% VWC). Only those plants grown in farm compost were significantly shorter than the control (Table 2.10). Pepper plants grown in farm compost also exhibited significantly lower fresh and dry weights. Plants grown in Black Gold exhibited significantly lower fresh weights than those grown in Johnny's 512 Mix and Sunshine Mix, but their dry weights were comparable. The main effect of media on height present at week 2 persisted throughout the course of the experiment, despite no significant differences being detected between all media and Sunshine Mix using Dunnett's test. At week 2 no significant effects of media on leaf number were apparent, though those grown in Johnny's 512 Mix at 80\% VWC irrigation were the tallest. Guang-Cheng et al. (2010) found that deficit irrigation during the first growth stage of hot pepper plants grown in field soil within a greenhouse resulted in depressed vegetative growth. However, we found no main effect of irrigation on the height, leaf number, fresh weight, or dry weight of sweet peppers studied, only a main effect of media. While we did not grow plants on to fruiting size, Kang et al. (2001) found that using alternate drip irrigation on containerized hot peppers (Capsicum anuum) resulted in a comparable fruit yield to a fully irrigated control while using $40 \%$ less water. 
In lettuce, a significant difference in leaf number among the treatments did not become apparent until week 6, when plants grown in Sunshine Mix across all irrigations produced significantly more leaves than those in any other treatments. At weeks 2 and 6 only those plants grown in farm compost exhibited a significantly shorter height; interestingly, no significant differences in height were observed at week 4 . By week 6 the heights of plants grown in all organic media were significantly shorter than those grown in the control, however, those grown in farm compost were the most similar to Sunshine Mix in terms of plant height. Fresh weights of all organic treatments at week 6 were significantly less than for Sunshine Mix-grown plants, with fresh weights of plants grown in Johnny's 512 Mix greater than those grown in Black Gold and farm compost. Dry weights of plants grown in Johnny's 512 Mix were comparable to those grown in Sunshine Mix, as well as those grown in Black Gold, though the p-value (0.052) is marginally significant. Lettuce plants did not differ significantly from one another in terms of leaf number at week 2 .

When taking height, leaf number, fresh weight, and dry weight into consideration, our results show that across all species Johnny's 512 Mix performs comparable to Sunshine Mix (our control), followed by Black Gold and then farm compost.

Second, we wanted to determine if organic transplants can be grown successfully under limited leaching/deficit irrigation conditions. We hypothesized that quality transplants can be successfully grown under water deficit irrigation of $80 \%$ and $100 \%$ container capacity compared to traditional leaching irrigation regimens (120\%). To test for this, we compared reduced water volumes to the standard practice of irrigating with $120 \%$ of container capacity. To determine when to water, a WaterScout sensor was used to measure \%VWC against a predetermined threshold of $40 \%$ VWC; when this level was reached in any media all treatments of that species 
were irrigated. A relationship between container capacity and irrigation frequency was not investigated. Initially, some species did not need to be watered daily, but as plants developed all required daily watering. This standard of measurement allowed for variations in water volume; for example, the difference between $80 \%$ and $100 \%$ container capacity was $77 \mathrm{~mL}$ for Black Gold, but only $14 \mathrm{~mL}$ for farm compost in 2015 . However, as these media inherently possess different container capacities and are being compared to a control instead of each other, we determined this to be the most reliable standard of measurement. We hypothesized that higher irrigation levels would result in a greater change in EC throughout the course of the study, since theoretically salts initially present in the media would be removed by the larger amounts of water applied daily. A more gradual decrease in salts was expected in those media irrigated at $80 \%$ container capacity. Generally, EC dropped throughout the course of the study for all treatments. EC played an important role in the performance of our tested media over the course of the experiment. Johnny's 512 Mix possessed a much higher initial EC than the other experimental media when compared to our control, Sunshine Mix (Table 2.2). No less important is the ability of the media to retain salts and therefore nutrients. In tomatoes, at week 6 the EC was still the highest in Johnny's 512 Mix (across all irrigations) and still the lowest in Black Gold. The EC remained highest in Johnny's 512 Mix throughout the course of the tomato trial. This difference was already present at week 4, with the highest EC in Johnny’s 512 Mix at $100 \%$ VWC irrigation and lowest in Black Gold at 120\% VWC irrigation (Table 2.4). Sunshine Mix at 120\% VWC had a significantly lower EC when compared to farm compost at $80 \%$ and $100 \%$ VWC irrigation, Johnny’s 512 Mix at 80\%, 100\% and 120\% VWC irrigation, and Sunshine Mix at 80\% VWC irrigation (Table 2.4). Sunshine Mix's EC would have likely been even lower without 
daily infusions of fertilizer to replenish some of the salts being used by the plants and leached from the media by irrigation.

Soil $\mathrm{pH}$ affects nutrient availability. The $\mathrm{pH}$ of leachate from these media changed over the course of the experiment. The extremes in $\mathrm{pH}$ between media decreased, with $\mathrm{pH}$ increasing in Black Gold and Sunshine Mix and decreasing in Johnny's 512 Mix and farm compost over the course of the experiment. Most $\mathrm{pH}$ values remained within the ranges for nutrient availability, 5.4-6.8 (Pennisi and Thomas, 2015). In tomatoes, week $6 \mathrm{pH}$ was highest in farm compost at $100 \%$ VWC irrigation $(8 \pm 0)$ and lowest in Black Gold at $80 \%$ VWC irrigation $(6.4 \pm 0.1)$ (Table 2.5). It is possible that these levels played some part in these media performing less favorably than Johnny's 512 Mix and Sunshine Mix.

In peppers, by week $6 \mathrm{EC}$ levels had decreased across all media even under decreased irrigation. By week 6 Johnny's 512 Mix experienced the most drastic decrease in EC across all irrigation levels. Week 6 EC across all irrigation levels was higher in farm compost and Johnny's 512 than in Sunshine Mix. At weeks 4 and $6 \mathrm{EC}$ at $80 \%$ was significantly higher than that at $100 \%$ and $120 \%$, which we expected. At week 4 the EC was highest in Johnny's 512 Mix and lowest in Black Gold across all irrigation levels.

In peppers at week 6 , all three media had significantly higher $\mathrm{pH}$ when compared to $\mathrm{pH}$ of Sunshine mix. There were no significant differences in $\mathrm{pH}$ among the three irrigation levels. At weeks 2 and 4, where only Johnny's 512 Mix and farm compost had a significantly higher $\mathrm{pH}$, but by week 6 the $\mathrm{pH}$ had risen in Black Gold to the point of significantly surpassing the $\mathrm{pH}$ of Sunshine Mix.

In lettuce at week 6, the EC was the highest in farm compost at $80 \%$ irrigation and lowest at Black Gold at 120\% irrigation. Dunnett's comparison to Sunshine at 120\% detected 
significantly higher EC than control in Johnny's 512 Mix across all levels. Studies with bald cypress (Taxodium distichum) in containers have shown that seedlings were not placed under water stress even under 60\% water capacity, where no leachate was produced (Sammons and Struve, 2008).

In lettuce, changes in $\mathrm{pH}$ over the course of the study remained consistent: at weeks 2,4 , and 6 farm compost at 80\%,100\%, and 120\% VWC irrigation as well as Johnny's 512 Mix at $80 \%, 100 \%$, and $120 \%$ VWC irrigation each had higher pH compared to Sunshine Mix at $120 \%$ VWC irrigation. An overall rise in pH in Black Gold was observed over the study period.

Third, we wanted to determine the effect of interaction of media and irrigation regimens on transplant production of three vegetables with varying production times and cultural requirements: lettuce, tomato and bell pepper. We found no statistical effect of interaction on any parameter of pepper growth (height, leaf number, fresh weight, dry weight) where the interaction could be teased apart, and only a specific statistical effect on EC at weeks 2 and 4 in tomato and week 2 in lettuce. The meaning of these observations is obscure, as these differences did not result in significant differences at the end of the experiment.

This experiment has enabled us to conclude that choice of media, rather than irrigation level, is the main driver behind levels of $\mathrm{EC}$ and $\mathrm{pH}$, and that not all organic media are created equal. However, it is possible to grow organic vegetable transplants with different cultural requirements under this protocol if the correct medium is used. Media with high initial EC that can retain that level of conductivity throughout the course of transplant production are the most beneficial for producers. Using media that can retain a high level of soluble salts and therefore nutrients will allow producers to bypass the application of fertilizers and still produce a competitive transplant. A medium whose formulation allows for a steady $\mathrm{pH}$ which remains 
within appropriate levels also ensures optimum nutrient availability throughout the course of transplant production. We can also conclude that deficit irrigation at $80 \% \mathrm{VWC}$ can produce quality transplants while avoiding excessive nutrient leaching. Therefore, our best organic medium for transplant production would be Johnny's 512 Mix, due to its high, steady EC, steady $\mathrm{pH}$, and ability to retain sufficient nutrients under $80 \%$ VWC irrigation. 


\section{CHAPTER III: ALTERNATIVE MULCHES IN ORGANIC VEGETABLE PRODUCTION}

\section{Introduction}

Plastic mulch has been popular for many years in both commercial agricultural and home garden use. The many benefits of its use include weed suppression, moisture retention, and temperature regulation. Monks et al. (1997) determined that under both wet and dry seasonal conditions, black plastic is efficient at suppressing weeds when compared to chopped and shredded newspaper, wheat straw, landscape fabric, and bare ground. Under ridge and furrow cultivation, plastic mulch forces soil water to move laterally from furrows to ridges under normal weather conditions (Rudisch et al., 2013). It has been shown that with perforated black plastic mulch, the smaller the ratio of open holes in the plastic to the area of the plastic, the higher the temperature under the plastic; however, smaller ratios also decrease water loss through evaporation (Yi et al., 2003). Plastic mulch also consistently maintains higher soil temperature than other mulches, which may favor some crops (Monks et al., 1997).

Leaf litter is often seen as a nuisance in autumn and disposed of through municipal waste streams, though such waste can be used as a mulch. Studies performed at the University of Florida showed that a mulch made up of utility trimming waste including leaves exhibits an allelopathic effect on lettuce seeds when leachate from fresh as well as aged mulch was applied to the seeds (Duryea et al., 1999). Dandelion (Taraxacum officinale) growth has been shown to be inhibited in an established bluegrass lawn when the shredded leaves of oak and maple were mulched into the turf in fall (Kowalewski et al., 2009). These allelopathic effects could possibly be used to discourage weed germination when organic transplants were placed in the field; however, studies are still necessary to evaluate the potential of such effects from entire leaves applied as a mulch to bare soil. 
Another alternative mulch is wool mulch. Felted wool matting used as a mulch on strawberry crops has been shown to be competitive with chemical herbicides and hand weeding in terms of weed suppression (Forcella et al., 2003). Wool mulch, both felted and non-felted, has been shown to reduce soil temperature variations in strawberry (Hoover, 2000). Wool mulch for this study was sourced from the West Virginia University Organic Farm. The flock maintained on the farm is composed of mixed-breed animals raised for meat production; lower value and waste wool are byproducts of their production. Using this wool will provide an outlet for an otherwise underutilized on-farm resource. While some studies (Hoover, 2000; Forcella et al, 2003) have demonstrated that wool will decompose and may be tilled into the soil, the fleeces used in this study were removed at the end of the season in order to free up the plots for the next season.

Aged hay was also trialed as an on-farm alternative to traditional black plastic mulch. Using hay that is unsuitable for livestock feed as mulch provides a use for a product that might otherwise go to waste. Hay mulch has been shown to conserve soil moisture at higher levels than in non-mulched soil under potato cultivation (Xing et al., 2012). Studies have shown that mulching with straw reduces soil temperature fluctuations (Monks et al., 1997; Smika 1983); however, studies incorporating hay as mulch while also evaluating soil temperature are less common.

\section{Purpose of the Study: Goals}

The purpose of this study is to clarify how alternative organic mulches compare with less eco-friendly plastic mulches in terms of moisture retention and temperature moderation, and whether large stretches of plastic mulch allow for adequate available water for crop production. 


\section{Specific Objectives}

To compare three alternative mulches, two sizes of plastic mulch, hand weeding, and no weeding in order to investigate the effect of each treatment on soil temperature, soil moisture, and yield.

\section{Research Hypotheses}

\section{Objective 1:}

Hypothesis: Daily soil temperature fluctuations will differ among mulches.

\section{Objective 2:}

Hypothesis: Soil moisture retention under organic mulches will be comparable or superior to that of plastic mulches.

\section{Objective 3:}

Hypothesis: Yield will be comparable between conventional and organic mulches.

\section{Materials and Methods}

\section{Location and environmental conditions}

A field experiment compared organic and plastic mulch treatments on a plot located within the market garden of the West Virginia University Organic Farm in Morgantown, WV. This farm consists of approximately 154 acres which began the transition from conventional to organic practices in 1999 and was certified organic in 2003 (Dr. William Bryan, personal communication). The market garden soil has been classified as a Tilsit silt loam "Fine-silty, mixed, semiactive, mesic Typic Fragiudults" (USDA-NRCS 2015). It lies within USDA Hardiness Zone $6 \mathrm{~b}\left(39^{\circ} 38^{\prime} 41 \mathrm{~N} / 79^{\circ} 56^{\prime} 19 \mathrm{~W}\right)$ with an average elevation of 1230 feet. 


\section{Research Design}

This experiment consisted of seven treatments in a randomized complete block design, with four replicate blocks, for a total of 28 plots. Blocks were laid out in two rows across the slope of the plot in order to account for small differences in soil moisture (Fig. 3.1). Beds were all tilled level; this removed any possibility of ridges and valleys under the plastic mulch which could affect water movement. Treatments were two sizes of 6-mil black plastic, hay, hardwood leaf litter, waste wool from the farm's organic sheep flock, hand-weeded bare soil, and unweeded soil. The plastic-mulched plots measured $3 \times 6.1 \mathrm{~m}$ and $6.1 \times 6.1 \mathrm{~m}$, while the other plots measured $2.8 \times 3 \mathrm{~m}$. Factors taken into consideration when determining plot sizes included available space, conventional plant spacing, and the necessity of boundary plants. Plastic sizes were chosen because of their commercial availability. Plastic was installed and incised before planting, while organic mulches were laid around the plants after they had been transplanted. Plants received hand irrigation when transplanted, but no other irrigation was supplied throughout the growing season. 


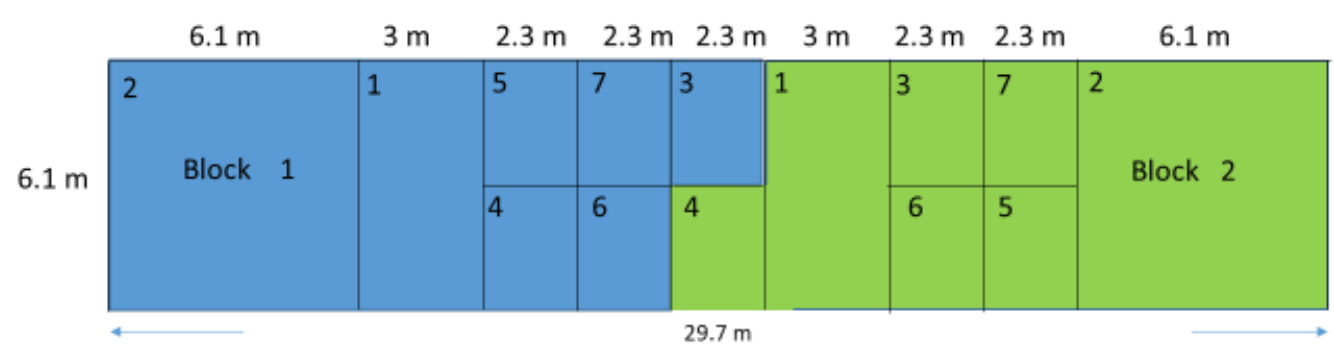

2016 Sweet Pepper Mulch Trial
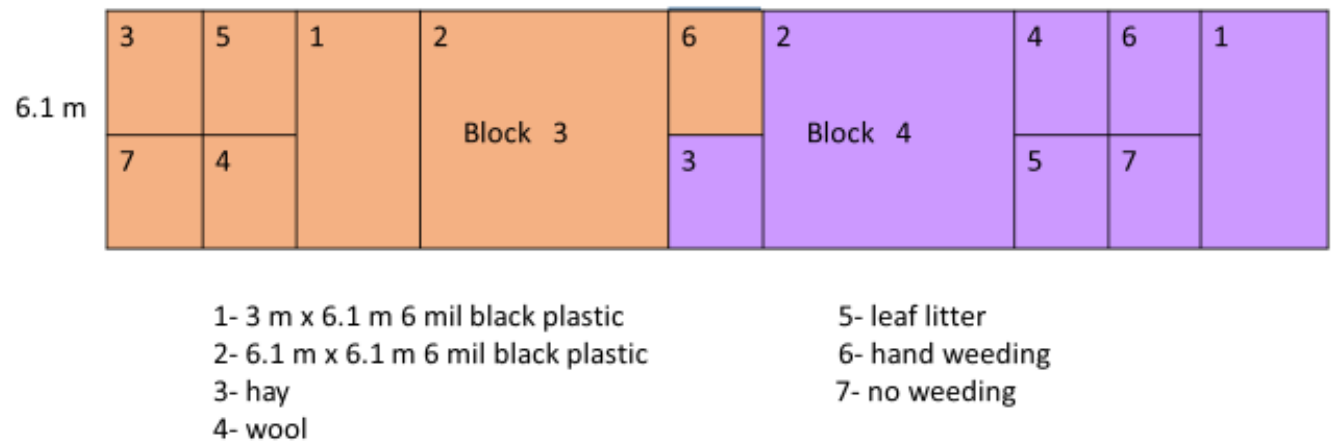

Figure 3.1. 2016 plot layout. Blocks were laid out in two rows across the slope of the plot in order to account for small differences in soil moisture (Fig. 3.1).

\section{Plant material}

Pepper (Capsicum annuum) 'Olympus F1' seeds for the trials were sourced from Johnny’s Selected Seeds (Johnny's Selected Seeds, Winslow, ME). Seeds were sown on 7 April in 2015 and 10 April in 2016. Seeds were planted in 288-cell plug trays and grown to transplanting size in the University greenhouse under organic protocols. Seeds were sown in Johnny's 512 Mix and lightly covered with fine vermiculite in order to conserve moisture. Plug trays were placed on a mist table and seedlings received supplemental bottom heat. Seedlings were transplanted into six-packs when their second set of true leaves had expanded. Nitrogen was supplied in the form of granular blood meal, applied at a rate of $167 \mathrm{~g} / \mathrm{m}^{2}$, as directed by the greenhouse manager. Meanwhile, mulches were purchased or gathered on farm and the market garden plots plowed and tilled. Peppers were grown in the greenhouse until one week before the 
transplant date, then moved outside to harden off on raised benches behind the university greenhouse. Once the market garden beds were tilled and black plastic installed, the plants were transplanted into study plots by hand. In 2015, peppers were transplanted into plots from 3 to 5 June; in 2016, 4 to 7 June. Plants were spaced approximately $0.6 \mathrm{~m}$ from the plot boundary and $0.6 \mathrm{~m}$ apart so that a $2.3 \mathrm{~m}$ by $3 \mathrm{~m}$ plot contained 12 plants in a $3 \times 4$ grid, a $3 \mathrm{~m} \times 6.1 \mathrm{~m}$ plot contained 50 plants, and a $6.1 \mathrm{~m}$ x $6.1 \mathrm{~m}$ plot contained 100 plants. Regardless of plot size, plants for measurement were always the two center plants.

\section{Mulches}

Plastic mulch treatments consisted of $6.1 \mathrm{~m}$ strips of 6 mil black plastic in $3 \mathrm{~m}$ and $6.1 \mathrm{~m}$ widths. Plastic was applied to the soil surface prior to planting and 10-cm X-shaped incisions were made through which peppers were transplanted. Organic mulches were not applied directly to the soil surface; a layer of blank newspaper was applied to the soil surface after planting and organic mulches spread around the bases of plants to a depth of $7.6 \mathrm{~cm}$. Organic mulches consisted of hardwood leaf litter collected from the Organic Farm's woodlots, orchard grass hay from the farm's surplus of hay, and waste wool from shearing the flock. The hand-weeding plots were weeded by hand on a weekly basis; no-weeding plots were left unweeded.

\section{Data Collection Procedures}

Soil data were collected as a percentage of volumetric water content and soil temperature data readings in degrees Celsius. WaterScout SM 100 Soil Moisture Sensors were placed $5 \mathrm{~cm}$ beneath the surface of the soil in the center of each plot and connected to WatchDog 1000 Series Micro Stations (Spectrum Technologies, Inc., Aurora, IL) in order to monitor soil moisture. On plastic-mulched plots, sensors were placed midway between planting holes. Spectrum External (Soil) Temperature Sensors were placed at the same depth in the same locations and also 
connected to WatchDog 1000 Series data loggers. A total of 56 soil sensors were used. A WatchDog 2700 Weather Station (Spectrum Technologies, Inc., Aurora, IL) was placed in the center of the plots in order to measure air temperature, relative humidity, rain fall, wind speeds and wind direction. Data from all sensors were collected hourly for a total of 90 days (7/3/169/30/16). Once peppers reached harvestable size, two central plants from each plot were harvested by hand twice per season. Fruits were weighed to generate a total yield per acre.

\section{Statistical Analysis}

The minimum, mean, and maximum daily values for soil temperature and moisture were determined for treatment, replication (plot) and day. Daily minimums, means and maximums were analyzed separately using repeated measures ANOVA with main effects of treatment and date and the interaction of treatment and date, while date was used as a repeated variable. The model described above included autoregressive covariance structure and least square (LS) means were compared and adjusted among the treatments by the Tukey-Kramer method. The weight of harvested peppers was transformed by Ln due to the positive skewness and then analyzed by repeated measures ANOVA with main effect of treatment, time ( 2 harvests) and their interaction. The LS means were also compared using the Tukey-Kramer method as above. 


\section{Results and Discussion}

Treatment, time of year (date), and their interaction had a significant effect on the minimum, mean, and maximum temperatures and moisture levels (Table 3.1). There was a significant effect of treatment on harvest weight, but no effect of time of year (date) or of the interaction of treatment and time on weight.

Table 3.1. Influence (P-value) of treatment, date and their interaction on Volumetric Water Content (\%) and Soil Temperature $\left({ }^{\circ} \mathrm{C}\right)$, and the effect of treatment, harvest $\left(1^{\text {st }}\right.$ and $\left.2^{\text {nd }}\right)$ and their interaction on Harvest Weight $(g)$.

\begin{tabular}{lcccc}
\hline \multicolumn{4}{c}{ Effect tests (Two-way RM ANOVA P-value) } \\
\hline Variable & Daily & Treatment & Time $($ Date) & Treatment*Time \\
\hline Volumetric Water & Minimum & $0.0158^{*}$ & $<0.0001^{*}$ & $<0.0001^{*}$ \\
\cline { 2 - 5 } Content $(\boldsymbol{\%})$ & Mean & $0.0306^{*}$ & $<0.0001^{*}$ & $<0.0001^{*}$ \\
\cline { 2 - 5 } & Maximum & $<0.0001^{*}$ & $<0.0001^{*}$ & $<0.0001^{*}$ \\
\hline \multirow{2}{*}{$\begin{array}{l}\text { Soil Temperature } \\
\left({ }^{\circ} \mathbf{C}\right)\end{array}$} & Minimum & $<0.0001^{*}$ & $<0.0001^{*}$ & $0.0213^{*}$ \\
\cline { 2 - 5 } & Mean & $<0.0001^{*}$ & $<0.0001^{*}$ & $<0.0001^{*}$ \\
\cline { 2 - 5 } & Maximum & $<0.0001^{*}$ & $<0.0001^{*}$ & $<0.0001^{*}$ \\
\hline Harvest Weight $(\mathbf{g})$ & Average & Treatment & Harvest & Treatment*Harvest \\
\hline & & $<0.0001^{*}$ & 0.6869 & 0.3371 \\
\hline
\end{tabular}

\section{Soil Temperature}

The $3 \mathrm{~m}$ x $6.1 \mathrm{~m}$ and $6.1 \mathrm{~m} \times 6.1 \mathrm{~m}$ plastic plots had minimum, mean, and maximum soil temperatures that were all significantly higher than the other treatments (Table 3.2). Variations in logger operation, such as probe damage by animals or premature battery discharge, resulted in a differing number of observations between treatments. 
Table 3.2. Least square means and standard errors of the means (SEM) for Soil Temperature $\left({ }^{\circ} \mathrm{C}\right)$.

\begin{tabular}{ccccc}
\hline Treatment & $\begin{array}{c}\text { Number of } \\
\text { observations } \\
\text { (4 plots x 90 } \\
\text { days) }\end{array}$ & \multicolumn{3}{c}{$\begin{array}{c}\text { Soil Temperature }\left({ }^{\circ} \mathbf{C}\right) \\
\text { Average Across Field Trial (90 days) }\end{array}$} \\
\cline { 3 - 5 } & 358 & $23.5 \pm 0.3^{\mathrm{a}}$ & $27.2 \pm 0.3^{\mathrm{a}}$ & $32.7 \pm 0.8^{\mathrm{a}}$ \\
\hline $3 \mathrm{~m} \times 6.1 \mathrm{~m}$ Plastic & 357 & $23.2 \pm 0.3^{\mathrm{a}}$ & $28.0 \pm 0.3^{\mathrm{a}}$ & $35.1 \pm 0.8^{\mathrm{a}}$ \\
\hline $6.1 \mathrm{~m} \times 6.1 \mathrm{~m}$ Plastic & 256 & $21.3 \pm 0.3^{\mathrm{b}}$ & $23.3 \pm 0.3^{\mathrm{b}}$ & $25.7 \pm 0.9^{\mathrm{b}}$ \\
\hline Hay & 210 & $21.5 \pm 0.4^{\mathrm{b}}$ & $23.0 \pm 0.4^{\mathrm{b}}$ & $24.2 \pm 1.1^{\mathrm{b}}$ \\
\hline Wool & 256 & $21.2 \pm 0.3^{\mathrm{b}}$ & $23.4 \pm 0.3^{\mathrm{b}}$ & $26.4 \pm 0.9^{\mathrm{b}}$ \\
\hline Leaf Litter & 328 & $21.2 \pm 0.3^{\mathrm{b}}$ & $23.0 \pm 0.3^{\mathrm{b}}$ & $25.2 \pm 0.8^{\mathrm{b}}$ \\
\hline Hand Weeding & 328 & $20.1 \pm 0.3^{\mathrm{b}}$ & $23.0 \pm 0.3^{\mathrm{b}}$ & $25.6 \pm 0.9^{\mathrm{b}}$ \\
\hline No Weeding & & & & \\
\end{tabular}

Treatments compared with Tukey-Kramer. LS-means with the same letter are not significantly different $(P \leq 0.05)$.

Minimum soil temperatures under $3 \mathrm{~m}$ x $6.1 \mathrm{~m}$ and $6.1 \mathrm{~m}$ x $6.1 \mathrm{~m}$ plastic were significantly higher than the other treatments (Fig. 3.2). Peaks and valleys indicate variation in temperature as a product of weather variations. Mean soil temperatures under $6.1 \mathrm{~m}$ x $6.1 \mathrm{~m}$ plastic were significantly higher than hay (Fig 3.3). Maximum soil temperatures under $3 \mathrm{~m}$ x 6.1 $\mathrm{m}$ were significantly higher than hay, while maximum soil temperatures $6.1 \mathrm{~m}$ x $6.1 \mathrm{~m}$ plastic were significantly higher than all non-plastic treatments (Fig 3.4). As expected, temperatures under black plastic were significantly higher than those under organic mulches. Lamont (2017) stated that, in general, soil temperatures under black plastic mulch during the daytime are $5^{\circ} \mathrm{F}$ $\left(2.8^{\circ} \mathrm{C}\right)$ higher at 2 in. $(5 \mathrm{~cm})$ beneath the soil surface and our results supported this, with mean soil temperatures under $6.1 \mathrm{~m} \times 6.1 \mathrm{~m}$ plastic being $28.0{ }^{\circ} \mathrm{C} \pm 0.3{ }^{\circ} \mathrm{C}$ and $23.0{ }^{\circ} \mathrm{C} \pm 0.3{ }^{\circ} \mathrm{C}$ under mostly bare, hand-weeded soil. While these temperatures reach levels that other studies (Sopher, 2012, for example) have shown may predispose peppers to disease as well as reduced growth and yield, these were not observed in our plants grown under plastic mulch. This is possibly due to nighttime relief from high soil temperatures reached during the day (Fig 3.2). The $6.1 \mathrm{~m} \mathrm{x} 6.1 \mathrm{~m}$ 
plots also experienced the greatest variation between minimum and maximum soil temperatures, from $23.2{ }^{\circ} \mathrm{C} \pm 0.3{ }^{\circ} \mathrm{C}$ to $35.1{ }^{\circ} \mathrm{C} \pm 0.8^{\circ} \mathrm{C}$. In contrast, soil under the wool mulch experienced the smallest variation in soil temperatures across the duration of the study (minimum $21.5^{\circ} \mathrm{C} \pm 0.4$ ${ }^{\circ} \mathrm{C}$ to maximum $24.2{ }^{\circ} \mathrm{C} \pm 1.1{ }^{\circ} \mathrm{C}$ ). Wool mulch, both felted and non-felted, has been shown to reduce soil temperature variations in strawberry (Hoover, 2000). Wool mulch also resulted in the lowest soil maximum temperature across all treatments, though its large standard error made it comparable to the other treatments.

\section{Soil Moisture}

The $6.1 \mathrm{~m}$ x $6.1 \mathrm{~m}$ plastic plots had a maximum \%VWC that was significantly lower than the hay treatment (Table 3.3). Wilting was occasionally observed in plants grown on the plasticmulched plots, especially the $6.1 \times 6.1 \mathrm{~m}$ plots; ponding on the plastic was observed after rainfall events.

Table 3.3. Least square means and standard errors of the means (SEM) for Volumetric Water Content (\%).

\begin{tabular}{|c|c|c|c|c|}
\hline \multirow[t]{2}{*}{ Treatment } & \multirow{2}{*}{$\begin{array}{c}\text { Number of } \\
\text { observations } \\
(4 \text { plots } x 90 \\
\text { days) }\end{array}$} & \multicolumn{3}{|c|}{$\begin{array}{l}\text { Volumetric Water Content (\%) } \\
\text { Average Across Field Trial ( } 90 \text { days) }\end{array}$} \\
\hline & & Minimum & Mean & Maximum \\
\hline $3 \mathrm{~m}$ x $6.1 \mathrm{~m}$ Plastic & 360 & $12.1 \pm 1.9^{\mathrm{ab}}$ & $13.2 \pm 2.2^{\mathrm{ab}}$ & $14.9 \pm 1.5^{\mathrm{bc}}$ \\
\hline $6.1 \mathrm{~m}$ x $6.1 \mathrm{~m}$ Plastic & 359 & $8.3 \pm 1.8^{b}$ & $9.1 \pm 2.2^{b}$ & $10.2 \pm 1.5^{c}$ \\
\hline Hay & 360 & $19.0 \pm 1.9^{a}$ & $20.8 \pm 2.2^{\mathrm{a}}$ & $23.5 \pm 1.5^{\mathrm{a}}$ \\
\hline Wool & 298 & $15.5 \pm 2.0^{\mathrm{ab}}$ & $17.0 \pm 2.3^{\mathrm{ab}}$ & $19.5 \pm 1.7^{\mathrm{ab}}$ \\
\hline Leaf Litter & 359 & $14.9 \pm 1.9^{\mathrm{ab}}$ & $16.6 \pm 2.2^{\mathrm{ab}}$ & $19.1 \pm 1.5^{\mathrm{ab}}$ \\
\hline Hand Weeding & 326 & $15.6 \pm 1.9^{a b}$ & $17.1 \pm 2.2^{\mathrm{ab}}$ & $19.4 \pm 1.6^{\mathrm{ab}}$ \\
\hline No Weeding & 323 & $15.0 \pm 1.9^{\mathrm{ab}}$ & $17.1 \pm 2.2^{\mathrm{ab}}$ & $20.1 \pm 1.6^{\mathrm{ab}}$ \\
\hline
\end{tabular}

Treatments compared with Tukey-Kramer. LS-means with a common letter are not significantly different $(P \leq 0.05)$. 
After transplants were established, no symptoms of wilting, discoloration or other indications of water stress were observed in plants grown in organic mulch plots. Plants grown under plastic mulches occasionally exhibited wilting during periods of especially hot, dry weather. Rainwater was also seen to pond on the depressions in the plastic mulches. While plastic mulches exhibit the smallest variations in soil moisture (Table 3.3), their low overall $\% \mathrm{VWC}$ is likely an effect of their large areas of impermeability — water is only able to enter the soil vertically via planting perforations. Tukey's test indicated that the \%VWC in the $6.1 \mathrm{~m} \times 6.1$ $\mathrm{m}$ plastic mulched plot was significantly lower than all non-plastic mulch treatments (Figure 3.5). Tukey's test indicated that the mean soil \%VWC under $6.1 \mathrm{~m}$ x $6.1 \mathrm{~m}$ plastic was only significantly lower than hay (Fig. 3.6). Tukey's test indicated that maximum moisture levels under $3 \mathrm{~m}$ x $6.1 \mathrm{~m}$ plastic were significantly lower than in soil mulched with hay. Additionally, maximum \%VWC under $6.1 \mathrm{~m}$ x $6.1 \mathrm{~m}$ plastic was significantly lower than all non-plastic mulched plots (Table 3.3).

It was expected that moisture levels would be higher under permeable alternative mulches than impermeable plastic mulch plots, as in the latter only their planting perforations admit any rainwater to the soil beneath (Monks et al., 1997). After rain events, pools of water collected in depressions on the black plastic, sometimes taking days to evaporate. This is relevant as this water is unavailable to plants. In contrast, no runoff or ponding was observed in organic mulch plots. The $6.1 \mathrm{~m} \times 6.1 \mathrm{~m}$ plots experienced the lowest mean and minimum soil moisture, plants in these plots occasionally showed slight wilting during periods of hot, dry weather (Table 3.3). Despite this, only the $6.1 \mathrm{~m}$ x $6.1 \mathrm{~m}$ plastic-mulched plots and the hay-mulched plots had statistically significant differences in mean and minimum soil moisture (Table 3.3). Only maximum moisture levels under the $6.1 \mathrm{~m}$ x $6.1 \mathrm{~m}$ plastic were significantly lower than the non- 
plastic treatments (Table 3.3), most likely due to the large area rendered impermeable to water infiltration. Hay mulch has been shown to conserve soil moisture at higher levels than in nonmulched soil under potato cultivation (Xing et al., 2012). Our results corroborated this, as the hay-mulched plots had the highest soil moisture content across all levels and treatments (Table 3.3).

Yield

Fruits were collected from two central plants per plot, for two harvests, and the weights were averaged. Each treatment had a significantly higher yield than no weeding; these plants were choked by weed growth.

Table 3.4. Pepper Yield.

\begin{tabular}{|c|c|c|c|}
\hline \multirow[t]{2}{*}{ Treatment } & \multirow{2}{*}{$\begin{array}{c}\text { Number of } \\
\text { observations } \\
\text { (4 plots x } 2 \\
\text { harvests) }\end{array}$} & $\begin{array}{l}\text { Yield Weight }(\mathrm{g}) \\
\text { Average Across } \\
\text { Both Harvests } \\
\end{array}$ & \multirow[t]{2}{*}{$\begin{array}{c}\text { Mean Yield Weight }(\mathrm{kg}) \mathbf{x} \\
26,909 \text { (plants per hectare) } / \\
2(\text { sample size })=\mathrm{kg} / \mathrm{Ha}\end{array}$} \\
\hline & & Means \pm SEM & \\
\hline $3 \mathrm{~m} \times 6.1 \mathrm{~m}$ Plastic & 8 & $1,380.8 \pm 134^{\mathrm{a}}$ & 18,578 \\
\hline $\begin{array}{c}6.1 \mathrm{~m} \times 6.1 \mathrm{~m} \\
\text { Plastic }\end{array}$ & 8 & $1,291.1 \pm 193.4^{\mathrm{a}}$ & 17,371 \\
\hline Hay & 8 & $518.1 \pm 80.4^{\mathrm{ab}}$ & 6,970 \\
\hline Wool & 8 & $903.3 \pm 99.5^{\mathrm{ab}}$ & 12,153 \\
\hline Leaf Litter & 8 & $578.1 \pm 106.3^{\mathrm{ab}}$ & 7,778 \\
\hline Hand Weeding & 8 & $266.1 \pm 39.3^{b}$ & 3,580 \\
\hline No Weeding & 8 & $21.6 \pm 12.2^{\mathrm{c}}$ & 29 \\
\hline
\end{tabular}

Treatments compared with Tukey-Kramer. LS-means with a common letter are not significantly different $(P \leq 0.05)$.

Our hypothesis that yield would be comparable between conventional and organic mulches was supported by our findings (Table 3.4). Similar to the findings of Monks et al. (1997), fruit numbers were greater in all mulch treatments than in the unweeded plot. Studies have shown that higher pepper yields are obtained from plants mulched with black plastic than those left unmulched, though how much of an advantage is due to the higher soil temperature 
under black plastic is unclear (Ravinder et al., 1997; Ashrafuzzaman et al., 2011). Multiple studies on various row crops have found that organic mulches increase yields over non-mulched controls (Sharma and Sharma, 2003; Olfati et al., 2008). Lal (1974) attributes an increase in grain yield to the decrease in soil temperature and improved soil moisture retention of organic mulches, attributes not possessed by plastic mulches. Hay, wool and leaf litter yields were statistically comparable to those obtained from plastic mulch treatments (Table 3.4). Our results allow us to calculate a yield per hectare for each treatment (Table 3.4). Projected yields would be highest under plastic mulches; however, a yield of approximately $12,000 \mathrm{~kg} / \mathrm{ha}$ would be possible using wool mulch (Table 3.4). Though individual fruit weights were not included in the results, those harvested from wool plots occasionally weighed over 500 grams (personal record). Wool could have been the best performer for several reasons: in addition to its moisture- and soil temperature-moderating abilities, it was noted that plants grown on wool mulch were an exceptionally deep and vibrant green. This could have been a product of the white wool reflecting light back into the plant canopy, as white plastic mulch has been shown to reflect more total photosynthetic light back into the canopy than darker mulches (DeCouteau et al, 1989).

Findings generated by this experiment will be used to better assist local farmers and producers in using biodegradable organic mulches on their crops, materials which might otherwise simply be discarded. This experiment has shown that wool mulch could be a viable competitor to plastic mulch. The use of wool mulch may increase soil organic matter, reduce weed competition, conserve soil moisture and regulate soil temperature better than plastic mulches, especially when plastic mulches are applied to larger areas. Using organic mulches as substitutes for conventional black plastic mulch has the potential to reduce the impact of waste plastics on landfills and the environment. 


\section{Appendix A}

Layout of treatments for each individual greenhouse experiment. Irrigation treatments are designated by percentage of container capacity. Treatments for each species are arranged in a completely randomized layout in a 12 column by 10 row layout in order to fit the available space. Media are designated by abbreviation: B- Black Gold; C- control (Sunshine Mix); F- farm compost; J- Johnny’s 512 Mix. Numbers indicate irrigation regimes: 80\%, 100\%, or 120\% container capacity. BP indicates the presence of a boundary plant. 


\begin{tabular}{|c|c|c|c|c|c|c|c|c|c|c|c|c|c|c|c|}
\hline & \multicolumn{15}{|c|}{ Lettuce } \\
\hline & & column & 1 & 2 & 3 & 4 & 5 & 6 & 7 & 8 & 9 & 10 & 11 & 12 & 13 \\
\hline & Row & BP & BP & BP & BP & BP & BP & BP & BP & BP & BP & BP & BP & BP & BP \\
\hline & 1 & BP & F100 & B100 & J100 & C100 & $\mathrm{C} 100$ & $\mathrm{C} 120$ & B80 & F100 & $\mathrm{C} 80$ & B120 & F120 & B100 & Tomatoes \\
\hline & 2 & $\mathrm{BP}$ & B80 & B120 & J100 & B80 & F80 & F100 & $\mathrm{J} 80$ & F100 & F100 & $\mathrm{J} 80$ & C100 & F120 & Tomatoes \\
\hline & 3 & $\mathrm{BP}$ & F120 & F80 & $\mathrm{C} 120$ & J100 & C120 & F80 & $\mathrm{C} 100$ & B100 & $\mathrm{J} 120$ & $\mathrm{C} 80$ & C120 & F120 & Tomatoes \\
\hline & 4 & BP & F80 & $\mathrm{J} 120$ & F100 & J100 & B100 & B120 & B100 & B80 & F120 & $\mathrm{J} 80$ & $\mathrm{~J} 100$ & C120 & Tomatoes \\
\hline Aisle & 5 & BP & B80 & F80 & B80 & C100 & B100 & F80 & C80 & $\mathrm{J} 100$ & $\mathrm{C} 80$ & F120 & B100 & B100 & Tomatoes \\
\hline & 6 & BP & J120 & $\mathrm{C} 120$ & B120 & F100 & J80 & J120 & $\mathrm{J} 80$ & B120 & C120 & J120 & J80 & $\mathrm{C} 80$ & Tomatoes \\
\hline & 7 & BP & $\mathrm{C} 80$ & F80 & B120 & C100 & B100 & B100 & J120 & F120 & C120 & $\mathrm{C} 100$ & C100 & $\mathrm{J} 80$ & Tomatoes \\
\hline & 8 & BP & $\mathrm{J} 80$ & B80 & F120 & B120 & B80 & $\mathrm{C} 80$ & J100 & $\mathrm{J} 120$ & J80 & B120 & $\mathrm{C} 80$ & F100 & Tomatoes \\
\hline & 9 & $\mathrm{BP}$ & B120 & B120 & F100 & F100 & F80 & F120 & J120 & $\mathrm{C} 120$ & C100 & B80 & B80 & F120 & Tomatoes \\
\hline & 10 & BP & $\mathrm{J} 80$ & F80 & F80 & $\mathrm{C} 80$ & $\mathrm{C} 80$ & J100 & $\mathrm{J} 120$ & $\mathrm{C} 100$ & $\mathrm{~J} 100$ & $\mathrm{~J} 120$ & C120 & $\mathrm{J} 100$ & Tomatoes \\
\hline & & BP & $\mathrm{BP}$ & $\mathrm{BP}$ & $\mathrm{BP}$ & $\mathrm{BP}$ & $\mathrm{BP}$ & BP & $\mathrm{BP}$ & BP & BP & $\mathrm{BP}$ & $\mathrm{BP}$ & BP & BP \\
\hline
\end{tabular}




\begin{tabular}{|c|c|c|c|c|c|c|c|c|c|c|c|c|c|c|}
\hline \multicolumn{15}{|c|}{ Tomatoes } \\
\hline & 12 & 13 & 14 & 15 & 16 & 17 & 18 & 19 & 20 & 21 & 22 & 23 & 24 & 25 \\
\hline row & $\mathrm{BP}$ & $\mathrm{BP}$ & $\mathrm{BP}$ & $\mathrm{BP}$ & $\mathrm{BP}$ & $\mathrm{BP}$ & $\mathrm{BP}$ & $\mathrm{BP}$ & $\mathrm{BP}$ & $\mathrm{BP}$ & $\mathrm{BP}$ & $\mathrm{BP}$ & $\mathrm{BP}$ & $\mathrm{BP}$ \\
\hline 1 & Lettuce & $\mathrm{C} 80$ & J80 & $\mathrm{C} 100$ & F120 & B80 & $\mathrm{C} 80$ & F80 & $\mathrm{J} 120$ & $\mathrm{~J} 120$ & F100 & F100 & B100 & Peppers \\
\hline 2 & Lettuce & B120 & F80 & J80 & F100 & $\mathrm{C} 120$ & $\mathrm{C} 120$ & $\mathrm{C} 80$ & $\mathrm{C} 120$ & B120 & $\mathrm{J} 120$ & F100 & B100 & Peppers \\
\hline 3 & Lettuce & $\mathrm{C} 100$ & F100 & B100 & $\mathrm{C} 120$ & B120 & $\mathrm{J} 100$ & $\mathrm{~J} 100$ & F80 & $\mathrm{J} 120$ & B120 & $\mathrm{C} 80$ & B80 & Peppers \\
\hline 4 & Lettuce & $\mathrm{J} 100$ & $\mathrm{C} 100$ & B80 & $\mathrm{J} 80$ & $\mathrm{C} 120$ & $\mathrm{C} 100$ & $\mathrm{~J} 100$ & F100 & $\mathrm{C} 120$ & F120 & F80 & $\mathrm{C} 80$ & Peppers \\
\hline 5 & Lettuce & F120 & $\mathrm{C} 80$ & $\mathrm{~J} 100$ & $\mathrm{C} 100$ & F120 & $\mathrm{B} 120$ & B100 & B80 & $\mathrm{C} 100$ & $\mathrm{~J} 100$ & F120 & $\mathrm{J} 120$ & Peppers \\
\hline 6 & Lettuce & B80 & $\mathrm{C} 100$ & J80 & B100 & $\mathrm{B} 100$ & J80 & $\mathrm{C} 120$ & $\mathrm{~B} 100$ & F80 & $\mathrm{J} 120$ & B80 & F100 & Peppers \\
\hline 7 & Lettuce & F120 & F100 & B120 & $\mathrm{J} 120$ & $\mathrm{~J} 80$ & $\mathrm{C} 120$ & $\mathrm{~J} 100$ & J80 & $\mathrm{B} 80$ & $\mathrm{~J} 80$ & F120 & B100 & Peppers \\
\hline 8 & Lettuce & $\mathrm{J} 100$ & B80 & $\mathrm{C} 80$ & F80 & $\mathrm{J} 120$ & B80 & J80 & $\mathrm{C} 120$ & $\mathrm{C} 120$ & B 100 & B100 & $\mathrm{J} 120$ & Peppers \\
\hline 9 & Lettuce & $\mathrm{C} 100$ & F80 & B80 & $\mathrm{B} 120$ & $\mathrm{C} 80$ & $\mathrm{~J} 100$ & B120 & B120 & $\mathrm{J} 100$ & $\mathrm{C} 80$ & F80 & F100 & Peppers \\
\hline 10 & Lettuce & F100 & F120 & $\mathrm{C} 80$ & $\mathrm{C} 100$ & F80 & F120 & J80 & F80 & $\mathrm{J} 120$ & $\mathrm{C} 100$ & B120 & F120 & Peppers \\
\hline & $\mathrm{BP}$ & $\mathrm{BP}$ & $\mathrm{BP}$ & $\mathrm{BP}$ & $\mathrm{BP}$ & $\mathrm{BP}$ & $\mathrm{BP}$ & $\mathrm{BP}$ & $\mathrm{BP}$ & $\mathrm{BP}$ & $\mathrm{BP}$ & $\mathrm{BP}$ & $\mathrm{BP}$ & $\mathrm{BP}$ \\
\hline \multicolumn{15}{|c|}{ Peppers } \\
\hline & 24 & 25 & 26 & 27 & 28 & 29 & 30 & 31 & 32 & 33 & 34 & 35 & 36 & \\
\hline row & $\mathrm{BP}$ & $\mathrm{BP}$ & $\mathrm{BP}$ & $\mathrm{BP}$ & $\mathrm{BP}$ & $\mathrm{BP}$ & $\mathrm{BP}$ & $\mathrm{BP}$ & $\mathrm{BP}$ & $\mathrm{BP}$ & $\mathrm{BP}$ & $\mathrm{BP}$ & $\mathrm{BP}$ & $\mathrm{BP}$ \\
\hline 1 & Tomatoes & F80 & B120 & $\mathrm{C} 100$ & $\mathrm{C} 120$ & B80 & $\mathrm{C} 100$ & F120 & $\mathrm{B} 100$ & $\mathrm{~B} 80$ & $\mathrm{~J} 80$ & $\mathrm{~J} 120$ & $\mathrm{C} 80$ & $\mathrm{BP}$ \\
\hline 2 & Tomatoes & F120 & F120 & J80 & F100 & $\mathrm{C} 80$ & F80 & $\mathrm{C} 120$ & $\mathrm{~J} 100$ & F100 & $\mathrm{C} 80$ & $\mathrm{C} 100$ & F100 & $\mathrm{BP}$ \\
\hline 3 & Tomatoes & B100 & F100 & B100 & $\mathrm{C} 100$ & $\mathrm{C} 80$ & $\mathrm{~J} 80$ & $\mathrm{~B} 80$ & $\mathrm{~J} 120$ & $\mathrm{~J} 120$ & $\mathrm{C} 100$ & B120 & $\mathrm{C} 100$ & $\mathrm{BP}$ \\
\hline 4 & Tomatoes & F80 & F80 & B80 & $\mathrm{C} 120$ & B120 & C120 & B100 & F100 & B100 & $\mathrm{C} 120$ & J80 & $\mathrm{J} 100$ & $\mathrm{BP}$ \\
\hline 5 & Tomatoes & C890 & $\mathrm{C} 120$ & F120 & B120 & F80 & $\mathrm{J} 100$ & $\mathrm{~J} 80$ & $\mathrm{~J} 120$ & B100 & B100 & F120 & F80 & $\mathrm{BP}$ \\
\hline 6 & Tomatoes & F100 & $\mathrm{C} 80$ & B120 & F120 & F100 & $\mathrm{C} 100$ & B100 & B120 & F120 & $\mathrm{J} 100$ & B100 & B80 & $\mathrm{BP}$ \\
\hline 7 & Tomatoes & $\mathrm{J} 120$ & F100 & $\mathrm{J} 100$ & $\mathrm{~B} 80$ & $\mathrm{C} 100$ & $\mathrm{~B} 80$ & F80 & $\mathrm{C} 80$ & F120 & $\mathrm{B} 80$ & $\mathrm{C} 120$ & F80 & $\mathrm{BP}$ \\
\hline 8 & Tomatoes & B120 & F80 & $\mathrm{J} 120$ & $\mathrm{C} 120$ & $\mathrm{~J} 80$ & $\mathrm{C} 80$ & $\mathrm{C} 120$ & F80 & $\mathrm{J} 80$ & B120 & $\mathrm{C} 100$ & $\mathrm{~J} 100$ & $\mathrm{BP}$ \\
\hline 9 & Tomatoes & B80 & B120 & F100 & J120 & F120 & F100 & F120 & $\mathrm{C} 80$ & $\mathrm{C} 100$ & B100 & $\mathrm{J} 100$ & B80 & $\mathrm{BP}$ \\
\hline 10 & Tomatoes & $\mathrm{J} 80$ & $\mathrm{~J} 100$ & $\mathrm{C} 80$ & $\mathrm{~J} 80$ & B120 & $\mathrm{J} 120$ & $\mathrm{~J} 100$ & $\mathrm{~J} 120$ & $\mathrm{~J} 80$ & $\mathrm{~J} 120$ & $\mathrm{C} 120$ & $\mathrm{~J} 100$ & $\mathrm{BP}$ \\
\hline & $\mathrm{BP}$ & $\mathrm{BP}$ & BP & $\mathrm{BP}$ & $\mathrm{BP}$ & BP & $\mathrm{BP}$ & $\mathrm{BP}$ & $\mathrm{BP}$ & BP & $\mathrm{BP}$ & $\mathrm{BP}$ & $\mathrm{BP}$ & $\mathrm{BP}$ \\
\hline
\end{tabular}




\section{Appendix B}

Chapter 3 soil temperature and soil moisture figures.

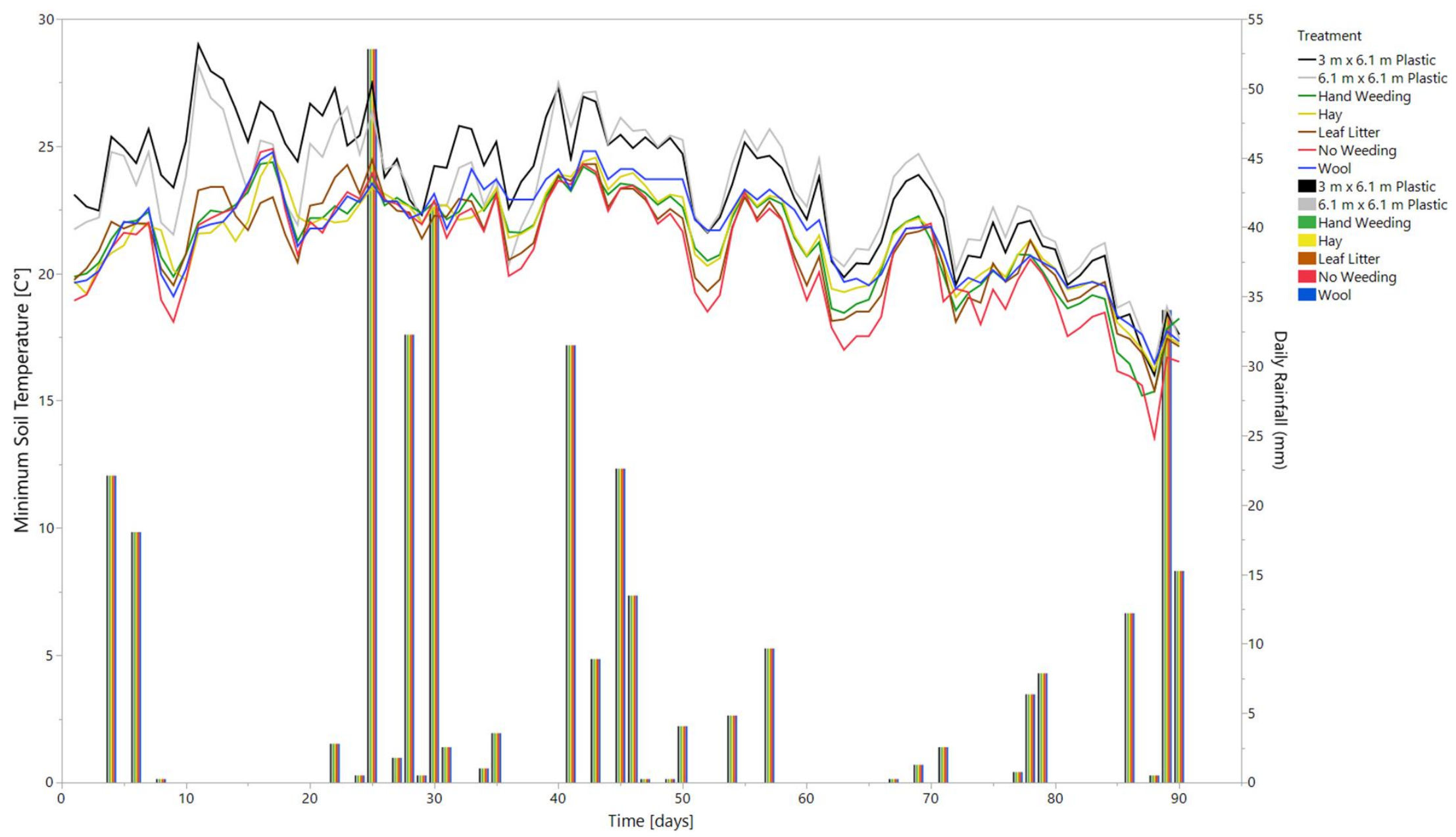

Daily minimum soil temperatures $\left({ }^{\circ} \mathrm{C}\right)$ under eight treatments from July 3 to Sept. 30, 2016. Pepper 'Olympus F1' was grown in the field under eight soil treatments. Lines indicate a daily minimum soil temperature over a 24-hour period as recorded $5 \mathrm{~cm}$ below the soil surface. Bars represent daily rainfall totals as recorded over a 24-hour period. 


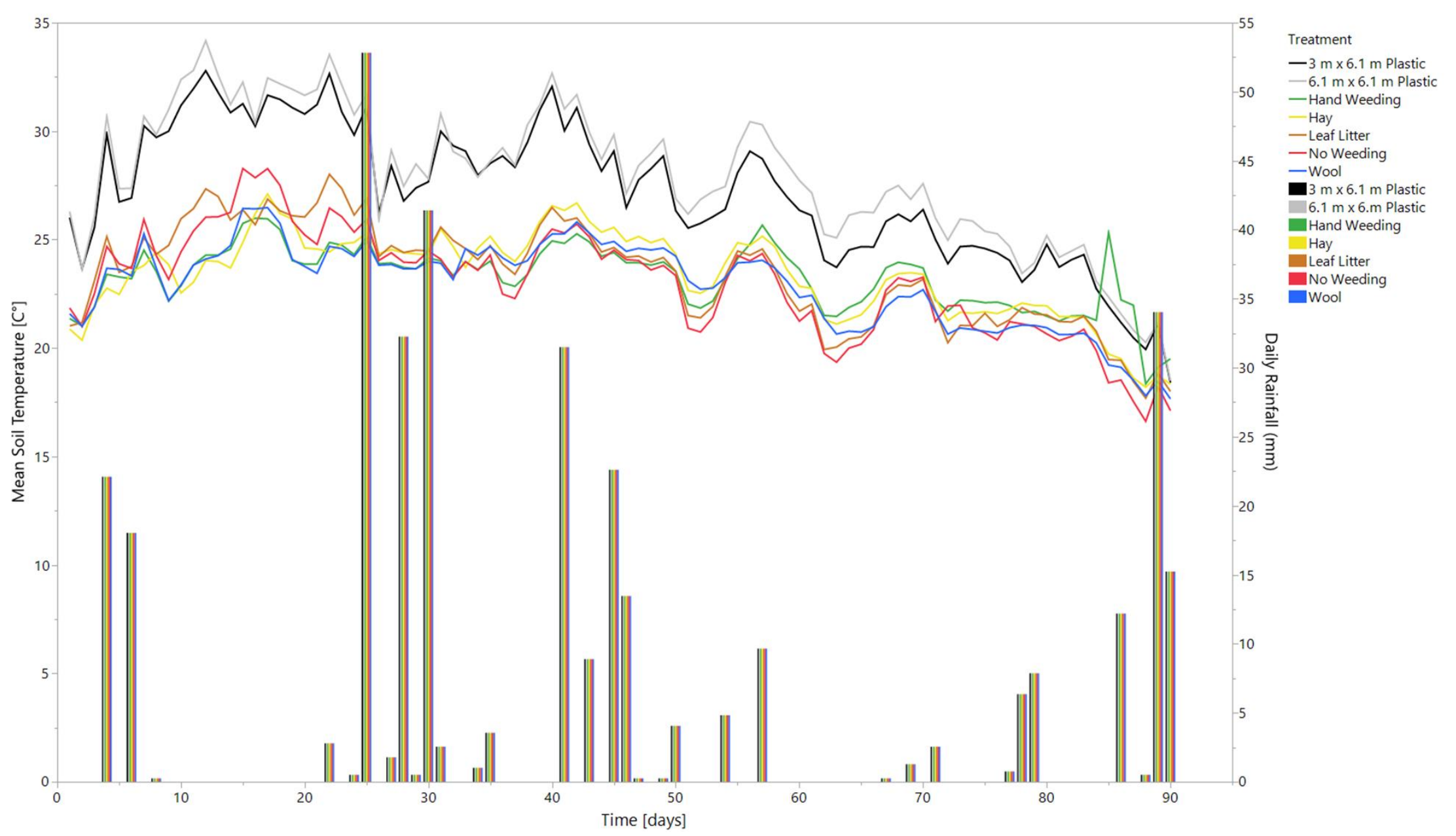

Daily mean soil temperatures $\left({ }^{\circ} \mathrm{C}\right)$ under eight treatments from July 3 to Sept. 30, 2016. Pepper 'Olympus F1' was grown in the field under eight soil treatments. Lines indicate a daily mean soil temperature over a 24-hour period as recorded $5 \mathrm{~cm}$ below the soil surface. Bars represent daily rainfall totals as recorded over a 24-hour period. 


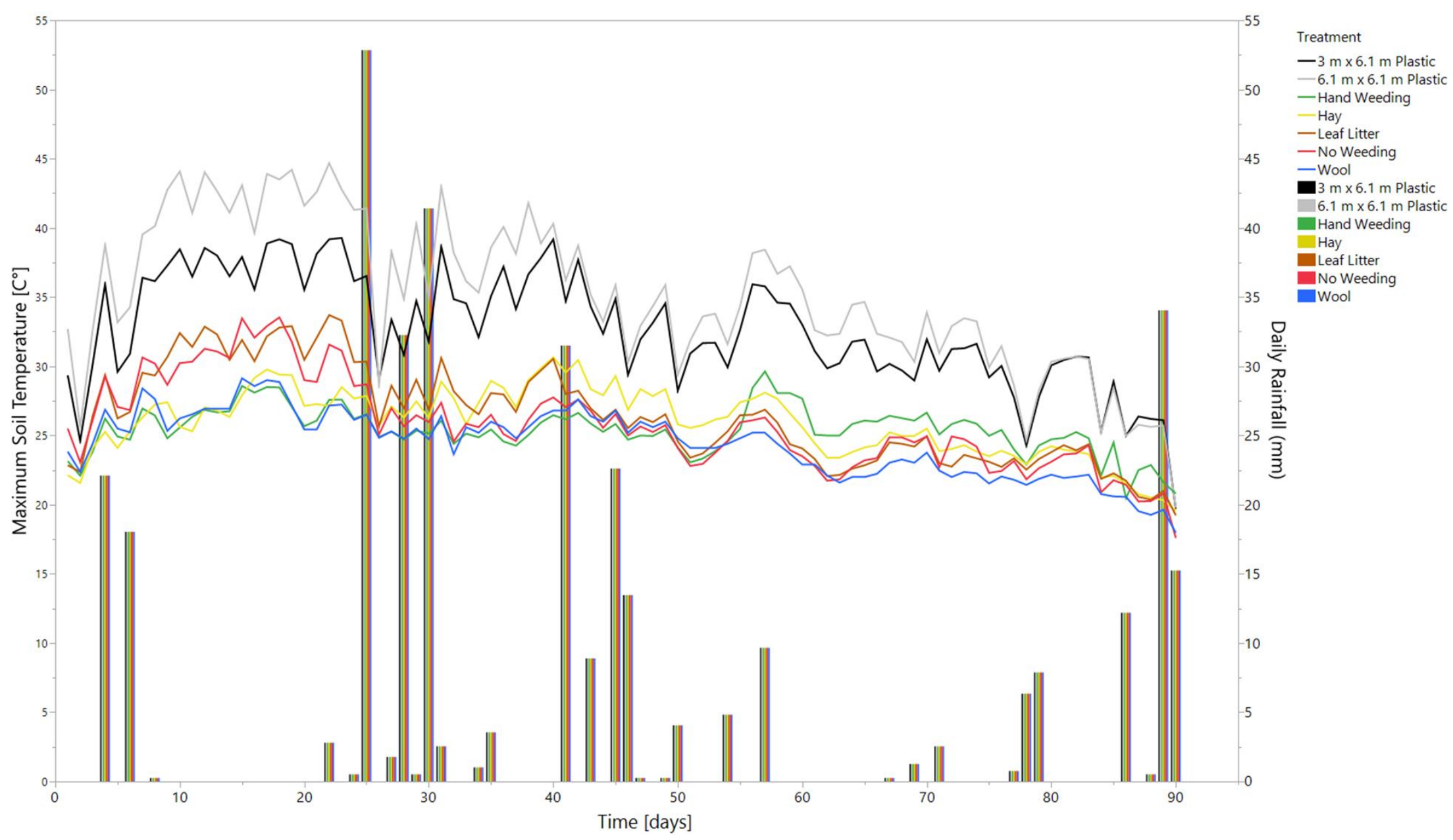

Daily maximum soil temperatures $\left({ }^{\circ} \mathrm{C}\right)$ under eight treatments from July 3 to Sept. 30, 2016. Pepper 'Olympus F1' was grown in the field under eight soil treatments. Lines indicate a daily maximum soil temperature over a 24-hour period as recorded $5 \mathrm{~cm}$ below the soil surface. Bars represent daily rainfall totals as recorded over a 24-hour period. 


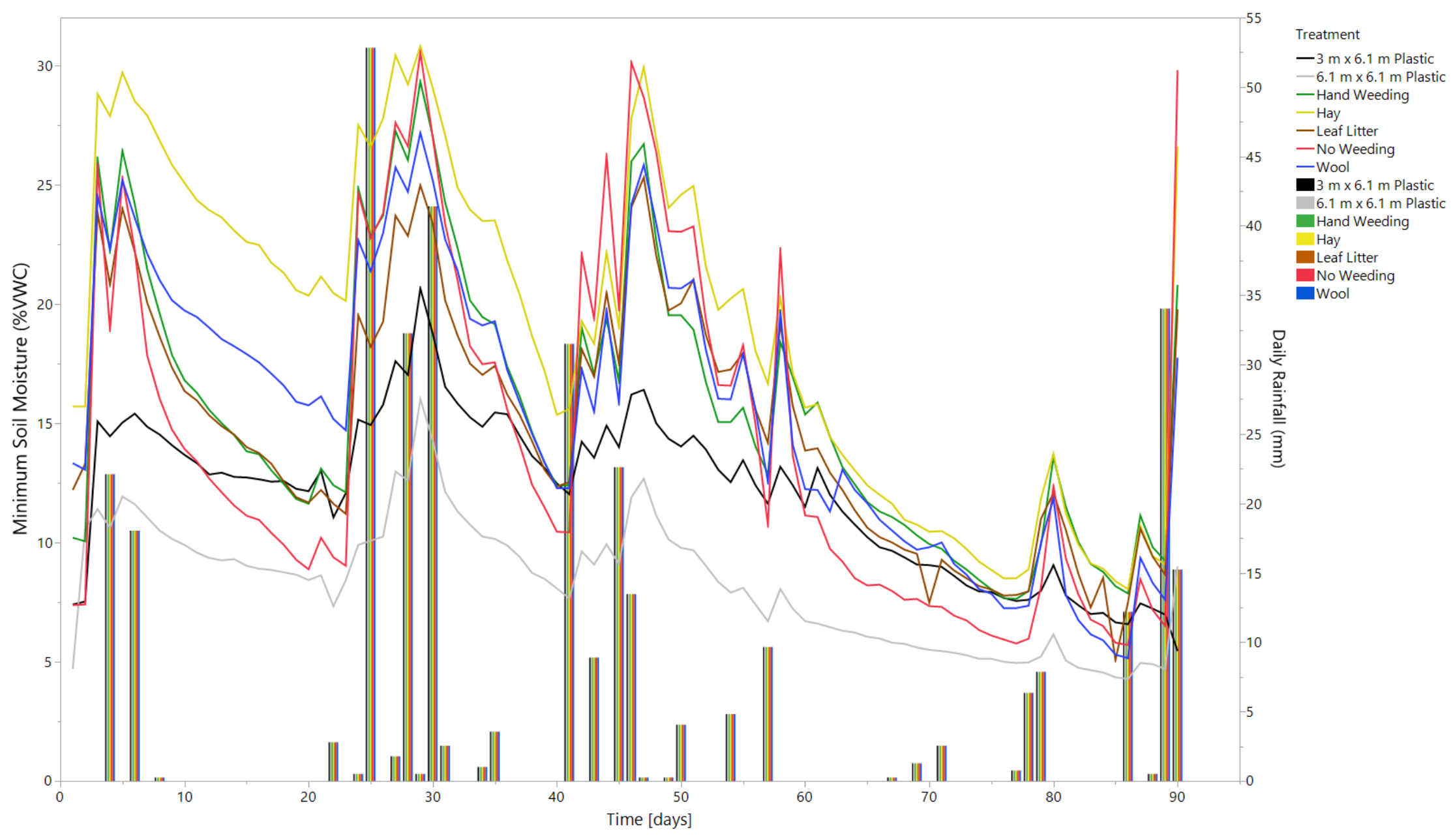

Minimum daily soil moisture (\%VWC) under eight treatments from July 3 to Sept. 30, 2016. Pepper 'Olympus F1' was grown in the field under eight soil treatments. Lines indicate a daily maximum soil temperature over a 24-hour period as recorded $5 \mathrm{~cm}$ below the soil surface. Bars represent daily rainfall totals as recorded over a 24-hour period. Reductions in soil temperature concurrent with increases in soil moisture are a product of rain events. 


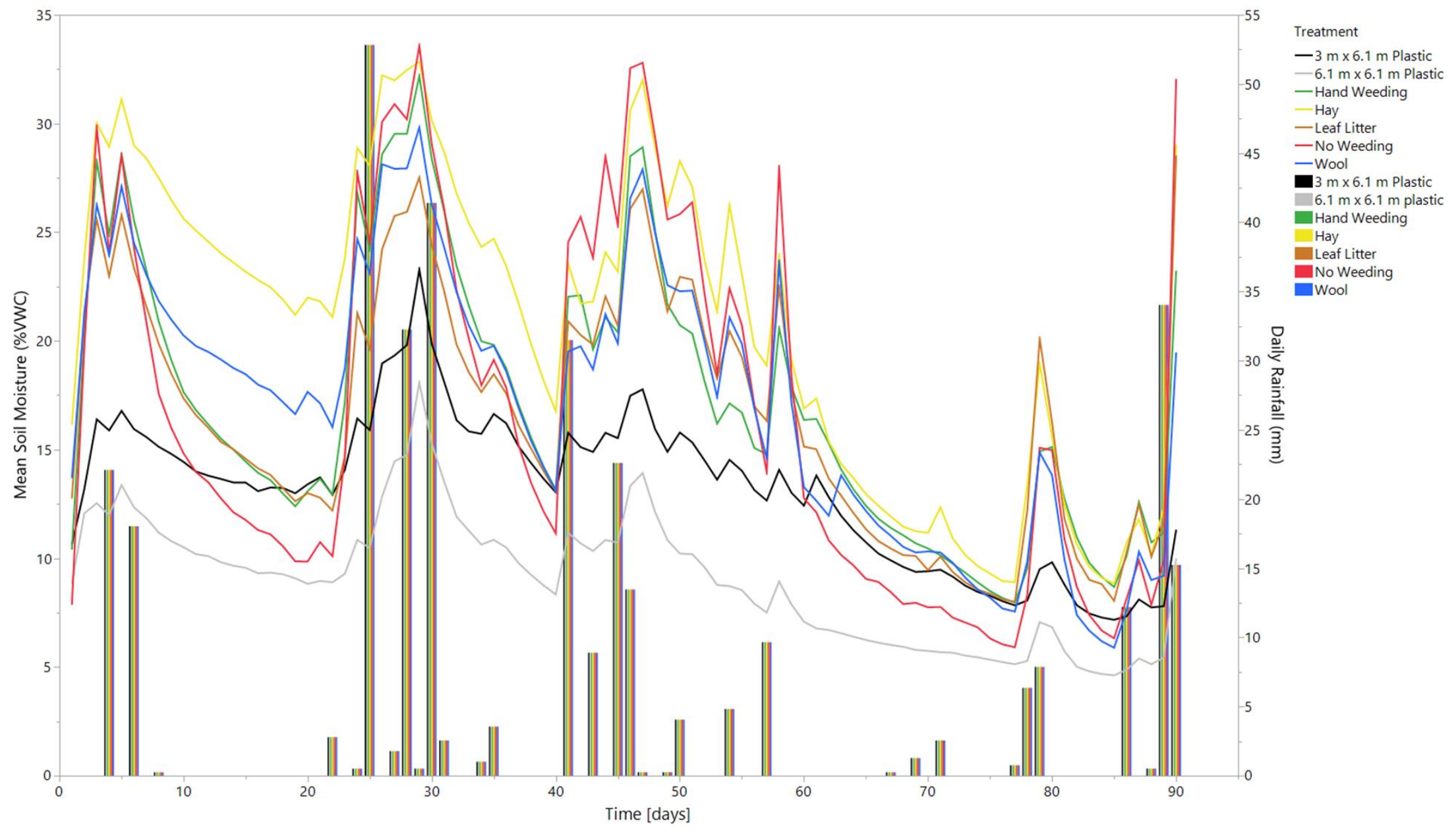

Mean daily soil moisture (\%VWC) under eight treatments from July 3 to Sept. 30, 2016. Pepper 'Olympus F1' was grown in the field under eight soil treatments. Lines indicate a daily maximum soil temperature over a 24-hour period as recorded $5 \mathrm{~cm}$ below the soil surface. Bars represent daily rainfall totals as recorded over a 24-hour period. Reductions in soil temperature concurrent with increases in soil moisture are a product of rain events. 


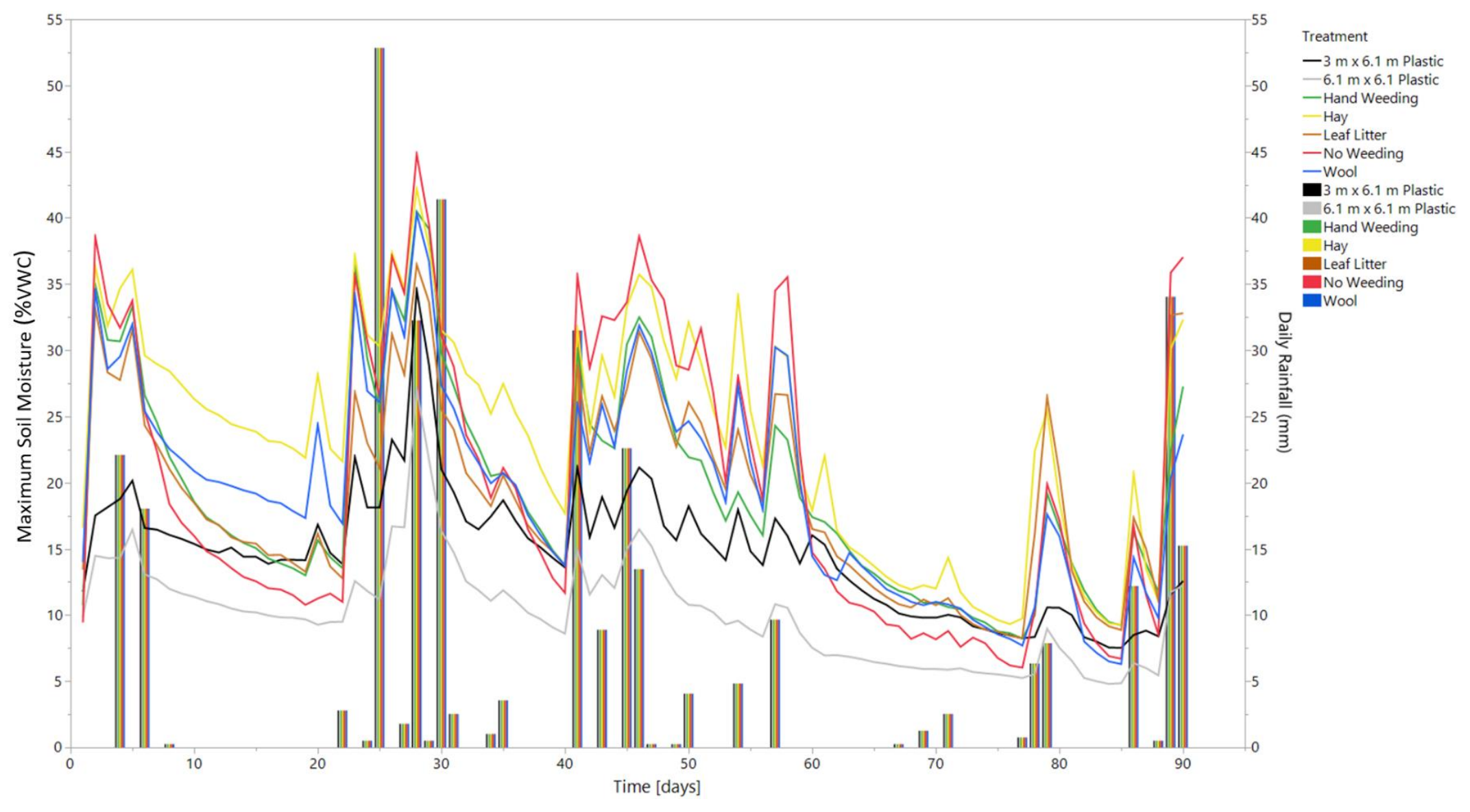

Maximum daily soil moisture (\%VWC) under eight treatments from July 3 to Sept. 30, 2016. Pepper 'Olympus F1' was grown in the field under eight soil treatments. Lines indicate a daily maximum soil temperature over a 24-hour period as recorded $5 \mathrm{~cm}$ below the soil surface. Bars represent daily rainfall totals as recorded over a 24-hour period. Reductions in soil temperature concurrent with increases in soil moisture are a product of rain events. 


\section{REFERENCES}

Almeida, D.O., O.K. Filho, H.C. Almeida, L. Gebler, and A.F. Felipe. 2011. Soil microbial biomass under mulch types in an integrated apple orchard from Southern Brazil. Scientia Agricola 68(2):217-222.

Ashrafuzzaman, M., M.A. Halim, M.R. Ismail, S.M. Shahidullah, and M.A. Hossain. 2011. Effect of plastic mulch on growth and yield of chilli (Capsicum annuum L.). Brazilian Archives of Biology and Technology 54(2):321-330.

Brooks, J.D. 1996. Method and apparatus for cleaning and recycling post-consumer plastic films. US Patent 5540244 A filed December 22, 1993 and issued July 30, 1996.

Carson, R. 1962. Silent Spring. Houghton-Mifflin, Boston.

Clark, S.S., and M.M. Cavigelli. 2005. Suitability of composts as potting media for production of organic vegetable transplants. Compost Sci. and Utilization 13(2):150-156.

Cox, D. A. 1994. Controlled-release fertilizers and nitrogen leaching. Georgia Commercial Flower Growers Association Newsletter, Nov-Dec, 38-41.

DeCouteau, D.R., M.J. Kasperbauer, and P.G. Hunt. 1989. Mulch surface color affects yield of fresh market tomatoes. J. Amer. Hort. Soc. 114(2):216-219.

De Prisco, N, B. Immirzi, M. Malinconico, P. Mormile, L. Petti, and G. Gatta. 2002. Preparation, physico-chemical characterization, and optical analysis of polyvinyl alcohol-based films suitable for protected cultivation. J. Appl. Polym. Sci. 86:622-632.

Duryea, M. L., J.R. English, and L.A. Hermansen. 1999. A comparison of landscape mulches: Chemical, allelopathic, and decomposition properties. J. of Arboriculture 25(2):88-97.

Dorais, M. 2007. Organic production of vegetables: State of the art and challenges. Can. J. Plant Sci. 87:1055-1066. 
Dry, P.R., and B.R. Loveys. 1998. Factors influencing grapevine vigor and the potential for control with partial root zone drying. Aust. J. Grape Wine Res. 4 140-148.

Egley, G.H. 1983. Weed seed and seedling reductions by solarization with transparent polyethylene sheets. Weed Sci. 31:404-409.

Emmert, E.M. 1957. Black polyethylene for mulching vegetables. Proc. of Am. Soc. for Hort. Sci. 69:464-468.

Forcella, F., S.R. Poppe, N.C. Hansen, W.A. Head, E. Hoover, F. Propsom, and J. McKensie. 2003. Biological mulches for managing weeds in transplanted strawberry (Fragaria ananassa). Weed Technol. 17:782-787.

Garnaud, J.C. 1974. The intensification of horticultural crop production in the Mediterranean basin by protected cultivation. FAO of the United Nations, Rome.

Guang-Cheng, S., L. Na, Z. Zhan-Yu, Y. Shuang-En, and C. Chang-ren. 2010. Growth, yield, and water use efficiency response of greenhouse-grown hot pepper under Time-Space deficit irrigation. Scientia Horticulturae 126:172-179.

Gravel, V., M. Dorais, and C. Ménard. 2012. Organic fertilization and its effect on development of sweet pepper transplants. Hortscience 47(2):198-204

Hignett, T.P. (ed.). 1985. 'History of Chemical Fertilizers' pp.3-10. In Hignett, T.P. (ed.). Fertilizer Manual. Springer, Dordrecht.

Hoover, E. 2000. Bio-based weed control in strawberries using sheep wool mulch, canola mulch, and canola green manure. MN Dept. of Agr. Greenbook 2000:83-86.

JMP®, Version Pro 12.2, SAS Institute Inc., Cary, NC, Copyright $\odot 2015$; SAS $®$, Version 9.3, SAS Institute Inc., Cary, NC, Copyright @2002-2010. 
Kang, S., L. Zhang, X. Hu, and P. Jerie. 2001. An improved water use efficiency for hot pepper grown under controlled alternate drip irrigation on partial roots. Scientia Horticulturae 89(4):257-267.

Kasirajan, S. and M. Ngouajio. 2012. Polyethylene and biodegradable mulches for agricultural applications: a review. Agr. For Sustainable Dev. 32(2):501-529.

Keddy, P.A. 2010. Wetland Ecology: Principles and Conservation. Cambridge Univ. Press, Cambridge, UK.

Koller, M. M., T.T. Alföldi, M.M. Siegrist, and F.F. Weibel. 2004. A comparison of plant and animal based fertiliser for the production of organic vegetable transplants. Acta Horticulturae 631:209-215.

Kowalewski, A., D.D. Buhler, S. Lang, M.G. Nair, and J.N. Rogers III. 2009. Mulched maple and oak leaves associated with a reduction in common dandelion populations in established Kentucky bluegrass. HortTechnology 19(2):297-304.

Kristiansen, P. 2006. 'Overview of Organic Agriculture' pp.1-23. In Kristiansen, P., A. Taji, and J. Reganold (eds.) Organic Agriculture: A Global Perspective. CSIRO Publishing, Victoria.

Kwabiah, A.B. 2004. Growth and yield of sweet corn (Zea mays L.) cultivars in response to planting date and plastic mulch in a short-season environment. Scientia Horticulturae 102(2):147-166.

Lal, R. 1974. Soil temperature, soil moisture, and maize yield from mulched and unmulched tropical soils. Plant and Soil 40(1):129-143.

Lamont, W.J., Jr. 2005. Plastics: modifying the microclimate for the production of vegetable crops. HortTechnology 15:477-481. 
Lamont, W.J., Jr. 2017. Plastic Mulches for the Production of Vegetable Crops, p. 45-60. In M.D. Orzolek (ed.). A Guide to the Manufacture, Performance, and Potential of Plastics in Agriculture. $1^{\text {st }}$ ed. Elsevier, Cambridge.

Lee, J. G., H. Y. Hwang, M.H. Park, C. H. Lee, and P. J. Kim. 2019. Depletion of organic carbon stocks are larger under organic film mulching for maize. Eur. J. Soil Sci. 70:807-818.

Levitan, L., and A. Barro. 2003. Recycling agricultural plastics in New York state. Environmental Risk Analysis Program, Cornell Center for the Environment, Cornell University, Ithaca. 14 April 2016. <http://cwmi.css.cornell.edu/recyclingagplastics.pdf>.

Li, Y., M. Shao, W. Wang, Q. Wang, and R. Horton. 2003. Open-hole effects of perforated plastic mulches on soil water evaporation. Soil Sci. 168(11):751-758.

Lightfoot, D.R. 1996. The nature, history, and distribution of lithic mulch agriculture: An ancient technique of dryland agriculture. The Ag. Hist. Rev. 44(2):206-222.

McCraw, D., and J.E. Motes. 2007. Use of plastic mulch and row covers in vegetable production. Coop. Ext. Serv. Oklahoma State University. OSU Extension Facts HLA-6034. 27 April 2016. <http://pods.dasnr.okstate.edu/docushare/dsweb/Get/Version-14121/HLA6034web.pdf>.

Michael, A.H. 2017. Horticulture Plastics, p. 129-142. In: M. D. Orzolek (ed.). A Guide to the Manufacture, Performance, and Potential of Plastics in Agriculture. $1^{\text {st }}$ ed. Elsevier, Cambridge.

Monks, C. D., D.W. Monks, T. Basden, A. Selders, S. Poland, and E. Rayburn. 1997. Soil temperature, soil moisture, weed control, and tomato (Lycopersicon esculentum) response to mulching. Weed Technol. 11(3):561-566. 
Murray, R., and R.G. Anderson. (n.d.). Organic fertilizers and composts for vegetable transplant production [University publication]. College of Agriculture, Univ. of Kentucky, Lexington, KY. 10 May 2015. <http://www.uky.edu/Ag/CDBREC/anderson/orgfert3.pdf>.

Olfati, J.A., G. Peyvast, and Z. Nosrati-Rad. 2008. Organic mulching on carrot yield and quality. Int. J. of Veg. Sci. 14(4): 363-368.

Orzolek, M.D. 2015. Evaluating Vegetable Transplants [University publication]. Virginia Cooperative Extension, Virginia Tech, Blacksburg, VA. 5 April 2019. <https://www.pubs.ext.vt.edu/content/dam/pubs_ext_vt_edu/2906/2906-1358/29061358_pdf.pdf>.

Orzolek, M.D. 2017. Introduction, p1-20. In: M. D. Orzolek (ed.). A Guide to the Manufacture, Performance, and Potential of Plastics in Agriculture. $1^{\text {st }}$ ed. Elsevier, Cambridge.

Pennisi, B.V., and P.A. Thomas. 2015. Essential pH Management in Greenhouse Crops [University publication]. UGA Cooperative Extension, University of Georgia, Athens, GA. 15 November 2019. <https://secure.caes.uga.edu/extension/publications/files/pdf/B\%201256_8.PDF>.

Ravinder, K., B. K. Srivastava, and R. Kumer. 1997. Effect of different mulch materials on the soil temperature and moisture in winter tomato. Crop Res. 14:137-141.

Raviv, M., B.Z. Zaidman, and Y. Kapulnik. 1998. The use of compost as a peat substitute for organic vegetable transplants production. Compost Sci. and Utilization 6(1):46-52.

Rice, P.J, L.L. McConnell, L.P. Heighton, A.M. Sadeghi, A.R. Isensee, J.R. Teasdale, A.A. Abdul-Baki, J.A. Harman-Fetcho, and C.J. Hapeman. 2001. Runoff loss of pesticides and 
soil: A comparison between vegetative mulch and plastic mulch in vegetable production systems. J. of Environ. Quality 30:1808-1821.

Rice, P.J., J.A. Harman-Fetcho, A.M. Sadeghi, L.L. McConnell, C.B. Coffman, J.R. Teasdale, A. Abdul-Baki, J.L. Starr, G.W. McCarty, R.R. Herbert, and C.J. Hapeman. 2007. Reducing insecticide and fungicide loads in runoff from plastic mulch with vegetative-covered furrows. J. of Agr. and Food Chem. 55(4):1377-1384.

Rippy, J.F.M., M.M. Peet, F.J. Louws, P.V. Nelson, D.B. Orr, and K.A. Sorensen. 2004. Plant development and harvest yield of greenhouse tomatoes in six organic growing systems. HortScience 39:223-229.

Rivise, C.W. 1929. Mulch paper. Paper Trade J. 89:55-57.

Ruidisch, M., J. Kettering, S. Arnhold, and B. Huwe. 2013. Modeling water flow in a plastic mulched ridge cultivation system on hillslopes affected by South Korean summer monsoon. Agri. Water Mgt. 116:204-217.

Russel, D.A., and G.G. Williams. 1977. History of chemical fertilizer development. Soil Sci. Soc. of Amer. 41(2):265-265.

Russo, V.M. 2005. Organic vegetable transplant production. HortScience 40(3):623-628.

Russo, V. M. 2006. Biological amendment, fertilizer rate, and irrigation frequency for organic bell pepper transplant production. HortScience 41(6):1402-1407.

Sammons, J.D., and D.K. Struve. 2008. Monitoring effective container capacity: A method for reducing over-irrigation in container production systems. J. of Environ. Hort. 26(1):1923. 
Savic, S., R. Stikic, V. Zaric, B. Vucelic-Radovic, Z. Jovanovic, M. Marjanovic, S. Djordjevic, and D. Petkovic. 2012. Deficit irrigation technique for reducing water use of tomato under polytunnel conditions. J. of Central European Agr. 12(4):590-600.

Seufert, V., N. Ramankutty, and J.A. Foley. 2012. Comparing the yields of organic and conventional agriculture. Nature 485:229-232.

Sharma, R.R., and V.P. Sharma. 2003. Mulch type influences plant growth, albinism disorder and fruit quality in strawberry (Fragaria $\times$ ananassa Dusch.). Fruits 58(4): 221-227.

Smika, D.E. 1983. Soil water change as related to wheat straw mulch on the soil surface. Soil Sci. Soc. Amer. J 47:488-491.

Smil, V. 2011. Nitrogen cycle and world food production. World Agriculture 2:9-13.

Sopher, C.J. 2012. High temperature predisposition of sweet pepper to Pythium root rot and its remediation by Pseudomonas chlororaphis. U. of Guelph. PhD dissertation.

Stowe, D.C., M.S. Lamhamedi, S. Carles, B. Fecteau, H.A. Margolis, M. Renaud, and P.Y. Bernier. 2010. Managing irrigation to reduce nutrient leaching in containerized white spruce seedling production. New Forests 40(2):185-204.

Thouet, J., M. Quinet, S. Ormenese, J.M. Kinet, and C. Périlleux. 2008. Revisiting the involvement of SELF-PRUNING in the sympodial growth of tomato. Plant Phys. 148(1):61-64.

U.S. Congress. House. 2002. Farm Security and Rural Investment Act of 2002, HR 2646, $107^{\text {th }}$ Cong. <https://www.congress.gov/107/plaws/publ171/PLAW-107publ171.pdf〉.

U.S. Department of Agriculture, Agricultural Marketing Service. 2000. National organic program; final rule. 7 CFR part 205. Fed. Reg. 21 Dec. 2000. 
U.S. Department of Agriculture, Agricultural Marketing Service. n.d. Allowed Mulches on Organic Farms and the Future of Biodegradable Mulch. 15 August 2019. <https://www.ams.usda.gov/sites/default/files/media/5\%20Mulches\%20incl\%20biodegra dable\%20FINAL\%20RGK\%20V2.pdf>.

U.S. Department of Agriculture, National Institute of Food and Agriculture. n.d. Organic Agriculture Program. 15 August 2019. <https://nifa.usda.gov/program/organicagriculture-program>.

U.S. Department of Agriculture, National Resources Conservation Service. 2015. Web Soil Survey. 15 August 2019. <https://soilseries.sc.egov.usda.gov/OSD_Docs/T/TILSIT.html>

U.S. Environmental Protection Agency. 2002. National Water Quality Inventory 2000 Report. 23 April 2015. <http://water.epa.gov/lawsregs/guidance/cwa /305b /2000 report_ index.cfm>.

Wilson, D.J., and R.L. Jefferies. 1996. Nitrogen mineralization, plant growth and goose herbivory in an Arctic coastal ecosystem. J. of Ecology 84:841-851.

Wilson, P.C., and J.P. Albano. 2011. Impact of fertigation versus controlled-release fertilizer formulations on nitrate concentrations in nursery drainage water. HortTechnology 21(2):176-180.

Wright, R.D. 1986. The pour-through nutrient extraction procedure. Hortscience 21:227-229.

Xing, Z., P. Toner, L. Chow, H.W. Rees, S. Li, and F. Meng. 2012. Effects of hay mulch on soil properties and potato yield under irrigation and nonirrigation in New Brunswick, Canada. J. Irr. Drain Eng. 138:703-714. 
Yeager, T., R. Wright, D. Fare, C. Gilliam, J. Johnson, T. Bilderback, and R. Zondag. 1993. Six state survey of container nursery nitrate nitrogen runoff. J. Environ. Hort. 11:206-208.

Yi, L., M. Shao, W. Wang, Q. Wang, and R. Horton. 2003. Open-hole effects of perforated plastic mulches on soil water evaporation. Soil Sci. 168:751-758. 